\title{
Carbon Nitrides and Metal Nanoparticles: From Controlled Synthesis to Design Principles for Improved Photocatalysis
}

Ivo F. Teixeira, ${ }^{1}$ Eduardo Barbosa, ${ }^{1}$ Shik Chi Edman Tsang, ${ }^{2}$ Pedro H. C. Camargo ${ }^{1}$

${ }^{1}$ Departamento de Química Fundamental, Instituto de Química, Universidade de São Paulo, São Paulo, SP, Brazil

${ }^{2}$ Wolfson Catalysis Centre, Department of Chemistry, University of Oxford, Oxford, UK 


\begin{abstract}
The use of sunlight to drive chemical reactions via photocatalysis is of paramount importance towards a sustainable future. Among several photocatalysts, earth-abundant graphitic carbon nitride ( $\left(\mathrm{g}-\mathrm{C}_{3} \mathrm{~N}_{4}\right.$ ) has emerged as an attractive candidate due to its ability to absorb light efficiently in the visible and near-infrared range, chemical stability, non-toxicity, straightforward synthesis, and versatility as a platform for constructing hybrid materials. Especially, hybrids with metal nanoparticles offer the unique possibility of combining the catalytic, electronic, and optical properties of metal nanoparticles with g- $\mathrm{C}_{3} \mathrm{~N}_{4}$. Here, we provide a comprehensive overview of $\mathrm{g}-\mathrm{C}_{3} \mathrm{~N}_{4}$ materials their hybrids, emphasizing heterostructures with metal nanoparticles. We focus on recent advances encompassing synthetic strategies, design principles, photocatalytic applications, and charge-transfer mechanisms. We also discuss how local surface plasmon resonance (LSPR) effect of some noble metals NPs (e.g. $\mathrm{Au}, \mathrm{Ag}$, and $\mathrm{Cu}$ ), bimetallic compositions, and even non-noble metals NPs (e.g., $\mathrm{Bi}$ ) synergistically contribute with g- $\mathrm{C}_{3} \mathrm{~N}_{4}$ in light-driven transformations. Finally, we provide a perspective on the field, in which the understanding of the enhancement mechanisms combined with truly controlled synthesis can act as a powerful tool to the establishment of the design principles needed to take the field of photocatalysis with $g-\mathrm{C}_{3} \mathrm{~N}_{4}$ to a new level, where the desired properties and performances can be planned in advance, and the target material synthesized accordingly.
\end{abstract}




\section{Introduction}

The adverse environmental problems caused by the intensive consumption of fossil fuels have led to an increasing interest in the use of alternative energy sources to serve and deliver power to human activities. ${ }^{1-3}$ Solar energy has an enormous potential as a clean, abundant, and economical resource. ${ }^{4}$ Therefore, the efficient harvesting and conversion of solar energy have been a worldwide priority target in the past decade.

In this context, the use of sunlight to drive chemical reactions (solar to chemical energy conversion) via photocatalysis represents a very promising approach. ${ }^{5}$ In photocatalysis, the most studied examples are endothermic reactions, such as $\mathrm{H}_{2} \mathrm{O}$ splitting and $\mathrm{CO}_{2}$ reduction, where the energy of solar photons can be stored in chemical bonds by using semiconductors as photocatalysts. ${ }^{6,7}$ Even though a lot of progress has been achieved in the development of semiconductor photocatalysts, most systems require solar energy input in the UV region for band gap excitation. ${ }^{8-10}$ Thus, most photocatalysts present low solar-energy utilization, as solar light is composed of ultraviolet, visible and infrared components (accounting for 5, 43, and $52 \%$, respectively). ${ }^{11}$ These features illustrate that is still very challenging design new photocatalysts that are abundant, stable, facile to fabricate, and showing high performances under visible-light or near-infrared excitation. ${ }^{10}$

The search for suitable semiconductor photocatalysts to optimise existing or design novel chemical processes is one of the persistent goals of sustainable chemistry. An optimal material would combine an ability to absorb light efficiently, especially in the visible and near-infrared range, and be stable in working chemical and thermal conditions. Moreover, it should be non-toxic, preferentially composed by abundant elements, and easily processable. Mostly explored semiconductors are so far constructed from transition metal ions with $\mathrm{d}^{0}$ or $\mathrm{d}^{10}$ electronic configuration, along with counter-anion such as chalcogens. ${ }^{12,}{ }^{13}$ However, it remains challenging to engineer and tune the electronic properties of metal chalcogenides. As a result, rarely these structures have been targets of systematic optimisation. ${ }^{14,15}$ Traditional inorganic semiconductors are limited in the nature of their active sites and thus the scope of applications that they can accomplish. ${ }^{16,17}$ On the other hand, while organic polymeric catalysts have the advantage of flexibility for optimization, they suffer from serious swelling and stability problems. ${ }^{17}$ Consequently, it is extremely desirable to have an active and stable photocatalyst that could allow large variation in the structure without having to change its overall composition. 
Graphitic carbon nitride $\left(\mathrm{g}-\mathrm{C}_{3} \mathrm{~N}_{4}\right)$ is a highly active photocatalyst which, at least in principle, meets above-mentioned requirements. The history of $\mathrm{C}_{3} \mathrm{~N}_{4}$ can be traced back to the embryonic form, “melon”, made by Berzelius and named by Liebig in 1834 being regarded as one of the oldest synthetic polymers. ${ }^{14,} 16,18$ The framework topology of linear polymer "melon" is presumably consisting of interconnected tri-s-triazines via secondary nitrogens, while defect-rich $\mathrm{C}_{3} \mathrm{~N}_{4}$ is in the form of p-conjugated planar $2 \mathrm{D}$ sheets of poly(tris-triazines) interconnected via tertiary amines. ${ }^{18,} 19$ The "perfect" ${ }^{g}-\mathrm{C}_{3} \mathrm{~N}_{4}$ material is comprised solely of $\mathrm{C}$ and $\mathrm{N}$ bonds with no active basicity, due to the lack of electron localized in the $\pi$ state. ${ }^{20}$ However, it is difficult to synthesize "perfect" g- $\mathrm{C}_{3} \mathrm{~N}_{4}$. In general, most of the synthesis routes lead to predominantly materials with medium to poor crystallinity and a high degree of disorder, but still showing high photocatalytic activity. ${ }^{14-16}$ Bulk g- $\mathrm{C}_{3} \mathrm{~N}_{4}$ is typically prepared by the direct thermal condensation of low-cost nitrogen containing precursors (cyanamide, dicyandiamide). ${ }^{21-24}$ This results in carbon nitrides with several shortcomings, including low specific surface area, insufficient visible light utilization, and, particularly, rapid recombination of photogenerated charge carriers. ${ }^{24-28}$ High separation/transfer efficiency of photogenerated electron-hole pairs is the most desirable property in g- $\mathrm{C}_{3} \mathrm{~N}_{4}$-based photocatalysts. Several strategies can be employed to achieve this objective, such as $i$ ) doping the $\mathrm{C}_{3} \mathrm{~N}_{4}$ structure with sulphur, ${ }^{29,}{ }^{30}$ boron, $^{31}$ oxygen $^{32}$ and phosphorous $29,33,34 ;$ ii) modifying its synthesis method (e.g. changing and combining different nitrogen containing precursors, ${ }^{18,35,36}$ introduce mesoporous using hard templates, ${ }^{37}$, ${ }^{38}$ microwave-assisted synthesis, ${ }^{39}$ synthesis in molten salt, ${ }^{40}$ synthesis in ionic liquid ${ }^{41}$ ); iii) performing a post treatment (e.g. exfoliation ${ }^{42-45}$ and thermal treatment ${ }^{18,35,36}$ ); iv) controlling the defects in its structure; ${ }^{46} v$ ) and/or combining it with other structures (e.g. semiconductors, ${ }^{24,47-51}$ metal nanoparticles (NPs) ${ }^{24,}$ 52-54 and metal-organic frameworks (MOFs) ${ }^{23 \text {, }}$ $55-57)$.

Among the recent strategies in the development of g- $\mathrm{C}_{3} \mathrm{~N}_{4}$ photocatalytic systems, g- $\mathrm{C}_{3} \mathrm{~N}_{4}-$ based heterostructures are one the most promising materials due to its feasibility and effectiveness for the spatial separation of photogenerated electron-hole pairs. ${ }^{24}$ The g- $\mathrm{C}_{3} \mathrm{~N}_{4}$ based heterostructures are capable to suppress the recombination of photogenerated charge carriers while endowing the photocatalysts with unique features that arise from the synergism between $g-\mathrm{C}_{3} \mathrm{~N}_{4}$ and the other components. Therefore, we believe that the rational design of g- $\mathrm{C}_{3} \mathrm{~N}_{4}$-based heterostructures could provide promising routes for creating highly efficient visible-light-driven photocatalysts for chemical synthesis, environmental remediation, and energy applications. 
Herein, we aim at providing a general overview on heterostructures comprised of g- $\mathrm{C}_{3} \mathrm{~N}_{4}$ and metal NPs. The synthesis, applications in photocatalytic reactions, and the mechanisms behind the synergistic effects involving g- $\mathrm{C}_{3} \mathrm{~N}_{4}$ and metal NPs will be covered. This review will also focus on how local surface plasmon resonance (LSPR) effect of some noble metals NPs (e.g. Au, Ag, and Cu), bimetallic compositions (AuPd, AuAg, AuPt, etc), and even nonnoble metals NPs (e.g., $\mathrm{Bi}$ ) can enhance the catalytic properties of $\mathrm{g}-\mathrm{C}_{3} \mathrm{~N}_{4}$ in several lightdriven transformations.

\section{Synthesis of $\mathrm{g}-\mathrm{C}_{3} \mathrm{~N}_{4}$}

g- $\mathrm{C}_{3} \mathrm{~N}_{4}$ is commonly synthesized by thermal treatment that leads to a combination of polyaddition and polycondensation reactions of the nitrogen-rich precursors such as urea, thiourea, melamine, cyanamide, and dicyandiamide. ${ }^{58-64}$ This approach is described in Fig. 1. The precursors condensate into dicyandiamide 1 and melamine (triamino-s-triazine) 2, which forms tri-s-triazine units, also known as melem 3, by polycondensation of melamines. Then, the $g-\mathrm{C}_{3} \mathrm{~N}_{4} \mathbf{4}$ are formed through the further condensation of the tri-s-triazine units. ${ }^{28,65}$

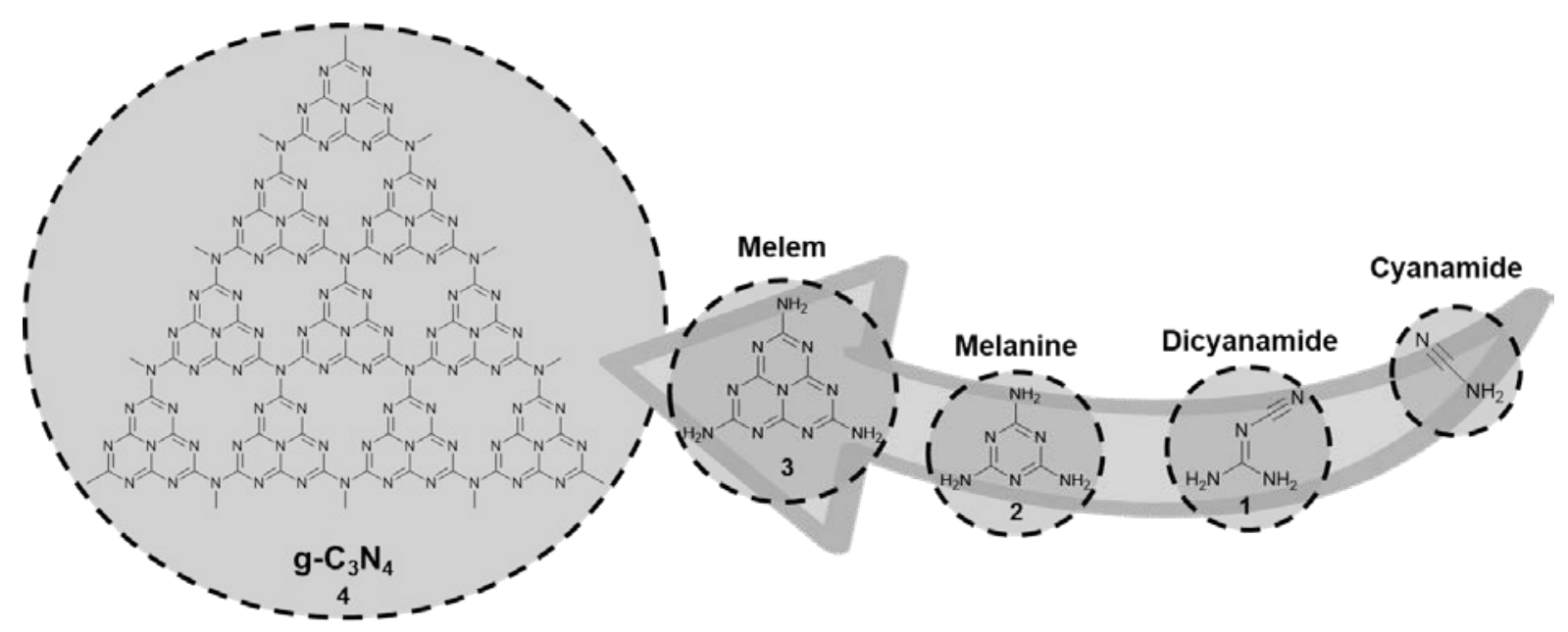

Figure 1. Schematic illustration for the synthesis of $\mathrm{g}_{-} \mathrm{C}_{3} \mathrm{~N}_{4}$ by polyaddition and polycondensation of the nitrogen-rich precursors.

Interestingly, it has been established that the choice of precursors significantly influences the electronic band structures and textual properties of obtained pristine bulk g- $\mathrm{C}_{3} \mathrm{~N}_{4} \cdot{ }^{24}$ For example, when thiourea is used to prepare the g- $\mathrm{C}_{3} \mathrm{~N}_{4}$, it exhibits a slightly smaller bandgap when compared with the g- $\mathrm{C}_{3} \mathrm{~N}_{4}$ prepared from urea. ${ }^{66,67}$ On the other hand, the g- $\mathrm{C}_{3} \mathrm{~N}_{4}$ 
prepared from urea generally presents much higher specific surface area than that prepared from thiourea and melamine. ${ }^{18,66}$

Another aspect is that the $\mathrm{g}-\mathrm{C}_{3} \mathrm{~N}_{4}$ properties strongly depends on the nitrogen-rich precursors and temperature employed during the thermal polymerization, which represents an attractive method due to its simplicity and low cost. The nitrogen-rich small molecules polymerize into g- $\mathrm{C}_{3} \mathrm{~N}_{4}$ in temperatures ranging between 450 and $650{ }^{\circ} \mathrm{C} .{ }^{24,66,68}$ Bellow 450 ${ }^{\circ} \mathrm{C}$, the polymerization is incomplete. Over $650{ }^{\circ} \mathrm{C}$, the $\mathrm{g}-\mathrm{C}_{3} \mathrm{~N}_{4}$ start to decompose. ${ }^{59}$ Different precursors calcined at different temperatures can lead to a range of band-gaps and specific surface areas. For instance, urea can produce g- $\mathrm{C}_{3} \mathrm{~N}_{4}$ with band gaps varying from 2.68 to $2.78 \mathrm{eV}$ and surface areas from 31 to $288 \mathrm{~m}^{2} \mathrm{~g}^{-1}$, while thiourea can lead to carbon nitrides with band gaps from 2.58 to $2.76 \mathrm{eV}$ and surface areas significantly smaller $11-52 \mathrm{~m}^{2}$ $\mathrm{g}^{-1}{ }^{18}$ It is important to highlight that these examples involve only the modification in the nature of precursors and calcination temperature. Many other approaches can also be employed to tune carbon nitride properties, such as doping the $\mathrm{C}_{3} \mathrm{~N}_{4}$ structure, ${ }^{29-34}$ introduce mesoporous using hard templates, ${ }^{13}, 37,38$ using other synthesis methods apart from thermal condensation, ${ }^{39-41}$ adding a post-treatment (e.g. exfoliation ${ }^{42-45}$ and thermal treatment ${ }^{18,} 35,36$ ), controlling the defects in its structure, ${ }^{46}$ and combining it with other structures, such as semiconductors, ${ }^{24,47-51}$ metal NPs, ${ }^{24,52-54}$ and metal-organic frameworks (MOFs). ${ }^{23,}$,5-57

The successful preparation of $\mathrm{g}-\mathrm{C}_{3} \mathrm{~N}_{4}$ photocatalysts can be confirmed by several analytical measurements, such as X-rays diffraction (XRD), X-ray photoelectron spectroscopy (XPS) and thermogravimetric analysis (TGA). XRD is an important technique due the two characteristic diffraction peaks at ca. 27.4 and ca. $13.0^{\circ}$ that appear for the g$\mathrm{C}_{3} \mathrm{~N}_{4}{ }^{18}$ XPS measurements are especially useful to investigate the chemical environment of carbon and nitrogen elements in g- $\mathrm{C}_{3} \mathrm{~N}_{4}$, evidencing $\mathrm{sp}^{2}$-bonded carbon in $\mathrm{N}-\mathrm{C}=\mathrm{N}$ (ca. 288.1 $\mathrm{eV}$ ) and the $\mathrm{sp}^{2}$-bonded nitrogen in $\mathrm{C}-\mathrm{N}=\mathrm{C}$ (ca. $398.7 \mathrm{eV}$ ). Furthermore, XPS allows to characterize elemental doped g- $\mathrm{C}_{3} \mathrm{~N}_{4}$ and estimates the degree of defects in the $\mathrm{g}_{-} \mathrm{C}_{3} \mathrm{~N}_{4}$ structure by the nitrogen in tertiary nitrogen groups (ca. $400.3 \mathrm{eV}$ ) and the presence of amino groups $(\mathrm{C}-\mathrm{N}-\mathrm{H}$, ca. $401.4 \mathrm{eV})$. Because the high thermal stability of $\mathrm{g}_{-} \mathrm{C}_{3} \mathrm{~N}_{4}$, the decomposition temperature obtained by TGA can be a simple way to confirm the proper polymerization of the nitrogen-rich precursors ${ }^{18}$ 


\section{Properties}

\subsection{Morphological features}

As a polymer, g- $\mathrm{C}_{3} \mathrm{~N}_{4}$ has a flexible structure and is suited to form different morphologies with the assistance of different templates during the synthesis as well as post-treatments. However, differently from most polymeric materials, g- $\mathrm{C}_{3} \mathrm{~N}_{4}$ can endure high temperatures (until $650{ }^{\circ} \mathrm{C}$ ), even in oxidizing atmosphere. ${ }^{66} \mathrm{~g}^{-} \mathrm{C}_{3} \mathrm{~N}_{4}$ have been obtained in several morphologies, such as porous g- $\mathrm{C}_{3} \mathrm{~N}_{4}$ (3D nanostructures), ${ }^{37,} 38,69$ hollow spheres, ${ }^{70}$ nanorods $/{ }^{71}$ nanowires $/{ }^{72}$ nanotubes ${ }^{73}$ (1D nanostructures), and nanosheets (2D nanostructures). ${ }^{45,} 74$

Mesoporous carbon nitrides (mpg- $\mathrm{C}_{3} \mathrm{~N}_{4}$ ) can be easily obtained by a hard template method. It has been successfully synthesized using various nitrogen-rich precursors in the presence of silica NPs ${ }^{37,38}$ or ordered mesoporous silica (e.g. SBA-15) ${ }^{69}$ as a hard template. The removal of those silica structures by a treatment with HF then generates a 3D structure of g- $\mathrm{C}_{3} \mathrm{~N}_{4}$ with a large surface area, which can reach up to $373 \mathrm{~m}^{2} \mathrm{~g}^{-1}{ }^{18}$ The mpg- $\mathrm{C}_{3} \mathrm{~N}_{4}$ synthesis, functionalization, and applications was recently reviewed by Lakhi and colleagues. $^{75}$

The preparation of hollow g- $\mathrm{C}_{3} \mathrm{~N}_{4}$ spheres is challenging due to its layered structure, which is more susceptible to collapse. However, Sun et $a .^{70}$ were successful in coating monodisperse silica NPs with thin mesoporous silica shells and then used it as a hard template to prepare hollow g- $\mathrm{C}_{3} \mathrm{~N}_{4}$ nanospheres. This strategy is similar to the one used to prepare mesoporous g- $\mathrm{C}_{3} \mathrm{~N}_{4}$. The silica was then removed by a post-treatment with $\mathrm{HF}$ at the end of the synthesis. g- $\mathrm{C}_{3} \mathrm{~N}_{4}$ in the form of hollow spheres are very attractive because they are able to harvest more incident light through successive reflections within the hollow structure, producing more photoinduced charge carriers serving as light-harvesting antennas. $^{18}$

$1 \mathrm{D}$ nanostructured g- $\mathrm{C}_{3} \mathrm{~N}_{4}$ such as nanorods, nanowires, nanobelts, and nanotubes are also attractive morphologies because their length, diameter, and aspect ratio can be tuned. This, in turn, can lead to unique and tunable chemical, optical and electronic properties. ${ }^{18} 1 \mathrm{D}$ nanostructured g- $\mathrm{C}_{3} \mathrm{~N}_{4}$ displaying porous structures, large surface areas, and charge-carrier mobility can be prepared using different templating (e.g. SBA-15) ${ }^{69}, 71$ or non-templating (e.g. reflux in solvent) ${ }^{73,76,77}$ methods. 
Bulk g- $\mathrm{C}_{3} \mathrm{~N}_{4}$ display a low specific surface area, corresponding to $<10 \mathrm{~m}^{2} \mathrm{~g}^{-1}$, due to the stacking of g- $\mathrm{C}_{3} \mathrm{~N}_{4}$ layers. Thus, several studies have been focused on exfoliation methods to obtain nanosheets from bulk g- $\mathrm{C}_{3} \mathrm{~N}_{4}$. The most common strategies include ultrasonicationassisted liquid exfoliation, ${ }^{43}$, 45, 74, 78-83 acid exfoliation, ${ }^{84,} 85$ liquid ammonia-assisted lithiation, ${ }^{79}$ and thermal oxidation. ${ }^{43,86} 2 \mathrm{D}$ g- $\mathrm{C}_{3} \mathrm{~N}_{4}$ nanosheets exhibit interesting features, such as large specific surface areas, prolonged lifetime of charge carriers, enhanced electron transport property, reduced recombination rate of charge carriers, and improved charge transfer and separation efficiencies. ${ }^{28}$ Due to the combination of these very attractive features, it represents the most studied g- $\mathrm{C}_{3} \mathrm{~N}_{4}$ morphology.

\subsection{Surface Basic and Acid Sites}

Among the several features of g- $\mathrm{C}_{3} \mathrm{~N}_{4}$, the presence of acid and basic sites in its surface is one of the most interesting but poorly understood properties. g- $\mathrm{C}_{3} \mathrm{~N}_{4}$ has Lewis basic sites (Fig. 2a), which can be the nitrogen present in the six-membered ring (A) or nitrogen present as primary (C) and/or secondary (B) amine groups on the terminating edges due to defects in the $\mathrm{g}-\mathrm{C}_{3} \mathrm{~N}_{4}$ structure. ${ }^{59}$ The surface basicity of $\mathrm{g}-\mathrm{C}_{3} \mathrm{~N}_{4}$ can be confirmed by temperatureprogrammed desorption of $\mathrm{CO}_{2}\left(\mathrm{CO}_{2}-\mathrm{TPD}\right){ }^{59}$ This powerful technique also allows differentiate and estimate the amount of the three basic site types. These basic sites can be applied to catalyze several reactions, such as $\mathrm{C}-\mathrm{C}$ coupling, ${ }^{37} \alpha-\mathrm{C}-\mathrm{H}$ activation, ${ }^{31} \mathrm{NO}$ decomposition, ${ }^{87}$ and Knoevenagel condensations. ${ }^{20,88-90}$

The formation of Brønsted acid sites on $\mathrm{g}-\mathrm{C}_{3} \mathrm{~N}_{4}$ surface under oxidation conditions was first proposed by Shiraishi et al. ${ }^{91}$ in 2014 by the approach shown in Fig. 2b. Ever since, many recent studies have confirmed the presence of highly labile hydrogen adsorption sites at the g- $\mathrm{C}_{3} \mathrm{~N}_{4}$ edges under photooxidation conditions $\left(\mathrm{O}_{2}\right.$ atmosphere and light) in the presence of alcohol, which can be the substrate or the solvent in the reaction. ${ }^{92,} 93$ These Brønsted acid sites were recently confirmed experimentally by post-mortem temperature programmed desorption and in-situ X-ray photoelectron spectroscopy analysis (XPS), which indicates $\mathrm{H}_{\text {ads }}$ weakly adsorbed on the catalyst surface. ${ }^{92}$ This same study also confirmed the presence of $\mathrm{H}_{\mathrm{ads}}$ on $\mathrm{g}-\mathrm{C}_{3} \mathrm{~N}_{4}$ by semi-empirical MOPAC2016 calculations and estimated the relative adsorption energies of $\mathrm{H}$ pairs (two $\mathrm{H}$ atoms) on a model crystalline $\mathrm{g}_{-} \mathrm{C}_{3} \mathrm{~N}_{4}$ structure consisting of two H-bonded strips with 6 melem units, which evidenced that the Brønsted acid sites are more likely to be present at the edges of the $\mathrm{g}_{-} \mathrm{C}_{3} \mathrm{~N}_{4}$ and bonded to $\mathrm{N}$ atoms in 
the same ring adjacent to the bridging $\mathrm{N}$ atoms between melem units, as shown in Fig. $\mathbf{2} \mathbf{b} .^{92}$ The Brønsted acid sites can be applied to catalyse a series of reactions, especially those which depend on a dehydration, which include the conversion of nitroaromatics into azo- and azoxyaromatics $^{92}$ and the photoacetalization of ketones and aldehydes. ${ }^{93}$ Moreover, Lewis acid sites can be introduced into $\mathrm{g}_{-} \mathrm{C}_{3} \mathrm{~N}_{4}$ by elemental doping with boron ${ }^{31,94-96}$ or phosphorous. ${ }^{29}$, 33, 34, 97 Despite that fact that Lewis acid sites are less active than the Brønsted ones, they presented helpful synergistic effects in a range of photoreactions, such as $\mathrm{H}_{2}$ evolution, ${ }^{34,} 94$ photodegradation, ${ }^{34,} 96$ photooxidations, ${ }^{95} \mathrm{C}-\mathrm{H}$ activations ${ }^{31}$ and $\mathrm{CO}_{2}$ cycloaddition. ${ }^{97}$

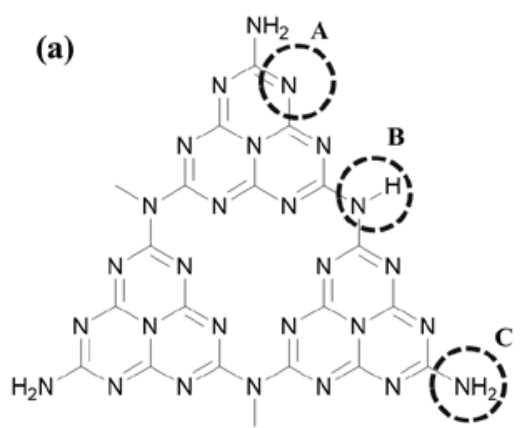

Basic Sites (b)

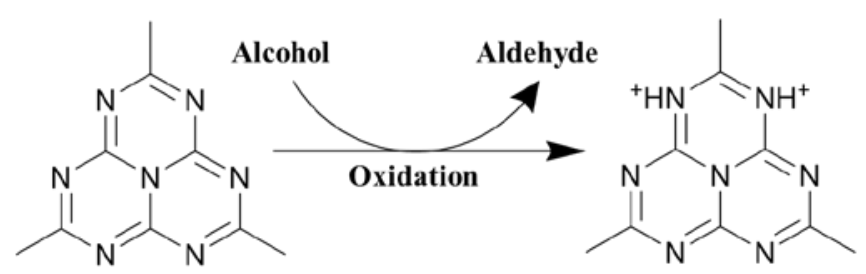

Acid Sites

Figure 2. Acid and basic sites on g- $\mathrm{C}_{3} \mathrm{~N}_{4}$ surface. (a) Lewis basic sites present on the $\mathrm{g}-\mathrm{C}_{3} \mathrm{~N}_{4}$ surface: $\mathrm{N}$ in six-membered ring (A), secondary amine (B), and primary amine (C). ${ }^{59}$ (b) Proposed mechanism for the formation of Brønsted acid sites on the g- $\mathrm{C}_{3} \mathrm{~N}_{4}$ surface. ${ }^{91}$

\section{4. g- $\mathrm{C}_{3} \mathrm{~N}_{4}$ Based Heterojunctions: Non-Noble Metals, Metal Oxides, Metal Sulphides, and Metal-Organic Frameworks}

Elemental doping is widely used to engineer the band gap of $\mathrm{g}-\mathrm{C}_{3} \mathrm{~N}_{4}$ through the addition of other elements instead of $\mathrm{C}$ and $\mathrm{N}$ in the $\mathrm{g}-\mathrm{C}_{3} \mathrm{~N}_{4}$ structure. This makes it possible to modulate the light absorption and redox band potentials for targeted photocatalytic applications according to Fig. $3 .^{28}$ As previously mentioned, the most commonly used elements are $\mathrm{S},{ }^{29}, 30,98 \mathrm{~B},{ }^{31,96} \mathrm{O},{ }^{32} \mathrm{I}^{29,} 99,100$ and $\mathrm{P} .{ }^{29,33,34}$ However, metal cations also can be included into g- $\mathrm{C}_{3} \mathrm{~N}_{4}$ framework, such as $\mathrm{Zn}^{2+}, \mathrm{Fe}^{2+},{ }^{101} \mathrm{Ni}^{2+}, \mathrm{Cu}^{2+}, \mathrm{Co}^{3+},{ }^{102} \mathrm{Cu}^{1+},{ }^{103} \mathrm{Mn}^{3+}$, $\mathrm{K}^{+},{ }^{104} \mathrm{Na}^{+}$and $\mathrm{Li}^{+} \cdot{ }^{105-108}$ The recent review by Zhang et. al. provides a detailed discussion of several strategies that can be employed to obtain $\mathrm{g}-\mathrm{C}_{3} \mathrm{~N}_{4}$ structures and how they affect photocatalytic activities. ${ }^{109}$ In another interesting review Jiang and collaborators overview the 
recent advances in doping of g- $\mathrm{C}_{3} \mathrm{~N}_{4}$ for photocatalytic applications. ${ }^{110}$ Among them, we believe that an efficient way to improve the $\mathrm{g}-\mathrm{C}_{3} \mathrm{~N}_{4}$ electronic properties is by combining it with other semiconductors and nanostructures to form $\mathrm{g}-\mathrm{C}_{3} \mathrm{~N}_{4}$ based heterojunctions.

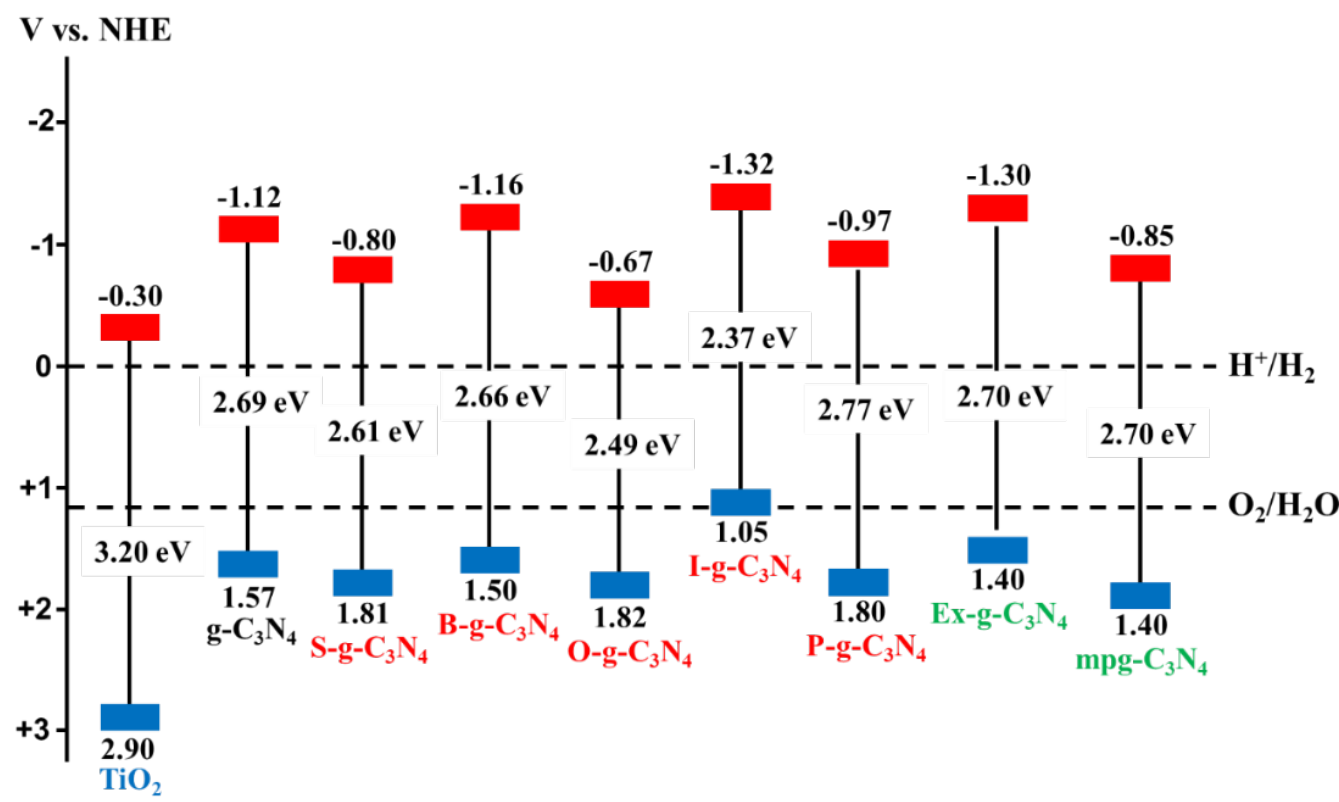

Figure 3. Schematic illustration of the band structure of typical g- $\mathrm{C}_{3} \mathrm{~N}_{4}$ samples, including g$\mathrm{C}_{3} \mathrm{~N}_{4},{ }^{111} \mathrm{~S}-\mathrm{g}-\mathrm{C}_{3} \mathrm{~N}_{4},{ }^{98} \mathrm{~B}-\mathrm{g}-\mathrm{C}_{3} \mathrm{~N}_{4},{ }^{96} \mathrm{O}-\mathrm{g}-\mathrm{C}_{3} \mathrm{~N}_{4},{ }^{32} \mathrm{I}-\mathrm{g}-\mathrm{C}_{3} \mathrm{~N}_{4},{ }^{29}$ P-g- $\mathrm{C}_{3} \mathrm{~N}_{4},{ }^{33}$ ex-g- $\mathrm{C}_{3} \mathrm{~N}_{4},{ }^{112} \mathrm{mpg}-$ $\mathrm{C}_{3} \mathrm{~N}_{4}{ }^{113}$ The band structure for $\mathrm{TiO}_{2}$ is also shown for comparison. Adapted from ref 18 . Copyright 2015 John Wiley \& Sons, Inc.

Similarly to other typical inorganic semiconductor photocatalysts (e.g., $\mathrm{TiO}_{2}$ ), g- $\mathrm{C}_{3} \mathrm{~N}_{4}$ also suffers several intrinsic drawbacks such as low electrical conductivity, high recombination rate of electron-hole pairs, and limited absorption above $460 \mathrm{~nm} .{ }^{114}$ Highly efficient g- $\mathrm{C}_{3} \mathrm{~N}_{4}$ based nanostructures must attend some important criteria. These include low recombination rates, enhanced solar light absorption, and high photochemical stability. In this context, the development of g- $\mathrm{C}_{3} \mathrm{~N}_{4}$-based nanohybrids is attractive for several reasons: $i$ ) in enables more efficient charge transfer and separation through the Schottky junction (metal/semiconductor heterostructures) or the p-n junction (semiconductor/semiconductor heterostructures); ii) the presence of cocatalysts lowers the redox overpotential at the active sites; iii) the visible light utilization can be improved; and iv) the system stability by protecting the active sites and functional groups on the surface of the semiconductor through proper surface passivation is ameliorated. ${ }^{28}$ 
It is well established that charge recombination processes are disadvantageous to the photocatalytic efficiency. When the recombination process takes place, excited electrons return to the valence band, dissipating the energy as heat without reacting with the adsorbed species on the surface of $\mathrm{g}-\mathrm{C}_{3} \mathrm{~N}_{4}$. Thus, many strategies have been investigated to suppress recombination in $\mathrm{g}-\mathrm{C}_{3} \mathrm{~N}_{4}$ and consequently improve the photocatalytic performances. ${ }^{28}$ Among them, the construction of $\mathrm{g}-\mathrm{C}_{3} \mathrm{~N}_{4}$-based heterojunction nanohybrids is particularly appealing has received a lot of attention in the field of photocatalysis. This strategy will be discussed in the subsequent sections.

\section{1. g- $\mathrm{C}_{3} \mathrm{~N}_{4}$ and Noble-metal Free Materials}

Noble-metal free materials (e.g. g- $\mathrm{C}_{3} \mathrm{~N}_{4}$, graphene, carbon nanotubes, etc) have various advantages, such as being low cost and environmentally friendly. Hence, they have attracted tremendous attention to their potential in tacking environmental and energy problems. Thus, it becomes attractive to construct hybridized materials via coupling two noble-metal free materials. For example, graphene, a two-dimensional macromolecular sheet of carbon atoms, has received much attention due to its outstanding mechanical, thermal, easily-obtained, and electrical properties. ${ }^{115,} 116$ Thus, it represents an intuitive noble-metal free candidate to construct heterojunction nanohybrids with $\mathrm{g}-\mathrm{C}_{3} \mathrm{~N}_{4} \cdot{ }^{117}$

Sun et al. prepared graphene/g- $\mathrm{C}_{3} \mathrm{~N}_{4}$ heterojunctions which presented enhanced conductivities and electrocatalytic performance towards the oxygen reduction reaction (ORR). ${ }^{118}$ Xiang et al. obtained graphene/g- $\mathrm{C}_{3} \mathrm{~N}_{4}$ nanohybrids by a combined impregnationchemical reduction strategy, and successfully tested it towards the photocatalytic $\mathrm{H}_{2}$ production in the presence of Pt as a cocatalyst under visible light. ${ }^{117,}{ }^{119} \mathrm{Li}$ and collaborators synthesised cross-linked g- $\mathrm{C}_{3} \mathrm{~N}_{4} / \mathrm{rGO}$ (reduced graphene oxide) nanohybrids with tunable band structure, which demonstrated significantly enhanced visible light photocatalytic activity. ${ }^{120}$ In another example, Ong et al. have assembled rGO and $g-\mathrm{C}_{3} \mathrm{~N}_{4}$ for successful $\mathrm{CO}_{2}$ hydrogenation into methane. ${ }^{121}$ Other successful attempts have been made to explore novel materials coupling carbon nanostructures with $\mathrm{g}-\mathrm{C}_{3} \mathrm{~N}_{4}$, such as MWNTs (multi-walled carbon nanotubes)/g- $\mathrm{C}_{3} \mathrm{~N}_{4},{ }^{122,} 123 \mathrm{C}_{60} / \mathrm{g}-\mathrm{C}_{3} \mathrm{~N}_{4},{ }^{124}, 125$ carbon nanodots/g- $\mathrm{C}_{3} \mathrm{~N}_{4}{ }^{126-131}$ and polymers/g- $\mathrm{C}_{3} \mathrm{~N}_{4} \cdot{ }^{132-137}$

Another carbon structure that has gained huge attention recently is carbon nanodots. They present excellent optical and electronic features, acting as both light absorbers and electron 
reservoirs. ${ }^{126}$ Different methods have been used to synthesize carbon nanodots on g- $\mathrm{C}_{3} \mathrm{~N}_{4}$, such as hydrothermal ${ }^{138}$ and pyrolysis. ${ }^{126}$ Due to the unique nature of carbon nanodots as spectral converters, they allow for the up conversion of infrared light to visible light. The emitted light can then be used by the $\mathrm{g}-\mathrm{C}_{3} \mathrm{~N}_{4}$ for various photo-driven transformations. Carbon nanodots can also be employed as a cocatalyst in some reactions. For example, $\mathrm{H}_{2} \mathrm{O}_{2}$ is a typical intermediate of photocatalytic water splitting and its adsorption on the surface of the g- $\mathrm{C}_{3} \mathrm{~N}_{4}$ results in the poisoning of the active sites. When carbon nanodots are added on g$\mathrm{C}_{3} \mathrm{~N}_{4}$ surface, the photocatalyst maintain a high activity during the entire process. ${ }^{128}$

It is important to mention noble-metal free heterojunctions between carbon nitrides displaying different electronic structures. For instance, Wang et al. obtained two types of host-guest CN/CNS heterojunctions with a facile band alignment by the surface-assisted polymerization: CNS-CN (CN serving as the host) and CN-CNS (CNS serving as the host). ${ }^{139}$ This heterojunction is called isotype heterojunctions. Interestingly, these two types of CN/CNS heterojunctions have demonstrated significant enhancement in the photocatalytic activity and stability for $\mathrm{H}_{2}$ evolution. Inspired by Wang's work, Dong et al. synthesised layered $\mathrm{g}-\mathrm{C}_{3} \mathrm{~N}_{4} / \mathrm{g}-\mathrm{C}_{3} \mathrm{~N}_{4}$ metal-free isotype heterojunction by treating the molecular composite precursors of urea and thiourea under the same thermal conditions. This CN-T/CN-U heterojunction was constructed on the basis that the $\mathrm{g}-\mathrm{C}_{3} \mathrm{~N}_{4}$ prepared from urea and thiourea have different band structures. Upon visible light irradiation, the photogenerated electrons transfer from g- $\mathrm{C}_{3} \mathrm{~N}_{4}$ (thiourea) to g- $\mathrm{C}_{3} \mathrm{~N}_{4}$ (urea). This is driven by the conduction band offset of $0.10 \mathrm{eV}$. Also, the photogenerated holes transfer from g- $\mathrm{C}_{3} \mathrm{~N}_{4}$ (urea) to g- $\mathrm{C}_{3} \mathrm{~N}_{4}$ (thiourea) driven by the valence band offset of $0.40 \mathrm{eV} .{ }^{35}$ These two charge transfer processes are beneficial for overcoming the high dissociation barrier of the Frenkel exciton and for the stabilization of electrons and holes. The redistribution of electrons on the one side of the heterojunction (CN-U) and holes on the opposite side (CN-T) reduces the electron-hole pair recombination, extending the lifetime of charge carriers and resulting in noticeably higher photocatalytic activity. These two examples demonstrated that the rational design and construction of isotype heterojunctions could open new strategies to development of more efficient visible-light photocatalysts. ${ }^{117}$ 


\section{2. $g-\mathrm{C}_{3} \mathrm{~N}_{4}$ and Metal Oxides or Sulphides}

During the past few years, many groups have reported different types of heterojunction photocatalysts comprised of g- $\mathrm{C}_{3} \mathrm{~N}_{4}$ and metal oxides or sulphides showing improved efficiencies relative to their individual components. ${ }^{24,28,117,140} 141$

Among abundant metal oxides, $\mathrm{TiO}_{2}$ (e.g. $3.2 \mathrm{eV}$ ), which represents one of the most widely used photocatalyst, has been employed as a promising candidate for constructing g$\mathrm{C}_{3} \mathrm{~N}_{4}$ based heterojunctions. Several studies on the successful formation of $\mathrm{TiO}_{2} / g-\mathrm{C}_{3} \mathrm{~N}_{4}$ hybrid nanohybrids have been reported to enhance photocatalytic activities. ${ }^{142-153}$ Zhou et al. reported the synthesis of $\mathrm{TiO}_{2}$ nanotube array/g- $\mathrm{C}_{3} \mathrm{~N}_{4}$ heterojunction photocatalysts by a facile electrochemical approach. ${ }^{47}$ Recently, heterojunctions between g- $\mathrm{C}_{3} \mathrm{~N}_{4}$ and $\mathrm{TiO}_{2}$ with different morphologies (0D nanoparticles, 1D nanowires, 2D nanosheets, and 3D mesoporous crystals $)^{154}$ and exposed facets ( $\{001\}$ and $\left.\{101\}\right)$ have been reported. ${ }^{144,}{ }^{155-159}$ Besides the incorporation anatase $\mathrm{TiO}_{2}$ with g- $\mathrm{C}_{3} \mathrm{~N}_{4}$, other $\mathrm{TiO}_{2}$ crystal phases such as brookite and rutile have been coupled with g- $\mathrm{C}_{3} \mathrm{~N}_{4}$ for photocatalytic applications. ${ }^{160-162}$

In addition to the widely reported $\mathrm{TiO}_{2} / \mathrm{g}-\mathrm{C}_{3} \mathrm{~N}_{4}$ photocatalysts, $\mathrm{ZnO} / \mathrm{g}-\mathrm{C}_{3} \mathrm{~N}_{4}$ have also been reported ( $\mathrm{ZnO}$ presents a band gap of around $3.2 \mathrm{eV}) .{ }^{163-166}$ Several examples on the synergism between $\mathrm{ZnO}$ and g- $\mathrm{C}_{3} \mathrm{~N}_{4}$ have been observed, such as increase in photocurrent of $\mathrm{ZnO} / \mathrm{g}-\mathrm{C}_{3} \mathrm{~N}_{4}$ hybrid nanomaterials by 5 folds under visible light irradiation $(\lambda>450 \mathrm{~nm})^{48}$ and the use of $\mathrm{N}$-doped $\mathrm{ZnO} / \mathrm{g}-\mathrm{C}_{3} \mathrm{~N}_{4}$ core-shell nanoplates for visible-light photodegradation of Rhodamine B (RhB). ${ }^{167}$

Differently from $\mathrm{TiO}_{2}$ and $\mathrm{ZnO}, \mathrm{WO}_{3}$ has a relatively lower band gap of ca. 2.6-2.8 eV, which lies in the visible light region. Therefore, $\mathrm{WO}_{3} / \mathrm{g}-\mathrm{C}_{3} \mathrm{~N}_{4}$ heterostructures exhibits the Type II heterojunction charge transfer process, which drastically suppress the recombination of charge carriers. ${ }^{168-170}$ It is noteworthy that other oxides have also been employed to generate g- $\mathrm{C}_{3} \mathrm{~N}_{4}$ based hybrids, such as $\mathrm{Cu}_{2} \mathrm{O} / \mathrm{g}-\mathrm{C}_{3} \mathrm{~N}_{4}$ (which promoted a red-shifted in the absorption edge from 460 to $600 \mathrm{~nm})^{171}, \mathrm{Fe}_{2} \mathrm{O}_{3} / g-\mathrm{C}_{3} \mathrm{~N}_{4}$ (makes the material magnetically recoverable and improves photoredox activity), ${ }^{172}$ and the $\mathrm{Co}_{3} \mathrm{O}_{4} / \mathrm{g}-\mathrm{C}_{3} \mathrm{~N}_{4}$ water oxidation catalysts displaying high stabilities. ${ }^{173}$ Hybrid photocatalysts containing composite oxides have also been receiving attention. For instance, $\mathrm{Bi}_{2} \mathrm{WO}_{6}$ has been the most widely employed example. Ge et al. prepared $\mathrm{Bi}_{2} \mathrm{WO}_{6} / \mathrm{g}-\mathrm{C}_{3} \mathrm{~N}_{4}$ heterostructured photocatalysts, which presented a strong light absorption in the visible region. ${ }^{174}$ The synergistic effect between $g-\mathrm{C}_{3} \mathrm{~N}_{4}$ and $\mathrm{Bi}_{2} \mathrm{WO}_{6}$ promoted the charge transfer and separation due to the joined electric fields, whereby the excited electrons from g- $\mathrm{C}_{3} \mathrm{~N}_{4}$ were injected into the conduction band of the 
$\mathrm{Bi}_{2} \mathrm{WO}_{6}$. Simultaneously, the holes on the valence band of $\mathrm{Bi}_{2} \mathrm{WO}_{6}$ were transferred to that of g- $\mathrm{C}_{3} \mathrm{~N}_{4}$, retarding charge recombination. ${ }^{28}$

In addition to metal oxides, cadmium sulphide (CdS) is a fascinating semiconductor with a relatively low band gap of $2.4 \mathrm{eV}$, which makes it able to absorb solar light up to $520 \mathrm{~nm}$ or even longer wavelengths. ${ }^{175}$ The well-matched energy levels of g- $\mathrm{C}_{3} \mathrm{~N}_{4}$ and CdS allows for the formation of heterostructures through the Type II band alignment, which enables charge migration transfer upon light irradiation. ${ }^{28,} 176,177$ To date, CdS/g- $\mathrm{C}_{3} \mathrm{~N}_{4}$ materials, that are composed of two visible light responsive semiconductors, have been fabricated via an in situ precipitation-deposition method developed by $\mathrm{Fu}$ et al. The resulting $\mathrm{CdS} / \mathrm{g}-\mathrm{C}_{3} \mathrm{~N}_{4}$ heterostructure exhibited outstanding visible light photocatalytic in 4-aminobenzoic acid removal. ${ }^{178}$ Other studies have also reported higher stability and inhibition of photocorrosion of CdS when it is combined with g- $\mathrm{C}_{3} \mathrm{~N}_{4} \cdot{ }^{179}, 180$ Two-dimensional (2D) $\mathrm{MoS}_{2}$ nanosheets have become a promising cocatalyst to produce hybrid photocatalysts with g- $\mathrm{C}_{3} \mathrm{~N}_{4} \cdot \mathrm{MoS}_{2}$ nanosheets are robust, highly active (especially for the $\mathrm{H}_{2}$ evolution reaction), can be obtained in the layered morphology, and it is relatively inexpensive. ${ }^{181-183}$ Interestingly, under the same loading of cocatalysts $\left(\mathrm{MoS}_{2}\right.$ or $\mathrm{Pt}$ ), it has been shown that $\mathrm{MoS}_{2} / \mathrm{g}_{-} \mathrm{C}_{3} \mathrm{~N}_{4}$ outperformed the $\mathrm{Pt} / \mathrm{g}-\mathrm{C}_{3} \mathrm{~N}_{4}$ for $\mathrm{H}_{2}$ production under similar experimental conditions. ${ }^{50}$ Mechanistic investigations extensively examined the interface region between $\mathrm{g}_{-} \mathrm{C}_{3} \mathrm{~N}_{4}$ and $\mathrm{MoS}_{2}$. These studies concluded that valence band maximum and conduction band minimum of g- $\mathrm{C}_{3} \mathrm{~N}_{4}$ were greater by ca. 0.15 and $0.83 \mathrm{eV}$, respectively, relative to $\mathrm{MoS}_{2}$. This led to the formation of a Type II heterojunction system. ${ }^{184}$ As the charge redistribution occurs preferentially at the heterointerfaces, a polarized field is created at the interface region, which inhibited the recombination of charge carriers and prolonged the lifetime of photogenerated charge carriers. ${ }^{28,} 184$ Apart from CdS and $\mathrm{MoS}_{2}$, many other sulphides have been employed for improved charge separation in hybrids with g- $\mathrm{C}_{3} \mathrm{~N}_{4}$. These include $\mathrm{WS}_{2} / g-\mathrm{C}_{3} \mathrm{~N}_{4},{ }^{50}, 185$ $\mathrm{SnS}_{2} / \mathrm{g}-\mathrm{C}_{3} \mathrm{~N}_{4},{ }^{186} \mathrm{NiS}_{2} / \mathrm{g}-\mathrm{C}_{3} \mathrm{~N}_{4},{ }^{187} \mathrm{CoS} / \mathrm{g}-\mathrm{C}_{3} \mathrm{~N}_{4},{ }^{188} \mathrm{ZnS} / \mathrm{g}-\mathrm{C}_{3} \mathrm{~N}_{4},{ }^{189-191}$ and $\mathrm{Ag}_{2} \mathrm{~S} / \mathrm{g}-\mathrm{C}_{3} \mathrm{~N}_{4}{ }^{192}$

\section{3. g- $\mathrm{C}_{3} \mathrm{~N}_{4}$ and metal-organic frameworks (MOF)}

Metal-organic frameworks (MOFs) are compounds composed by metal ions coordinated to organic ligands to form one-, two-, or three-dimensional structures. Similar to what has been described for metal oxide and sulfide semiconductors, MOF materials can photogenerate holes and electrons upon visible-light irradiation, which can lead to the 
transfer of holes and electrons to target reactant molecules to initiate light-driven photoredox processes. $^{28,193}$ In terms of band structures, the MOF's valence band correspond to the outer orbitals of organic linkers, whereas the empty outer orbitals of the metal contribute to the conduction band. In this context, the incorporation of MOFs with $g-\mathrm{C}_{3} \mathrm{~N}_{4}$ is interesting due to the variety of MOF structures and species as well as their tunable cavities, porosities, and high surface areas. Several successful examples of $\mathrm{MOF} / \mathrm{g}-\mathrm{C}_{3} \mathrm{~N}_{4}$ systems have been reported, including MIL-125(Ti)/g- $\mathrm{C}_{3} \mathrm{~N}_{4},{ }^{56}$ ZIF-8/g- $\mathrm{C}_{3} \mathrm{~N}_{4},{ }^{194}$ and UiO-66/g- $\mathrm{C}_{3} \mathrm{~N}_{4} .{ }^{55}$ These systems have shown improved photocatalytic activities, high porosity and surface area, thermal stability and accelerated mass transfer processes relative to $g-\mathrm{C}_{3} \mathrm{~N}_{4} \cdot{ }^{57,195}$

\section{5. g- $\mathrm{C}_{3} \mathrm{~N}_{4}$ based Heterojunctions with Metal NPs}

\subsection{Plasmonic Photocatalysis with Metal Nanoparticles (NPs)}

Among all classes of nanomaterials, metals deserve special attention. They represent almost two-thirds of all elements in the periodic table. Moreover, metal nanostructures display remarkable chemical, electronic, optical and magnetic properties that have enable novel and/or improved applications in areas such as catalysis, electronics, plasmonics, biomedicine, separation, information storage, and biomedicine..$^{5,196-203}$

Some metals, such as silver (Ag) and gold (Au), present remarkable optical properties in the visible range. These properties probably represent one of the most visual examples of property change as we transition from the macro to the nano dimension. The unique optical properties of $\mathrm{Ag}$ and $\mathrm{Au}$ in the visible and near-infrared range occur as a result of their localized surface plasmon resonance (LSPR) excitation, and enable applications in areas such as surface-enhanced Raman scattering (SERS), plasmonic photocatalysis, plasmon-enhanced fluorescence, the development of plasmonic solar cells, water splitting, and theranostics. ${ }^{204}$ The LSPR refers to the oscillation of free charges on a metallic nanoparticle relative to the static nuclei in response to an oscillating electric field from an incoming electromagnetic wave (Fig. 4). ${ }^{205}$ 


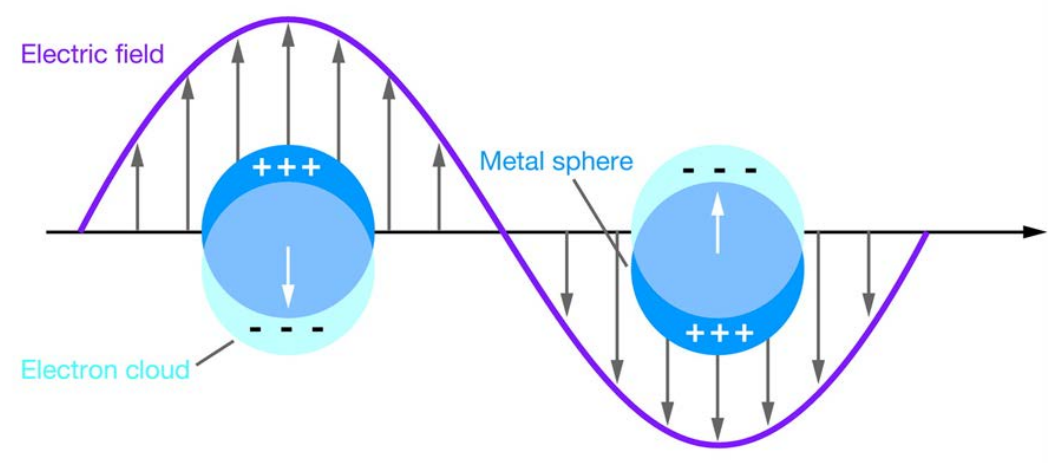

Figure 4. Schematic diagram illustrating the localized surface plasmon. Reprinted with permission from ref ${ }^{206}$. Copyright 2018 Annual Reviews.

Upon electromagnetic irradiation, the oscillating electric field component of light imposes a force onto the conduction electrons of the nanoparticle, which results in the formation of an induced dipole moment. In order to counterbalance this excitation, charge redistribution acts to provide a restoring force on the free electrons, thus granting these NPs an associated resonant frequency at a specific wavelength. The LSPR frequency is dependent on size (Fig. 5a), shape (Fig. 5b), composition (Fig. 5c), and structure of the nanoparticle as well as and the dielectric constant of the environment. ${ }^{205,196}$ The LSPR excitation leads to absorption and scattering of the incoming electromagnetic wave at frequencies close to the LSPR resonance together with the generation of intense electric fields close to the surface of the nanostructure. Fig. 5a displays the influence of size in Ag nanocubes over the LSPR resonance position. From the extinction spectra (that combines absorption and scattering), the LSPR band red shifted as size increased. This red shift can be assigned to the increased charge separation during plasmon oscillation as size increased. Fig. 5b shows the influence of Ag NPs shape their optical properties, illustrating that the optical properties are very sensitive over nanocrystal shape.

Among the metals, Ag, $\mathrm{Au}$, and cooper $(\mathrm{Cu})$ display LSPR in the visible and/or nearinfrared range (Fig. 5c). Because of this, these systems have been receiving increasing attention in the field of photocatalysis. ${ }^{207-209}$ In addition, non-noble metals such as $\mathrm{Al}, \mathrm{Bi}, \mathrm{Ga}$, $\mathrm{In}, \mathrm{Pb}$, Th, and Sn have also been receiving attention. ${ }^{210}$ These elements normally present LSPR at the UV region. In one example to circumvent this limitation, the LSPR excitation Al has been already expanded onto the visible side of the spectrum by tuning nanocrystal shape. ${ }^{211-216}$ 
(a)

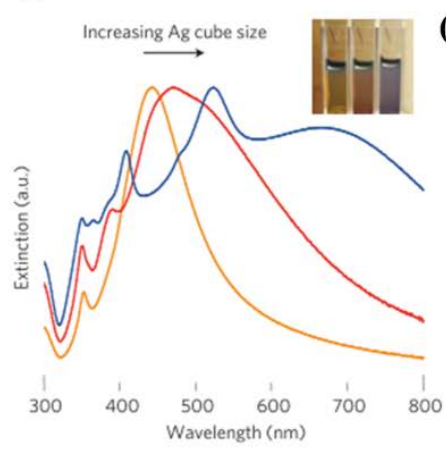

(d)

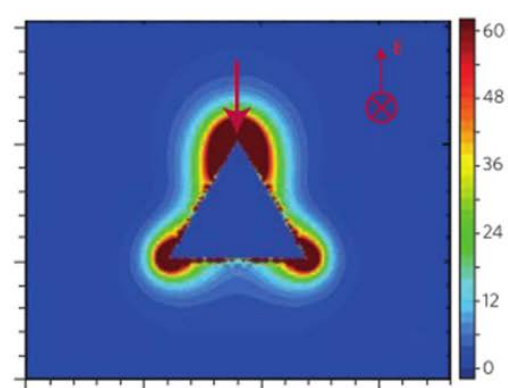

(b)

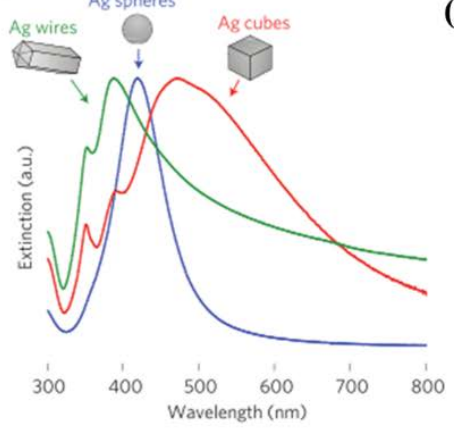

(e) (c)

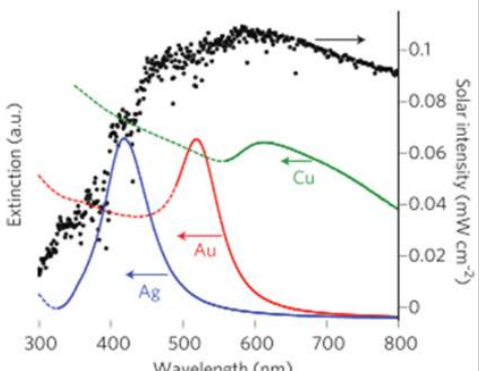

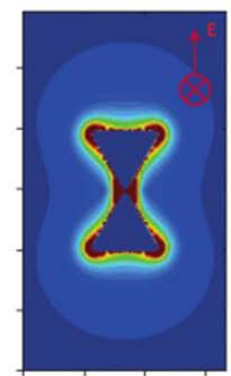

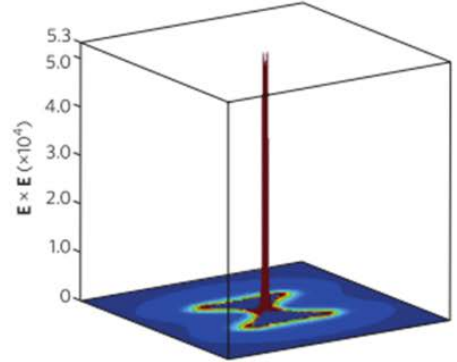

Figure 5. (a) LSPR extinction spectra as a function of size recorded for Ag nanocubes. (a) LSPR extinction spectra as a function of shape recorded for Ag nanowires, nanospheres, and nanocubes. (c) LSPR extinction and solar spectra (black) for Ag, Au and Cu NPs. Reprinted with permission from ref ${ }^{217}$. Copyright 2015 Springer Nature. (d) Simulated electric field enhancement distribution contours around an isolated silver nanoprism with a $60 \mathrm{~nm}$ edge length, excited at $700 \mathrm{~nm}$. (e) Simulated electric field enhancement distribution contours for a nanoprism dimer in a tip-to-tip configuration. The two Ag nanoprisms are set $2 \mathrm{~nm}$ from each other, and the 3D plot emphasizes the magnitude of field enhancement on the 'hot spot'. Reprinted with permission from ref ${ }^{218}$. AIP Publishing.

It has been recently established that the LSPR excitation in plasmonic nanoparticles can be put to work towards the enhancement in the rates of several chemical transformations .5, 217 This field, named plasmonic catalysis or plasmonic photocatalysis, has emerged as a new frontier in the field of catalysis and allows for the utilization of visible light as an abundant and green energy input to drive and, at least in principle, control chemical reactions. ${ }^{203,217,219}$ Importantly, plasmonic photocatalysis allows one to overcome some of the intrinsic limitations of conventional semiconductor photocatalysts, such as short-range light response, low light absorption, and high photo-generated carrier recombination rates. Photocatalytic transformations on plasmonic metallic nanostructures are singular in several respects, exhibiting different behavior as compared with semiconductors. ${ }^{220}$ Initial studies have revealed that the rates of photocatalytic reactions on excited plasmonic metallic 
nanostructures may show a super-linear power law dependence on light intensity (that is, rate is proportional to intensity ${ }^{\mathrm{n}}$, with $\left.\mathrm{n}>1\right) .{ }^{203,217,}{ }^{219}$ Consequently, photocatalytic reactions on plasmonic nanostructures may display a positive relationship between quantum efficiency and photon flux (semiconductors exhibit lower quantum efficiency at higher light intensity). Also, it has been recently observed that the rate and quantum efficiency of photocatalytic plasmonic reactions may increase with operating temperature (semiconductor photocatalysts exhibit lower reaction rates at higher temperatures). ${ }^{203,217,} 219$ This positive dependence of quantum efficiency and photocatalytic reaction rate on light intensity and operating temperature provides the possibility that, unlike semiconductor photocatalysts, plasmonic nanostructures may effectively couple thermal and photonic stimuli to drive chemical transformations. 5 , 217, 219-222

Two main enhancement mechanisms have been proposed for the observed activities in plasmonic photocatalysis: localized heating and charge transfer of LSPR-generated charge carriers at the metal-molecule interface via direct and indirect mechanisms. ${ }^{223}$ Upon light LSPR excitation (Fig. 6a), ${ }^{205}$ the LSPR oscillation decays via non-radiative and radiative pathways 197, 217, 224 While radiative damping involve scattering and is not so attractive for plasmonic photocatalysis, non-radiative damping (Landau damping) leads to the generation of hot electrons and hot holes (Fig. 6b). In other words, this creates the probability of finding the excited electrons between the fermi level of the nanoparticle $\left(E_{F}\right)$ and $E_{F}+h v \cdot{ }^{223}$ Further decay via electron-electron and electron-phonon coupling lead to a Fermi-Dirac distribution of charge carriers (Fig. 6c), which also decays via thermal dissipation to the surroundings (Fig. 6d). 225, 226,217, 227,228,223 This localized heating can provide the energy input to accelerate chemical reactions. It has also been employed in several biomedical applications ${ }^{229,230}$ and the development of photothermal motors using self-assembled Au NPs. Under light incidence, these NPs are responsible for raising the local temperature, which thus generates water vapor that propels the material to the opposite side of the vapor current. 231219,232 Another important application included the utilization of aluminium (Al) NPs for the desalinization of water. A three-dimensional porous membrane containing Al NPs, fabricated by its self-assembly, was employed as a plasmonic heat source. Through water vapor generation, saline water was efficiently purified under solar light irradiation. These applications provide huge environmental impact at remote locations where pure water is scarce. $^{233}$

Regarding the enhancement mechanism via charge transfer of LSPR excited hot carriers, two potential microscopic pathways, indirect and direct, can take place. In the indirect 
pathway, charge carriers are excited from occupied states to higher-energy unoccupied states in the metal particle. This leads to an excited electron distribution. Charge carriers of appropriate energy from this distribution can then scatter through the adsorbate states (orbitals) forming transiently charged adsorbates. The facilitation/activation of these species then lead to increased reaction rates. The role of LSPR in this process is to increase the rates of charge excitation. On the other hand, the direct transfer pathway involves an LSPRinduced electron excitation from occupied to unoccupied orbitals of the moleculenanoparticle complex that is not mediated by the formation of an excited electron distribution within the metal. Instead, there is the excitation of an electron directly into an unoccupied adsorbate orbital of matching energy. ${ }^{234,235}$

As aforementioned, the LSPR excitation also leads to the generation of intense electric fields close to the surface of the nanostructure. These electric fields are fundamental for applications such as the Surface-enhanced Raman scattering (SERS) phenomenon according to the electromagnetic mechanism of enhancement (Fig. 5d-e). ${ }^{236,237}$ In addition to its applications towards the development of ultrasensitive sensors, SERS can also be employed to monitor transformations triggered by the LSPR excitation. One example is the SPRmediated oxidation of 4-aminothiophenol (PATP) to 4,4'-dimercaptoazobenzene (DMAB). ${ }^{238}$ Moreover, some reports have shown that these electric fields may be related to plasmonic catalytic enhancements.

(a)

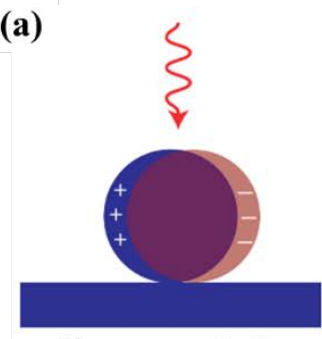

Plasmon excitation $t=0 \mathrm{~s}$

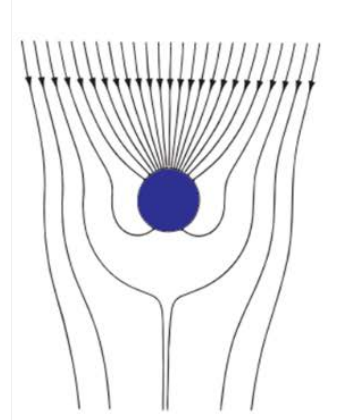

(b)
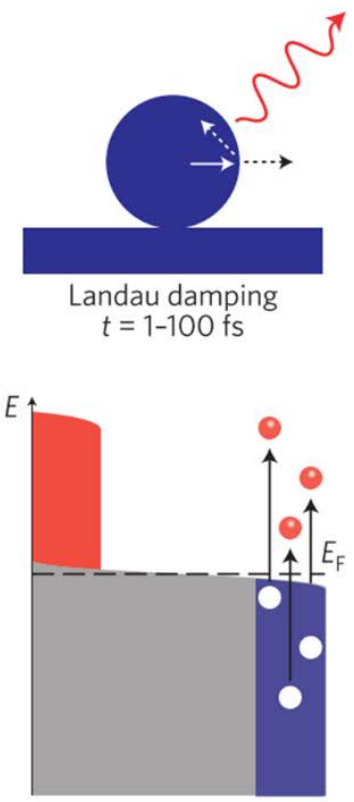

Population (c)
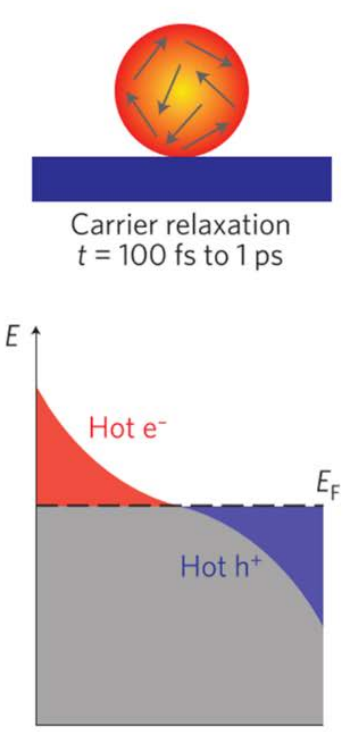

Population (d)
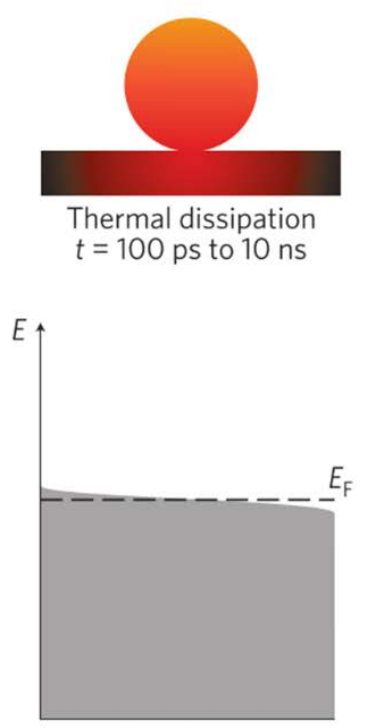

Population 
Figure 6. Photoexcitation and subsequent relaxation processes following the illumination of a metal nanoparticle with a laser pulse, and characteristic timescales; (a) First, the excitation of a localized surface plasmon redirects the flow of light (Poynting vector) towards and into the nanoparticle; (b-d) Schematic representations of the population of the electronic states (grey) following plasmon excitation: hot electrons are represented by the red areas above the Fermi energy $E_{F}$ and hot hole distributions are represented by the blue area below $E_{F}$; (b) In the first 1-100 fs following Landau damping, the a thermal distribution of electron-hole pairs decays either through re-emission of photons or through carrier multiplication caused by electronelectron interactions. During this very short time interval, the hot carrier distribution is highly non-thermal; (c) The hot carriers will redistribute their energy by electron-electron scattering processes on a timescale ranging from 100 fs to 1 ps; (d) Finally, heat is transferred to the surroundings of the metallic structure on a longer timescale ranging from 100 ps to $10 \mathrm{~ns}$, via thermal conduction. Reprinted with permission from ref ${ }^{228}$. Copyright 2015 Springer Nature.

Therefore, based on the remarkable optical properties of Ag, $\mathrm{Au}$, and $\mathrm{Cu}$ NPs in the visible and near-infrared range as a result of the LSPR excitation, it becomes intuitive that their hybrids with g- $\mathrm{C}_{3} \mathrm{~N}_{4}$ may lead to materials with interesting properties that combine plasmonic and photocatalytic effects. In the following sections, we will start by discussing some general aspects and principles involved in the construction of hybrid materials composed of plasmonic nanoparticles and semiconducting materials. Then, we will focus on the emerging class of hybrids composed of g- $\mathrm{C}_{3} \mathrm{~N}_{4}$ and plasmonic nanoparticles.

\subsection{Coupling plasmonic NPs and semiconducting materials}

It is well known that plasmonic NPs can act as both light absorbers and electron traps, enabling the lowering recombination rates when combined with semiconducting materials. ${ }^{239}$ When metal NPs are deposited on a semiconductor surface, a contact potential difference is generated at their interface due to their different work functions. This potential difference is called the Schottky barrier, and the band bending when a contact is formed after reaching equilibrium is dependent on the relative energies of the work functions of the metal and semiconducting component as illustrated in Fig. 7. This phenomenon can induce the directional migration of photogenerated electrons from semiconductor to metal, greatly enhancing the charge separation efficiency. ${ }^{24}$ Therefore, this system behaves as an effective electron trapping site to suppress the electron-hole recombination. 
(a)

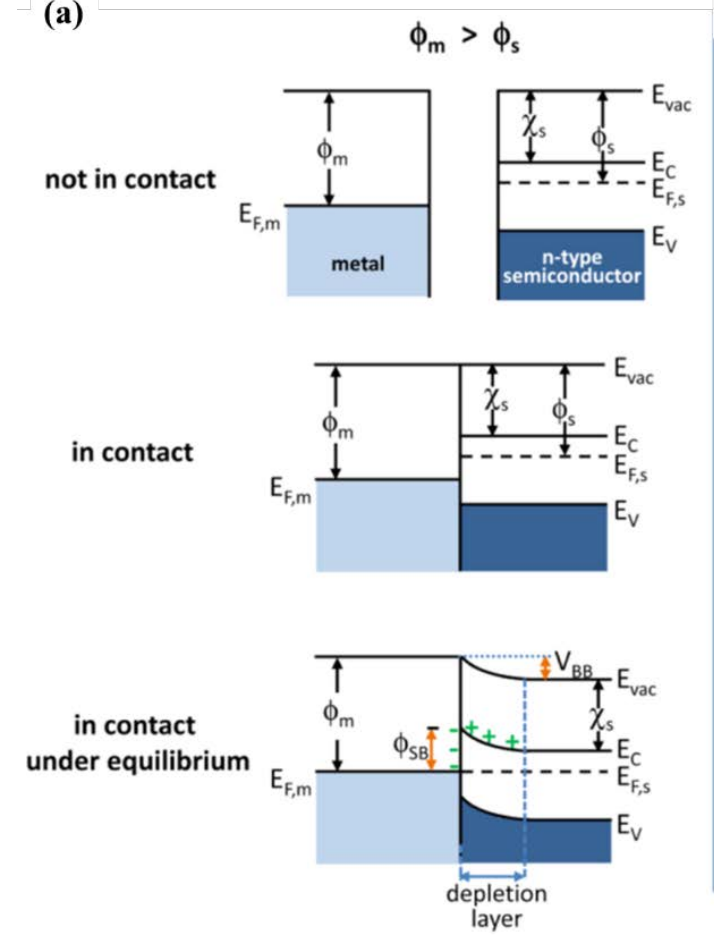

(b)
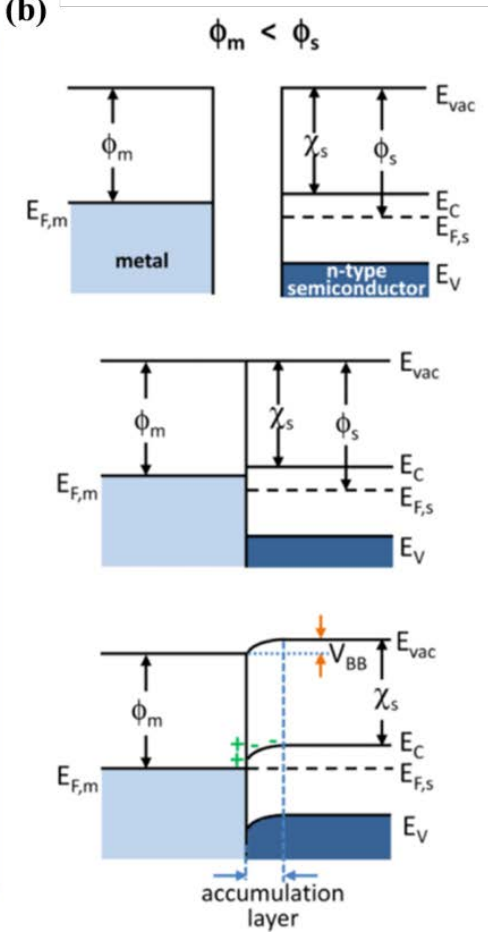

Figure 7. Band structures for a hybrid composed of a metal and a semiconductor nanoparticle (the not in contact, in contact, and in contact under equilibrium scenarios are shown in the top, middle and bottom panels, respectively.). (a) and (b) represent the band-bending effect on a metallic nanoparticle (light blue) attached to an n-type semiconductor (dark blue) in two scenarios: when the semiconductor work function $\left(\phi_{s}\right)$ is higher than the metal work function $\left(\phi_{\mathrm{m}}\right)$ (a), and when the semiconductor work function $\left(\phi_{\mathrm{s}}\right)$ is lower than the metal work function $\left(\phi_{\mathrm{m}}\right)$ (b). Reprinted with permission from ref ${ }^{240}$. Copyright 2012 American Chemical Society.

Fig. 8 displays the common mechanisms by which the LSPR excitation in hybrids between plasmonic NPs and semiconductors hybrids can lead to improvements in photocatalytic activities. ${ }^{223}$ When plasmonic NPs are coupled with semiconductors, in addition as acting as electron traps, localized heating (Fig. 8a) and near-field enhancements (Fig. 8b) as a result of the LSPR excitation can lead to an enhancement in the generation of charge carries at the semiconductor. Moreover, charge-transfer processes of SPR-excited hot electrons and holes between the metal and semiconductor can also take place (Fig. 8c). These processes also occur simultaneously in the hybrids. In this case, the elucidation of the mechanistic contribution of each effect over the detected activities represents an important challenge in the field. 238,196, 223, 241 
(a)

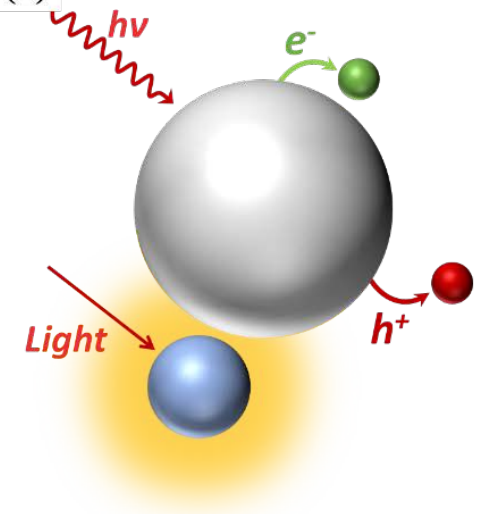

(b)

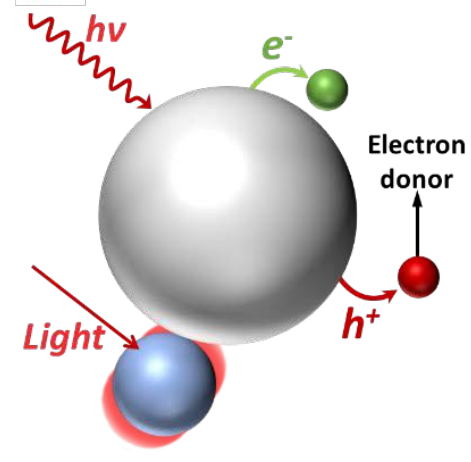

(c)

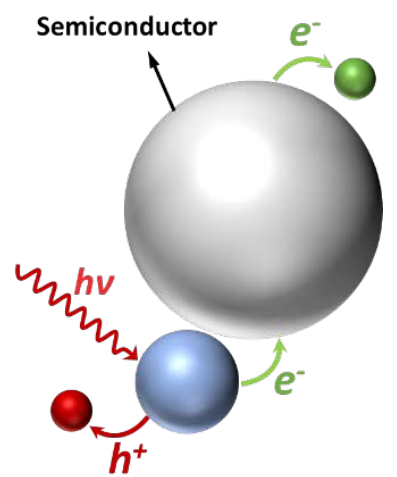

Figure 8. (a-c) LSPR-related mechanisms on hybrid materials composed of plasmonic NPs and semiconducting materials; (a) Local temperature increase causes the enhancement of exciton formation on the semiconductor; (b) Optical near-field enhancement promotes the transfer of photons to the semiconductor, thus increasing the exciton formation; (c) Hotelectrons and holes are transferred to the semiconductor, so reactions on their surface can also be enabled by LSPR. Reprinted with permission from ref ${ }^{223}$. Copyright 2014 Royal Society of Chemistry.

Three main approaches can be employed for the synthesis of these hybrids. The first consists in the heterogeneous nucleation and growth of metal NPs at the surface of the semiconductors, which are employed as seeds or physical templates for the formation of metal NPs. The second comprises the impregnation of pre-formed NPs at the surface of the semiconductor. Finally, the third involves the one-pot synthesis of both semiconductor and metal NPs. ${ }^{242-250}$ It is important to note that metal/semiconductor NPs hybrids displaying core-shell and other morphologies have also been reported (such as metal NPs decorated at the tips of semiconducting nanorods). However, these systems will not be the focus of our discussion in this review.

Among the several reported materials, hybrids composed of $\mathrm{Au} \mathrm{NPs}$ and $\mathrm{TiO}_{2}$ represent one of the most widely studied examples of a material comprising a plasmonic and semiconducting component. ${ }^{251-256}$ In the context of $\mathrm{g}-\mathrm{C}_{3} \mathrm{~N}_{4}$, it is clear that the LSPR excitation of noble (Au and Ag) ${ }^{4}$ and even non-noble (e.g. Bi) metals can expand the optical spectral response of $\mathrm{g}-\mathrm{C}_{3} \mathrm{~N}_{4}$ to visible light, while the excellent catalytic activity enabled by the metal NPs can provide catalytic sites for target transformations. ${ }^{28,257-261}$ 


\subsection{Hybrids between noble metal $\mathrm{NPs}$ and $\mathrm{g}-\mathrm{C}_{3} \mathrm{~N}_{4}$}

Au and Ag represent the most investigated noble metal NPs displaying LSPR effect in the visible or near-infrared range. Au-loaded on bulk ${ }^{53,262,263}$ and exfoliated ${ }^{264}$ g- $\mathrm{C}_{3} \mathrm{~N}_{4}$ have been reported for various photocatalytic applications. ${ }^{265}$ Different methods to decorate the g- $\mathrm{C}_{3} \mathrm{~N}_{4}$ surface with the metal NPs are commonly used, such as photoreduction, ${ }^{263,264,} 266$ impregnation, ${ }^{265}$ and deposition-precipitation. ${ }^{53}$ Di et al. compared Au/g- $\mathrm{C}_{3} \mathrm{~N}_{4}$ synthesized by photoreduction, impregnation, and deposition-precipitation. They reported a higher photocatalytic activity for the composite prepared by the deposition-precipitation, due to the formation of tight Au-semiconductor heterojunctions effectively promoting the transfer of charge from light-excited g- $\mathrm{C}_{3} \mathrm{~N}_{4} .{ }^{53}$ The stronger the interfacial contact between $\mathrm{Au}$ and g$\mathrm{C}_{3} \mathrm{~N}_{4}$, the easier the electron migration process will be. Moreover, the LSPR effect in $\mathrm{Au}$ helped in visible light absorption in the hybrid, also contributed to the superior photocatalytic activities. Samanta et al. compared pure g- $\mathrm{C}_{3} \mathrm{~N}_{4}$ with $1 \mathrm{wt} \% \mathrm{Au} / \mathrm{g}-\mathrm{C}_{3} \mathrm{~N}_{4}$. The plasmonic photocatalyst presented a photocurrent density that was 3000 folds higher than pure g- $\mathrm{C}_{3} \mathrm{~N}_{4}$. The dramatically enhanced photocurrent density of $\mathrm{Au} / \mathrm{g}-\mathrm{C}_{3} \mathrm{~N}_{4}$ was ascribed to the strong visible light absorption and boosted charge carrier separation due to the LSPR effect from Au NPs. ${ }^{54}$ Furthermore, it can be observed that the Au Fermi level can shift towards more negative potentials when the electrons were transferred from the $\mathrm{sp}^{2}$-hybridized $\pi$-conjugated g- $\mathrm{C}_{3} \mathrm{~N}_{4}$ network to $\mathrm{Au}$. Essentially, Au played a dual-function role as an electron collector and also as a plasmonic cocatalyst. ${ }^{28}$

Ag, which presents a characteristic LSPR peak centered at ca. $450 \mathrm{~nm}$, has also been employed to form heterojunctions with $\mathrm{g}_{-} \mathrm{C}_{3} \mathrm{~N}_{4}{ }^{52,267-272}$ It is important to note that in both $\mathrm{Au}$ and Ag, the LSPR frequency can be tuned by maneuvering their size and shape. ${ }^{5}$ Yang et al. reported that $\mathrm{Ag} / \mathrm{g}-\mathrm{C}_{3} \mathrm{~N}_{4}$ nanohybrids prepared by photo deposition were active under visible light due to the LSPR excitation in Ag NPs as well as the fast transportation and separation of charge carriers. ${ }^{273}$ It was demonstrated that the LSPR effect of Ag promoted an enhancement of local electromagnetic fields, which improved the generation of electron and holes within g$\mathrm{C}_{3} \mathrm{~N}_{4}$. In addition to the LSPR effect, the photogenerated electrons on g- $\mathrm{C}_{3} \mathrm{~N}_{4}$ can be scavenged promptly by Ag NPs, forming a Schottky barrier to inhibit the charge recombination process. ${ }^{28}$ Further details about Ag modified g- $\mathrm{C}_{3} \mathrm{~N}_{4}$ hybrid synthesis and their applications can be found in a recent review written by Patnaik et al. ${ }^{274}$

An interesting example that illustrated the importance of the strength of interaction between the noble metal and g- $\mathrm{C}_{3} \mathrm{~N}_{4}$ to ensure the smooth transfer of photoinduced electrons 
was reported in the Pt/g- $\mathrm{C}_{3} \mathrm{~N}_{4}$ material by Shiraishi and co-workers. They investigated the influence of two different synthesis methods over photocatalytic activities: $i$ ) reduction of Pt precursor by $\mathrm{H}_{2}$ at a high temperature, and ii) photoreduction. Both approaches yielded nearly similar Pt particle sizes (ca. 3.5-4 nm). Surprisingly, the catalyst prepared by the hightemperature method exhibited 10 times higher photocatalytic activity for $\mathrm{H}_{2}$ evolution when compared with samples prepared by photoreduction method. ${ }^{275}$ Several other studies also reported increased photocatalytic activity in Pt/g- $\mathrm{C}_{3} \mathrm{~N}_{4}$ heterojunctions, especially for photodegradation ${ }^{276}$ and $\mathrm{CO}_{2}$ photoreduction. ${ }^{277,} 278$

In addition to $\mathrm{Pt}, \mathrm{Pd} / \mathrm{g}-\mathrm{C}_{3} \mathrm{~N}_{4}$ heterojunctions have been widely investigated. A range of publications have addressed synthesis routes to decorate g- $\mathrm{C}_{3} \mathrm{~N}_{4}$ with Pd NPs. ${ }^{279-284}$ Among them, it is worth to highlight the results reported by Bai and co-workers on the effect of Pd facet selectivity as a cocatalyst in photocatalysis. They produced uniformly dispersed Pd NPs with different preferential exposed facets, $\{100\}$ and $\{111\}$, on $2 \mathrm{D} g-\mathrm{C}_{3} \mathrm{~N}_{4}$. They showed that reduction of $\mathrm{CO}_{2}$ can better occur on $\mathrm{Pd}\{111\}$ facets while $\mathrm{H}_{2} \mathrm{O}$ prefers to generate $\mathrm{H}_{2}$ on $\mathrm{Pd}-\{100\}$. The authors justified the higher activity of the $\mathrm{Pd}\{111\}$ facets towards $\mathrm{CO}_{2}$ reduction as a result of the higher adsorption energy of $\mathrm{CO}_{2}$ in these surface facets $(0.230 \mathrm{eV})$ when compared to $\mathrm{Pd}\{001\}(0.064 \mathrm{eV})$, as indicated by first-principles theoretical calculations. $^{283}$

\subsection{Hybrids Between Non-Noble Metals NPs and g-C $\mathrm{C}_{4}$}

Apart from the noble metals, $\mathrm{Bi}, \mathrm{Ni}$ and $\mathrm{Cu}$ have also been used to form hybrid composited with g- $\mathrm{C}_{3} \mathrm{~N}_{4}$. The semimetal Bi exhibits intriguing properties, being able to act as an electron reservoir and possessing plasmonic properties (which are in essence similar to the noble metals). Dong et al. deposited Bi nanospheres on thin $g-\mathrm{C}_{3} \mathrm{~N}_{4}$ layers and observed a wide additional absorption peak at ca. $500 \mathrm{~nm}$, thus improving visible light absorption and thus the generation of charge carriers. They also observed a higher surface photovoltage (SPV) response for $\mathrm{Bi} / \mathrm{g}-\mathrm{C}_{3} \mathrm{~N}_{4}$ due to the electric field generated from $\mathrm{Bi}$ accompanied by the transfer of electrons from $\mathrm{g}-\mathrm{C}_{3} \mathrm{~N}_{4}$ to $\mathrm{Bi}$ metal as an electron channel. These local electromagnetic fields emerge from the LSPR effect in $\mathrm{Bi}$, which was confirmed by using a finite integration technique simulation. ${ }^{285}$ Another non-noble metal displaying plasmonic properties which was reported in g- $\mathrm{C}_{3} \mathrm{~N}_{4}$ based hybrids is $\mathrm{Cu}$. To the best of our knowledge, only Zhang et al. have investigated Cu NPs to improve photocatalytic reactions in this context. They observed a red-shift on light absorption due to LSPR effect of Cu NPs and an 
increment in the $\mathrm{H}_{2}$ evolution rate under visible light irradiation. ${ }^{286}$ Wang et al. have tested $\mathrm{Cu} / \mathrm{g}-\mathrm{C}_{3} \mathrm{~N}_{4} \mathrm{NPs}$ composite as peroxidase-like to help in glucose detection in blood samples, which allow lower detection limits. ${ }^{287}$ Studies on $\mathrm{Cu} / \mathrm{g}-\mathrm{C}_{3} \mathrm{~N}_{4}$ heterojunctions have remained scarce mainly due to the instability of the Cu NPs towards oxidation in air. Hence, most of the reports tested $\mathrm{Cu}$ oxides or hydroxides with g- $\mathrm{C}_{3} \mathrm{~N}_{4} \cdot{ }^{171}, 288,289$

$\mathrm{Ni}$ has also been studied as a cocatalyst with g- $\mathrm{C}_{3} \mathrm{~N}_{4}$. Bi et al. reported increment on the SPV due to efficient charge separation at the heterojunction interface of $\mathrm{Ni} / \mathrm{g}-\mathrm{C}_{3} \mathrm{~N}_{4} .{ }^{290} \mathrm{Kong}$ and collaborators developed a robust and visible light active Ni/g- $\mathrm{C}_{3} \mathrm{~N}_{4}$ catalyst for $\mathrm{H}_{2}$ production. Their mechanistic studies concluded that the hybrid composite presented high visible light activity due to $\mathrm{Ni}$ NPs effectively preventing the recombination of the photogenerated electrons and holes of g- $\mathrm{C}_{3} \mathrm{~N}_{4}{ }^{291}$ In a recent publication, Wen and co-workers reported that the $\mathrm{H}_{2}$-evolution activity for the system $\mathrm{Ni} / \mathrm{g}-\mathrm{C}_{3} \mathrm{~N}_{4}$ can be further improved by the addition of NiS. They reported a significant synergistic effect between the multifunctional metallic $\mathrm{Ni}$ interface layers and amorphous $\mathrm{NiS}$ improving the charge separation/transportation. This effect could enhance both $\mathrm{H}_{2}$-production and TEOA-oxidation kinetics, thus resulting in the significantly boosted photocatalytic $\mathrm{H}_{2}$ evolution over the ternary composite photocatalysts. ${ }^{292}$ It is worth to highlight the recent $\mathrm{Al}$ decorated $\mathrm{g}-\mathrm{C}_{3} \mathrm{~N}_{4}$ reported by Choi and colleagues. The incorporation of this inexpensive and abundant metal significantly changed optical and photocatalytic properties and led to increments for $\mathrm{H}_{2}$ evolution and organic pollutant degradation under light excitation. ${ }^{293}$

\subsection{Hybrids between bimetallic NPs and $\mathrm{g}-\mathrm{C}_{3} \mathrm{~N}_{4}$}

Compared to monometallic NPs, bimetallic NPs have attracted massive interest in catalysis, in which the synergy between the two metals (electronic effect) have led to improved performances. ${ }^{24,294}$ In addition to catalytic activity, selectivity and stability have also been dramatically affected in the bimetallic systems. ${ }^{295}$ Han et al. reported g- $\mathrm{C}_{3} \mathrm{~N}_{4}$ nanohybrids modified with PtCo bimetallic alloy NPs. They were formed on $\mathrm{g}^{-} \mathrm{C}_{3} \mathrm{~N}_{4}$ by an in situ strategy based on chemical reduction. This material was investigated towards the photocatalytic $\mathrm{H}_{2}$ evolution. They showed that the bimetallic NPs increased the surface defect density and changed the Fermi level in comparison to monometallic Pt NPs. This lead to the better separation of photogenerated charge carriers and consequently to a more active catalyst

for generate $\mathrm{H}_{2}$ under visible light irradiation. ${ }^{296}$ The same group also reported $\mathrm{AuPd} / \mathrm{g}-\mathrm{C}_{3} \mathrm{~N}_{4}$ bimetallic photocatalysts with enhancement of visible light absorption and more efficient 
separation of electron-hole pairs as compared to $\mathrm{g}-\mathrm{C}_{3} \mathrm{~N}_{4}$ and their monometallic counterparts. ${ }^{297}$

The effect of the exposed facet (shape effect) is also important in bimetallic systems. PtCu concave nanocubes displaying high-index $\{730\}$ surface facets loaded on g- $\mathrm{C}_{3} \mathrm{~N}_{4}$ nanosheets exhibited higher photocatalytic activity and selectivity in $\mathrm{CO}_{2}$ reduction for methane $\left(\mathrm{CH}_{4}\right)$ production as compared to PtCu nanocubes (enclosed by $\{100\}$ facets) loaded on g- $\mathrm{C}_{3} \mathrm{~N}_{4}$. This enhancement was assigned to the presence of more low-coordinated, active metal active sites in the concave nanocubes with high index surface facets, favouring adsorption and activation of $\mathrm{CO}_{2} .{ }^{298}$

\subsection{Metal NPs in g- $\mathrm{C}_{3} \mathrm{~N}_{4}$-based Z-scheme photocatalysts}

An important class of application of metal NPs is to work as a conductor in Z-scheme photocatalytic systems. Metal NPs (such as $\mathrm{Au}, \mathrm{Ag}, \mathrm{Pt}, \mathrm{Cu}$, and $\mathrm{Bi}$ ), as well as carbon materials (such as GO, CNTs, rGO and carbon), can be applied as solid-state electron mediators for the g- $\mathrm{C}_{3} \mathrm{~N}_{4}$-based Z-scheme systems. They can promote a fast separation of the photogenerated electron-hole pairs at the interface of the two semiconductors. ${ }^{299-302}$ The metal NPs can also serve as a charge transmission bridge. When a conductor is added between two semiconductors, it forms an Ohmic contact with low contact resistance as depicted in Fig. 9. ${ }^{303,304}$ The photoinduced electrons in the conduction band semiconductor 2 can directly recombine with the holes in the valence band of semiconductor 1 through the Ohmic contact. Consequently, the holes and electrons with more efficient redox ability can be mostly reserved for efficient photocatalytic reactions. ${ }^{305,306}$ Z-scheme systems have attracted considerable attention because it not only boosts the spatial separation efficiency of photoinduced electron-hole pairs but also minimizes undesirable backward reaction of the photocatalytic process due to two different redox sites. ${ }^{307,} 308$ Moreover, maximum overpotentials can be obtained with this unique Z-scheme system, which benefits from the effective utilization of a high conduction band from semiconductor S2 and a low valence band from semiconductor S1. ${ }^{309,} 310$ Many recent advances have been done using g- $\mathrm{C}_{3} \mathrm{~N}_{4}$ in Zscheme heterojunctions. This topic was recently reviewed by Jiang et al., which covered the preparation and catalytic application of g- $\mathrm{C}_{3} \mathrm{~N}_{4}$-based Z-scheme systems. ${ }^{305}$ 


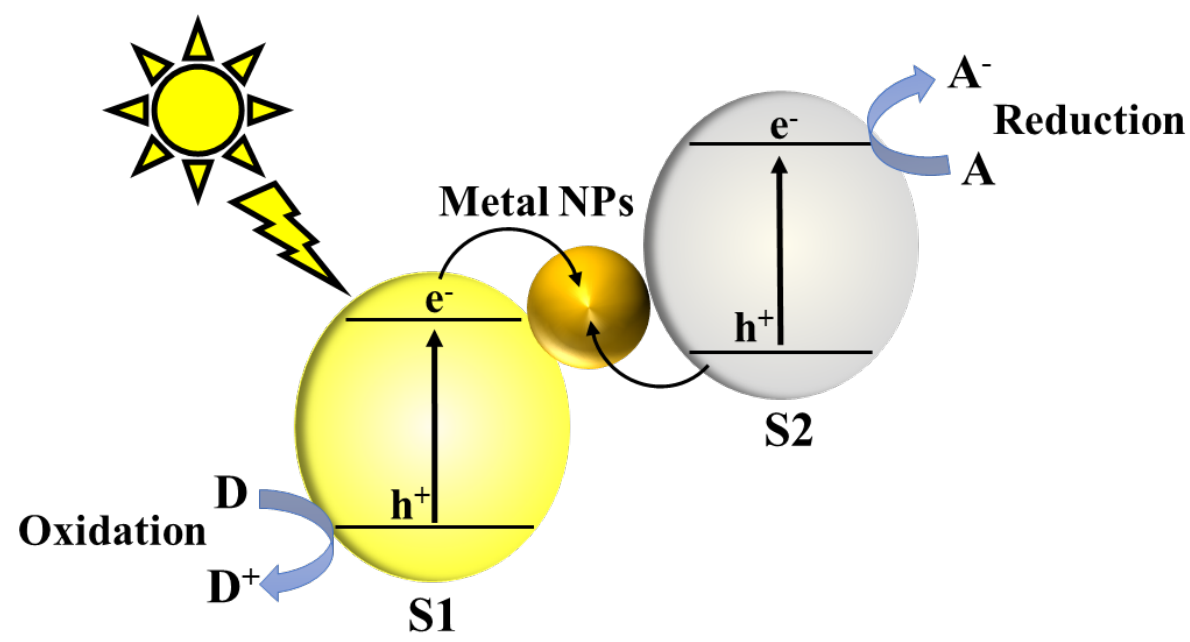

Figure 9. Schematic illustrations of two semiconductors (S1 and S2), coupled in a Z-scheme in the presence of a metal NPs as an electron mediator. Adapted with permission from ref ${ }^{306}$. Copyright 2015 John Wiley and Sons.

\section{Photocatalytic Applications of Metal NPs and g- $\mathrm{C}_{3} \mathrm{~N}_{4} \mathrm{Hybrids}$}

Metal NPs can have a wide range of catalytic applications. In fact, they can be coupled with g- $\mathrm{C}_{3} \mathrm{~N}_{4}$ to accomplish one or more of the following tasks: $i$ ) improve charge separation through heterojunctions with $\mathrm{g}-\mathrm{C}_{3} \mathrm{~N}_{4}$; ii) improve the visible light utilization; and iii) act as a cocatalysts lowering the redox overpotential at the active sites and helping in the activation of the reactant molecules. ${ }^{28}$ This section will focus on how each metal presented in the last section help to address one or more of those tasks when coupled with $g-\mathrm{C}_{3} \mathrm{~N}_{4}$ in different catalytic reactions together with a detailed discussion of their enhancement mechanisms.

\subsection{Photocatalytic Water Splitting}

Hydrogen is considered as an ultimate clean fuel because of its high-energy density (140 MJ kg-1), environmental benignancy, and recycling. ${ }^{1}$, 117, 311 The generation of $\mathrm{H}_{2}$ from water by employing a photocatalyst and solar energy has been considered a promising approach to produce hydrogen energy. ${ }^{312,313}$ A range of semiconductor photocatalysts have been reported to catalyse the evolution of $\mathrm{H}_{2}$ from water. However, the practical applications of this strategy are limited by the prompt recombination of photogenerated electron-hole pairs within photocatalysts. According to the requirement of thermodynamics, the conduction band potential should be more negative than the reduction potential of $\mathrm{H}_{2} \mathrm{O}\left(0 \mathrm{~V}\right.$ vs. NHE) for $\mathrm{H}_{2}$ 
generation, and the valence band potential should be more positive than the oxidation potential of $\mathrm{H}_{2} \mathrm{O}$ (1.23 V vs. NHE) for $\mathrm{O}_{2}$ generation. g- $\mathrm{C}_{3} \mathrm{~N}_{4}$ possess appropriate conduction and valence band positions to catalyse the water splitting reaction. ${ }^{24,314}$ Moreover, its visiblelight-driven properties and high specific surface area makes g- $\mathrm{C}_{3} \mathrm{~N}_{4}$ a promising photocatalyst to promote the $\mathrm{H}_{2}$-evolution from water. ${ }^{314,} 315$ The U.S. Department of Energy (DOE) has concluded that photocatalyst for water splitting must have solar-to-hydrogen (STH) efficiency equal or higher than 5\% to meet the economically viable price of US\$ 2-4 $/ \mathrm{kg} \mathrm{H}_{2}$. Up to now, one of the photocatalysts that are closer to this efficiency is a $\mathrm{g}-\mathrm{C}_{3} \mathrm{~N}_{4}$ based catalyst comprised of carbon nanodots on g- $\mathrm{C}_{3} \mathrm{~N}_{4} \cdot{ }^{128}$ Despite all the great properties of the $g-\mathrm{C}_{3} \mathrm{~N}_{4}$, when it is used to catalyse the water-splitting reaction, it produces $0.1-4 \mu \mathrm{mol}$ $\mathrm{h}^{-1}$ of $\mathrm{H}_{2}$ with a quantum efficiency (QE) of less than $1 \%$ under visible light. ${ }^{28,261,316,317}$ Hence, it is highly important modify g- $\mathrm{C}_{3} \mathrm{~N}_{4}$ to allow higher rates of $\mathrm{H}_{2}$ production and quantum efficiencies. For instance, Table 1 summarizes the recent advances in the photocatalytic water splitting photocatalysed by metal NPs/g- $\mathrm{C}_{3} \mathrm{~N}_{4}$-based nanohybrids.

Platinum is one of the most efficient cocatalysts for $\mathrm{H}_{2}$ generation and has been widely used for enhancing the performance of $\mathrm{g}-\mathrm{C}_{3} \mathrm{~N}_{4}$-based hybrid. ${ }^{13}, 260,261,275-278,318-322$ The intriguing mechanism of how the noble metals, especially Pt, act during the water-splitting reaction has been widely investigated. Fina et al. found that the oxygen content of the cocatalyst does not seem to affect the photocatalysts activity. Their investigation concluded that the main factor affecting the $\mathrm{H}_{2}$ evolution rate of the materials was the coverage, represented as the Pt:N ratio, with a lower coverage being more beneficial. Following the coverage, the crystallite size of the metal NPs also played an important role in the catalytic activity. Pt/g- $\mathrm{C}_{3} \mathrm{~N}_{4}$ materials in which Pt NPs were characterised by a higher crystallinity resulted in a higher $\mathrm{H}_{2}$ evolution. ${ }^{260} \mathrm{Li}$ and co-workers investigated single-atom $\mathrm{Pt}$ as a cocatalyst for g- $\mathrm{C}_{3} \mathrm{~N}_{4}$ in $\mathrm{H}_{2}$ production. They showed that isolated single Pt atoms induces an intrinsic change of the surface trap states leading to a longer lifetime of photogenerated electrons and thereby improved photocatalytic performance (Fig. 10). Single-atom Pt cocatalyst led to tremendous enhancements on photocatalytic $\mathrm{H}_{2}$ generation, being 8.6 times higher than that of Pt NPs the per Pt atom basis, and nearly 50 times of that for bare g$\mathrm{C}_{3} \mathrm{~N}_{4}{ }^{318}$ 


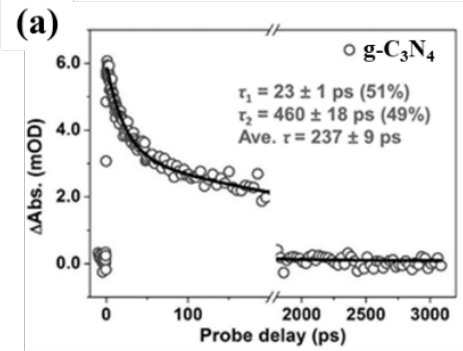

(d)

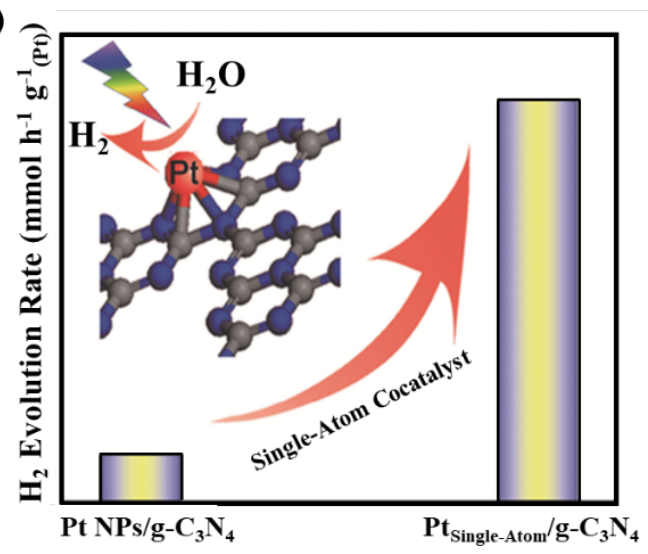

(b)

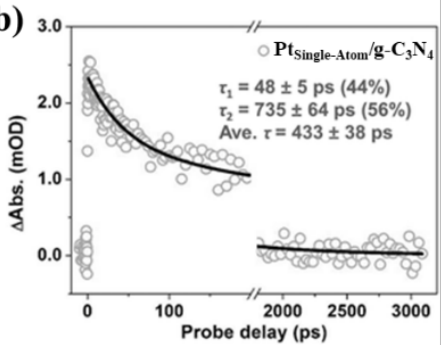

(e)

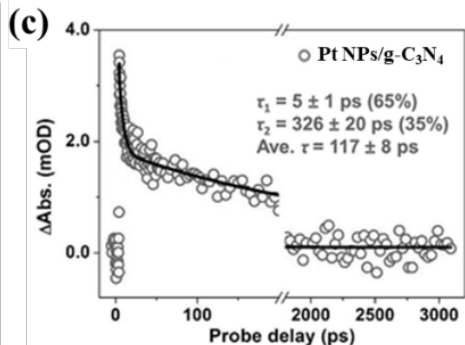

个 Probing

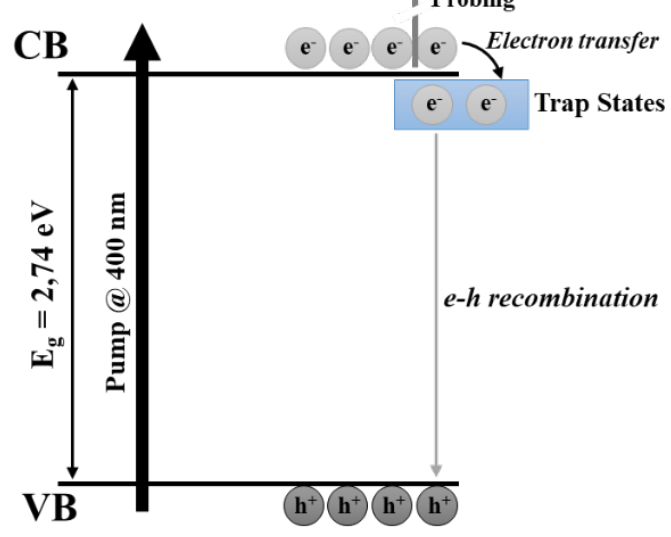

Figure 10. Representative ultrafast transient absorption (TA) kinetics probed at $750 \mathrm{~nm}$ (pump at $400 \mathrm{~nm}$ ) for (a) $\mathrm{g}-\mathrm{C}_{3} \mathrm{~N}_{4}$;

(b) $\mathrm{Pt}_{\text {Single-Atom }} / \mathrm{g}-\mathrm{C}_{3} \mathrm{~N}_{4}$ and

(c) Pt NPs/g- $\mathrm{C}_{3} \mathrm{~N}_{4}$.

Schematic model of Ptsingle-Atom/g- $\mathrm{C}_{3} \mathrm{~N}_{4}$ and photocatalytic comparison with Pt NPs/g- $\mathrm{C}_{3} \mathrm{~N}_{4}$; (d) Schematic illustration of the mechanisms which led to a longer lifetime of photogenerated electrons. Adapted with permission from ref ${ }^{318}$. Copyright 2016 John Wiley and Sons.

Although Pt is essentially the most efficient cocatalyst for water splitting, it is prohibitively expensive, which strongly limits its practical applications. In the past few years, the Pt-free approach has been successfully demonstrated for $\mathrm{H}_{2}$ evolution by combining g$\mathrm{C}_{3} \mathrm{~N}_{4}$ with a more inexpensive metal, such as $\mathrm{Ni}, \mathrm{Cu}, \mathrm{Zn}$, Co, and Fe. Chen et al. introduced single $\mathrm{Ni}$ active sites onto the surface of $\mathrm{g}-\mathrm{C}_{3} \mathrm{~N}_{4}$ by using a molecular-level design strategy. ${ }^{323}$ The resulting catalyst family (with less than $0.1 \mathrm{wt} \%$ of $\mathrm{Ni}$ ) was shown to generate $\mathrm{H}_{2}$ with a rate close to that attained with a 3 wt\% Pt on $\mathrm{g}_{-} \mathrm{C}_{3} \mathrm{~N}_{4}$. In another contribution, Bi et al. synthesized a series of $\mathrm{Ni}$-doped g- $\mathrm{C}_{3} \mathrm{~N}_{4}$ and demonstrated a surface band bending change of g- $\mathrm{C}_{3} \mathrm{~N}_{4}$ when contacted with $\mathrm{Ni}$. The results indicated that Ni-coating deepened the surface band bending of $\mathrm{g}-\mathrm{C}_{3} \mathrm{~N}_{4}$, thereby resulting in higher separation efficiency of photoinduced electron-hole pairs and improved $\mathrm{H}_{2}$ generation activity. ${ }^{290}$ Indra and collaborators proved that $\mathrm{Ni}^{2+}$ mesoporous g- $\mathrm{C}_{3} \mathrm{~N}_{4}$ can be reduced to $\mathrm{Ni}^{0} \mathrm{NPs}$ during the photocatalytic reaction in the presence of sacrificial agent (e.g., TEOA), and act as a cocatalyst to reduce protons to 
$\mathrm{H}_{2} .{ }^{324}$ Zhang et al. deposited cobalt on g- $\mathrm{C}_{3} \mathrm{~N}_{4}$ by using a homogeneously engineered strategy via chemical interaction. This modification promoted the surface kinetics of oxygen evolution reaction increasing its activity by two when compared with pure g- $\mathrm{C}_{3} \mathrm{~N}_{4} \cdot{ }^{325}$

Zhang et al. added the noble metal rhodium (Rh) as the cocatalyst on $\mathrm{g}_{-} \mathrm{C}_{3} \mathrm{~N}_{4}$ and investigated the influence of Rh NP size on the photocatalytic activity for $\mathrm{H}_{2}$ evolution. The authors demonstrated that the light-absorption properties of the $\mathrm{g}-\mathrm{C}_{3} \mathrm{~N}_{4}$ were not influenced by the presence of Rh and its activity is not significantly affected by the NPs size. However, the number of Rh NPs on the surface of $\mathrm{g}^{-} \mathrm{C}_{3} \mathrm{~N}_{4}$ and the metallic nature of $\mathrm{Rh}^{0}$ greatly influenced the photocatalytic $\mathrm{H}_{2}$ production activity of g- $\mathrm{C}_{3} \mathrm{~N}_{4} \cdot{ }^{259}$

Another metal which has shown promising results when coupled with g- $\mathrm{C}_{3} \mathrm{~N}_{4}$ is $\mathrm{Ag}$. Sridharan and co-workers compared the activity Ag NPs and Ag quantum clusters (Ag \QC) on $g-\mathrm{C}_{3} \mathrm{~N}_{4}$ towards the $\mathrm{H}_{2}$ evolution reaction. The authors reported an enhanced absorbance for the AgQC/g- $\mathrm{C}_{3} \mathrm{~N}_{4}$ originating from quantum confinement effect. Despite the fact that this improvement confers an activity 1.7 times higher than $\mathrm{g}_{-} \mathrm{C}_{3} \mathrm{~N}_{4}$ for $\mathrm{H}_{2}$ production, the AgQC/g- $\mathrm{C}_{3} \mathrm{~N}_{4}$ still was slightly less active than $\mathrm{AgNP} / \mathrm{g}-\mathrm{C}_{3} \mathrm{~N}_{4}$, because of surface hydroxyl radical formation on the AgQC/g- $\mathrm{C}_{3} \mathrm{~N}_{4}$ surface. ${ }^{326}$ Qin and Zeng reported improved activity using Ag NPs combined with carbon quantum dots (CQDs) and $\mathrm{g}-\mathrm{C}_{3} \mathrm{~N}_{4}$. The authors demonstrated a synergistic effect due to the combination of LSPR effect from Ag NPs with upconverted PL superiority of CQDs allowing a broader spectrum application (Fig. 11a), which lead to photocatalytic activities for $\mathrm{H}_{2}$ evolution 6.7 times higher than pure g- $\mathrm{C}_{3} \mathrm{~N}_{4}$ and 2.8 higher than CQDs/g- $\mathrm{C}_{3} \mathrm{~N}_{4} \cdot{ }^{327}$ The same research group also reported the improvement in photocatalytic $\mathrm{H}_{2}$ generation of $\mathrm{Ag} / \mathrm{g}-\mathrm{C}_{3} \mathrm{~N}_{4}$ nanohybrids, under visible-light illumination, through dye-sensitization with fluorescein. ${ }^{328}$ The addition of the photosensitizer fluorescein lead to an activity for $\mathrm{H}_{2}$ production 4.8 times higher than that of $3 \mathrm{wt} \% \mathrm{Ag} / \mathrm{g}-\mathrm{C}_{3} \mathrm{~N}_{4}$ in the absence of dye molecules, which was approximately 4.8 times higher than that of $3 \mathrm{wt} \%$ $\mathrm{Ag} / \mathrm{g}-\mathrm{C}_{3} \mathrm{~N}_{4}$ in the absence of dye molecules. The LUMO orbital of fluorescein is more negative than the conduction band of $\mathrm{g}-\mathrm{C}_{3} \mathrm{~N}_{4}$, while its HOMO is more positive than the redox potential of the sacrificial reagent, TEOA. ${ }^{28,} 328$ Upon the irradiation of visible light, both fluorescein and g- $\mathrm{C}_{3} \mathrm{~N}_{4}$ were excited, and the electrons from fluorescein can easily migrate to the conduction band of g- $\mathrm{C}_{3} \mathrm{~N}_{4}$. Subsequently, the electrons rapidly migrated to the Ag, accumulating onto Ag NPs to create a Schottky barrier, which could hinder the recombination of electron-hole pairs. The strong local electromagnetic field induced by the LSPR effect of Ag could also improve the captured electron energy and transfer rate, allowing them to react with $\mathrm{H}^{+}$increasing the $\mathrm{H}_{2}$ production (Fig. 11b). Simultaneously, the 
photogenerated holes of fluorescein and g- $\mathrm{C}_{3} \mathrm{~N}_{4}$ could be packed by electrons from TEOA for reuse. ${ }^{28,328}$

(a)

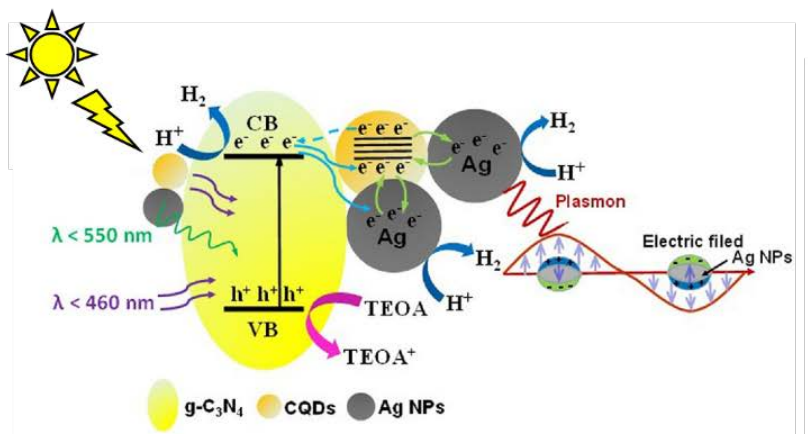

(b)

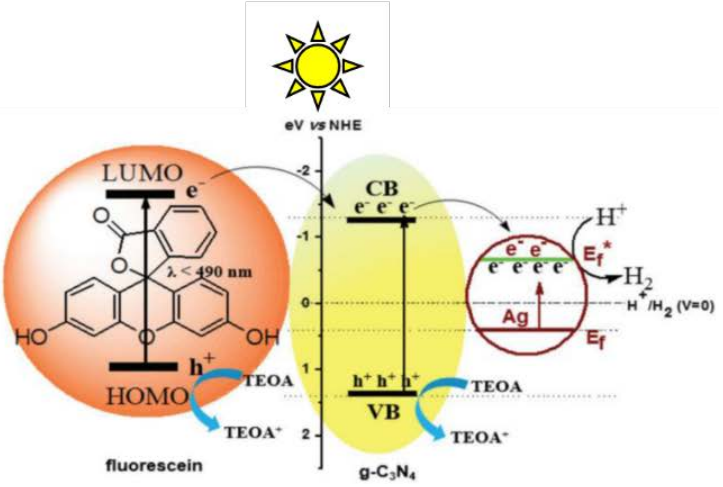

Figure 11. (a) Scheme showing the charge generation, transfer process, and photocatalytic $\mathrm{H}_{2}$ evolution mechanism over the Ag/CQDs/g- $\mathrm{C}_{3} \mathrm{~N}_{4}$ hybrids. Reproduced with permission from ref ${ }^{327}$. Copyright 2017 Elsevier; (b) Schematic representation of the charge migration and separation improvement promoted by fluorescein on Ag/g- $\mathrm{C}_{3} \mathrm{~N}_{4}$ hybrids. Reproduced with permission from ref ${ }^{328}$. Copyright 2015 Royal Society of Chemistry.

The promotion mechanism in Ag-modified g- $\mathrm{C}_{3} \mathrm{~N}_{4}$ photocatalysts was investigated for the first time by $\mathrm{Bu}$ and collaborators through an electrochemical method. ${ }^{268}$ The decoration of the g- $\mathrm{C}_{3} \mathrm{~N}_{4}$ surface with $\mathrm{Ag}$ NPs improved the conductivity and reduced the energy barrier of the interface reactions. As displayed in Fig. 12, both Fermi levels of g- $\mathrm{C}_{3} \mathrm{~N}_{4}$ and $\mathrm{Ag}$ are shifted positively when $\mathrm{Ag}$ is in contact with the g- $\mathrm{C}_{3} \mathrm{~N}_{4}$ surface because the conduction band potential of g- $\mathrm{C}_{3} \mathrm{~N}_{4}$ is less positive than the Fermi level of Ag. Therefore, when the Fermi level of $\mathrm{g}-\mathrm{C}_{3} \mathrm{~N}_{4}$, which is situated below the conduction band, is shifted to the positive direction. The conduction band of g- $\mathrm{C}_{3} \mathrm{~N}_{4}$ is simultaneously moved in the same direction. Consequently, the conduction band generates an upward band bending near to the interface between $\mathrm{Ag}$ and g- $\mathrm{C}_{3} \mathrm{~N}_{4}$ for the transfer of photoexcited electrons from g- $\mathrm{C}_{3} \mathrm{~N}_{4}$ to $\mathrm{Ag} \mathrm{NPs}$. This phenomenon leads to the formation of an interfacial electric field. When the electron exchange is held in equilibrium, the flat band potential $\left(\mathrm{E}_{\mathrm{fb}}\right)$ is positively shifted. This enhances the separation efficiency and prolongs the lifetime of electron-hole pairs, accredited to the heterojunction electric field formed on the interface of $\mathrm{Ag}$ and $\mathrm{g}-\mathrm{C}_{3} \mathrm{~N}_{4}$. 


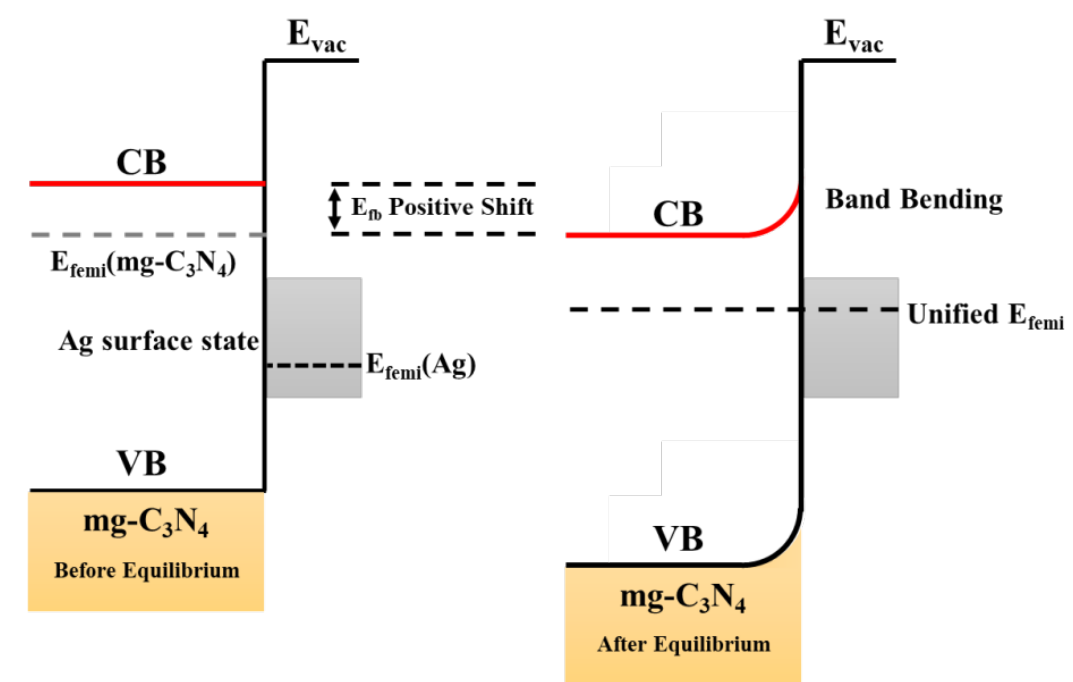

Figure 12. Schematic illustration of the electron energy level when Ag NPs are in contact with g- $\mathrm{C}_{3} \mathrm{~N}_{4}$. Adapted with permission from ref ${ }^{268}$. Copyright 2014 Elsevier.

In fact, when the LSPR absorption of the noble metal partly coincides with the optical absorption of the photocatalyst, the LSPR induces plasmon resonance energy transfer (PRET) from the plasmonic metal to the adjacent semiconductor will excite charge carriers at the interface of noble metal/semiconductor. ${ }^{329,330}$ Thus, the PRET effect facilitates the generation of charge carriers and, for this reason, it suppresses the charge recombination by reducing the migration distance for the surface catalysis. ${ }^{5}$ It is noted that the LSPR-induced electric field and the PRET effect will become greater when the distance between the semiconductor and the noble metal is optimised. ${ }^{220}$ For the system $\mathrm{Ag} / \mathrm{TiO}_{2}$, this optimal distance corresponds to around $5 \mathrm{~nm}$ as reported by Linic et al. ${ }^{5}$ If the semiconductor is located too near the noble metals, the nonradiative energy transfer, Förster resonance energy transfer (FRET), will primarily occur thus quenching the photoexcited semiconductor. ${ }^{331}$ As a result, the distance between a semi-conductor and a noble metal is essential to balance the PRET and FRET effects. Chen and collaborators using an approach similar to that reported by Linic's group investigated the distance-dependent plasmonic influence in the system g- $\mathrm{C}_{3} \mathrm{~N}_{4}$ and $\mathrm{Ag} \mathrm{NPs}$. They used a nanogap-engineering approach by loading the $\mathrm{Ag} @ \mathrm{SiO}_{2}$ plasmonic core-shell NPs onto the g- $\mathrm{C}_{3} \mathrm{~N}_{4}$ nanosheets. ${ }^{269}$ In view of the distance-dependent plasmonic influence, the nanogaps between $\mathrm{g}-\mathrm{C}_{3} \mathrm{~N}_{4}$ and $\mathrm{Ag} \mathrm{NPs}$ were tuned from 8 to $21 \mathrm{~nm}$ by modulating the $\mathrm{SiO}_{2}$ shell thickness (Fig. 13a-f) in order to balance both PRET and FRET effects. The electromagnetic field intensity induced by Ag NPs could be viewed from the finite difference time domain (FDTD) simulation, as shown in Fig. 13g-l. By this the nanogap engineering approach, the optimum activity for the $\mathrm{H}_{2}$ production reported by the authors was for the 
system with a nanogap of $12 \mathrm{~nm}$. This optimum distance balanced the positive PRET and the negative FRET effects on plasmonic photocatalysis (Fig. 13m). ${ }^{269}$ This interesting finding will be particularly helpful to designing more effective metal $\mathrm{NPs} / \mathrm{g}-\mathrm{C}_{3} \mathrm{~N}_{4}$ systems for photocatalytic applications. ${ }^{28}$
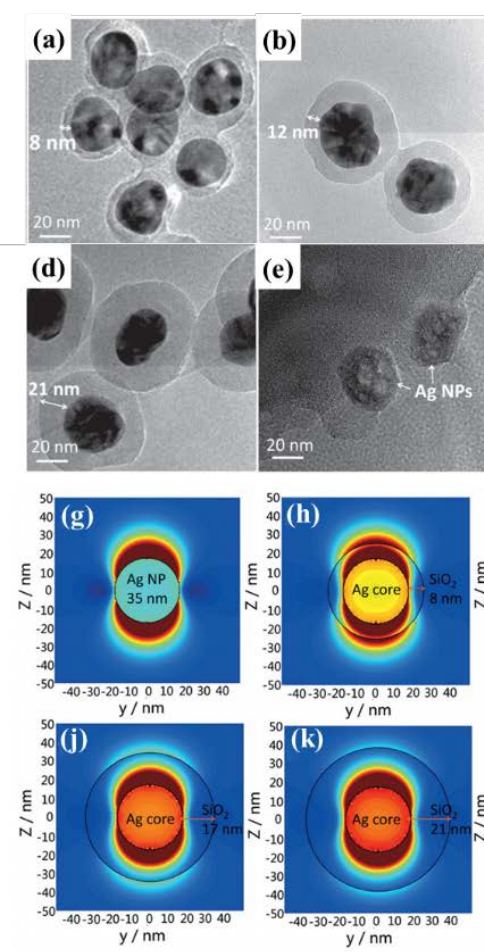
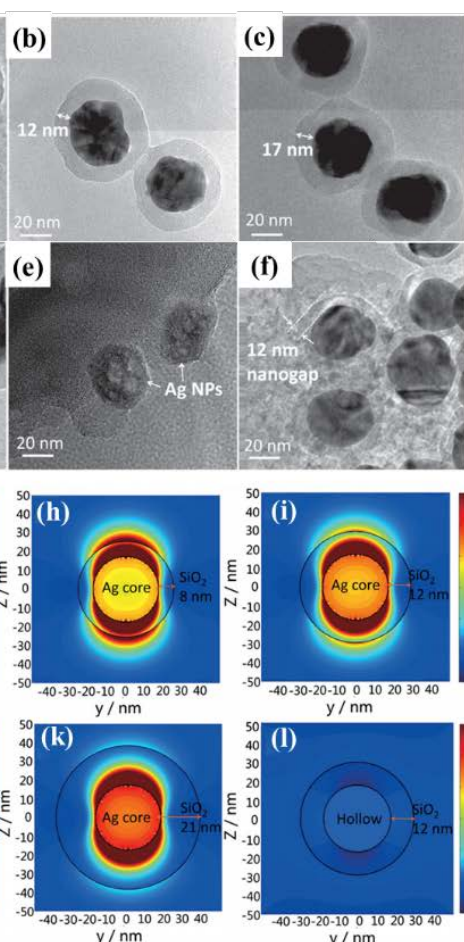
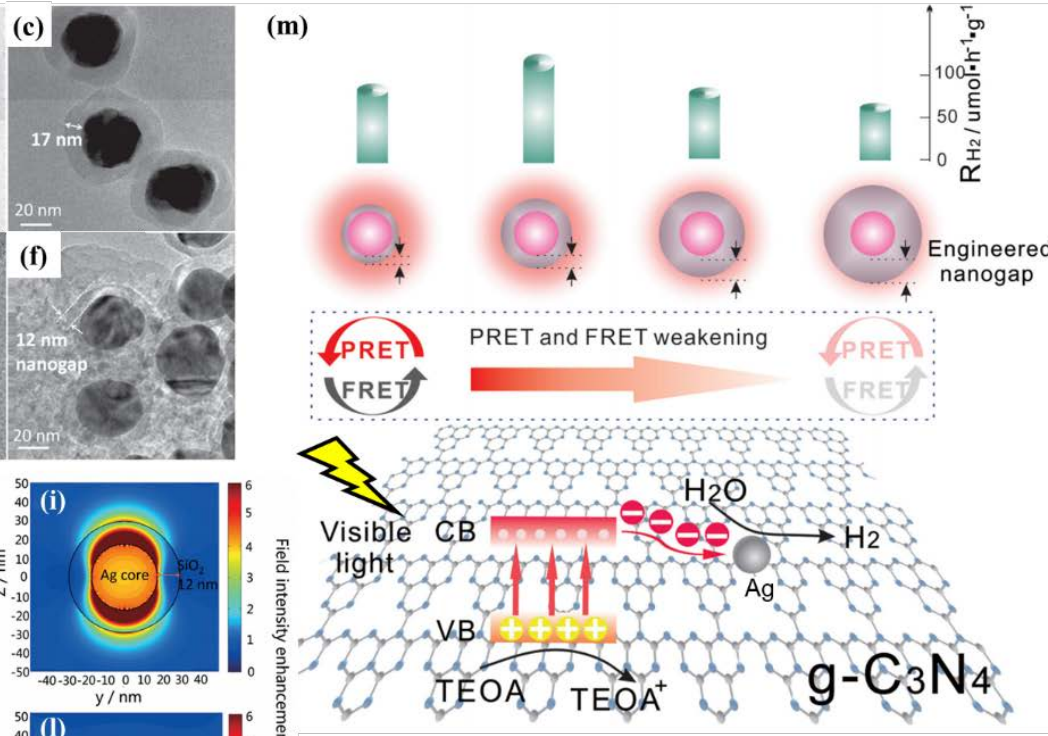

Figure 13. (a-d) TEM images of Ag@SiO 2 core-shell NPs in which the $\mathrm{SiO}_{2}$ shell thickness corresponding to 8 (a), 12 (b), 17 (c), and $21 \mathrm{~nm}$ (d). (e) TEM image of Ag NPs without the silica coating. (f) TEM image for $\mathrm{Ag} / \mathrm{g}-\mathrm{C}_{3} \mathrm{~N}_{4}$ without $\mathrm{SiO}_{2}$ capping.; (g-l) FDTD simulation for the field enhancements for Ag NPs (g), Ag@SiO $2-8$ nm (h), $\mathrm{Ag} @ \mathrm{SiO}_{2}-12$ nm (i), Ag@SiO $2-17$ nm (j), Ag@SiO $2-21$ nm (k), and a hollow $\mathrm{SiO}_{2}$ sphere with 12 nm shell thickness (l). (m) Representation of the mechanism for $\mathrm{H}_{2}$ production over $\mathrm{Ag@SiO} / \mathrm{g}-\mathrm{C}_{3} \mathrm{~N}_{4}$ in which the PRET and FRET effects gradually become weakened with the widening of the nanogap, as well as the $\mathrm{H}_{2}$ evolution rate for each system. Reprinted with permission from ref 269. Copyright 2015 John Wiley and Sons.

Regarding $\mathrm{Au} \mathrm{NPs}$, their combination with g- $\mathrm{C}_{3} \mathrm{~N}_{4}$ presented higher activity for $\mathrm{H}_{2}$ evolution than Pt/g- $\mathrm{C}_{3} \mathrm{~N}_{4}$, as reported by Di et al. ${ }^{53}$ They proposed that the Au NPs on the surface of g- $\mathrm{C}_{3} \mathrm{~N}_{4}$ trapped and stored the photogenerated electrons from the substrate. This shifted the Fermi level to more negative values, promoting the transfer, with low resistance, of electrons from the conduction band of g- $\mathrm{C}_{3} \mathrm{~N}_{4}$ to $\mathrm{Au}$. Despite the good activity presented by the $\mathrm{Au} \mathrm{NPs}$, the $\mathrm{Au} / \mathrm{g}-\mathrm{C}_{3} \mathrm{~N}_{4}$ photocatalytic system can have its activity further improved 
by combining it with other metals to generate bimetallic compositions as shown in Fig. 14. ${ }^{53}$ Other bimetallic cocatalysts, such as PtCo, ${ }^{296} \mathrm{PdAg},{ }^{332} \mathrm{AuPd}^{297}, 333$ and AuPtO, ${ }^{334}$ also have exhibited higher $\mathrm{H}_{2}$ photocatalytic activity than their monometallic counterparts.

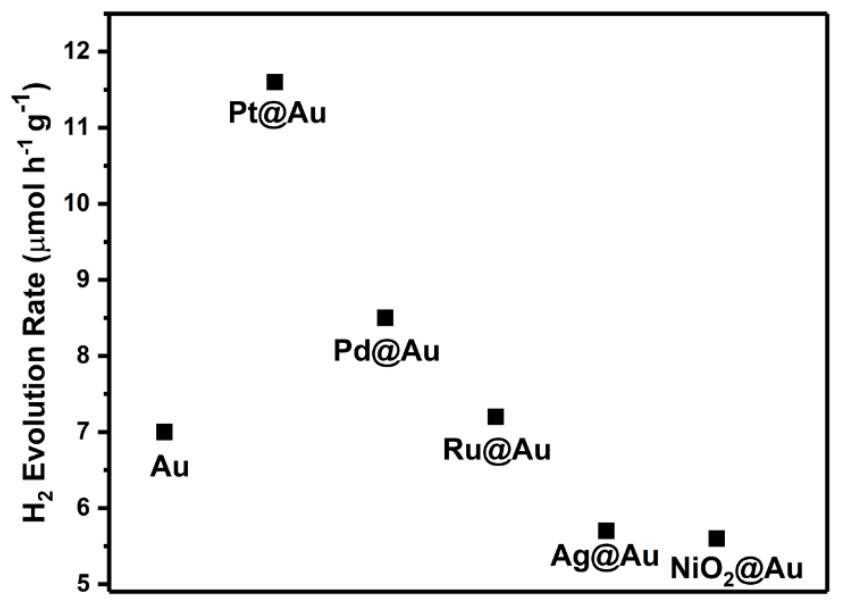

Figure 14. $\mathrm{H}_{2}$ evolution over various bimetallic cocatalysts loaded on g- $\mathrm{C}_{3} \mathrm{~N}_{4}$ under visiblelight irradiation. Reproduced with permission from ref 53. Copyright 2010 John Wiley and Sons.

Metal NPs can have an important role in Z-scheme systems as explained in Section 5.6 and some of those properties can be exploited to enhance the photocatalytic activity for the water-splitting reaction. For example, when sulphur-doped g- $\mathrm{C}_{3} \mathrm{~N}_{4} / \mathrm{CdS}$ is decorated with $\mathrm{Au}$ NPs, it becomes almost 2 times more active for $\mathrm{H}_{2}$ evolution and 20 times more active than only sulphur-doped $\mathrm{g}_{-} \mathrm{C}_{3} \mathrm{~N}_{4}$ under visible light irradiation. The $\mathrm{Au} \mathrm{NPs}$ in this Z-scheme system act as an intermediate agent between sulphur-doped $g-\mathrm{C}_{3} \mathrm{~N}_{4}$ and $\mathrm{CdS}$, promoting the efficient transfer of excited electrons. ${ }^{302}$ Ding et al. reported excellent results using a similar system comprised of an Au-core and CdS-shell (Au@CdS) NPs supported over g- ${ }_{3} \mathrm{~N}_{4}$. The author evaluated this Z-scheme photocatalyst for $\mathrm{H}_{2}$ evolution under visible-light irradiation $(\lambda>420 \mathrm{~nm}$ ) using methanol as a sacrificial reagent and observed that its activity was about 125.8 times higher than g- $\mathrm{C}_{3} \mathrm{~N}_{4}$ (and was even higher than that of Pt/g- $\mathrm{C}_{3} \mathrm{~N}_{4}$ ). ${ }^{335} \mathrm{Au}$ NPs were also successfully used in other Z-scheme systems to improve its activity in water splitting reaction, such as g- $\mathrm{C}_{3} \mathrm{~N}_{4} / \mathrm{Au} / \mathrm{CdZnS}^{336}$ and $\mathrm{Cd}_{\mathrm{x}} \mathrm{Zn}_{1-\mathrm{x}} \mathrm{S} / \mathrm{Au} / \mathrm{g}-\mathrm{C}_{3} \mathrm{~N}_{4} \cdot{ }^{337}$

Another interesting result for improved water splitting was reported by Yin and coworkers using core-shell nanocubes composed of a Pd-core and $\mathrm{Cu}_{2} \mathrm{O}$-shell $\left(\mathrm{Pd} @ \mathrm{Cu}_{2} \mathrm{O}\right)$, as shown in Fig. 15. The embedded Pd nanocubes not only promote the electron-hole separation by trapping the charge carriers from the semiconductors, but also act as a Z-scheme "bridge" in keeping the strong redox ability of the electrons/holes for surface reactions (as depicted in 
Fig. 15h). The authors observed a $\mathrm{H}_{2}$ evolution activity dramatically higher than that of its counterpart g- $\mathrm{C}_{3} \mathrm{~N}_{4} / \mathrm{Cu}_{2} \mathrm{O}$ structure without $\mathrm{Pd} .{ }^{338}$
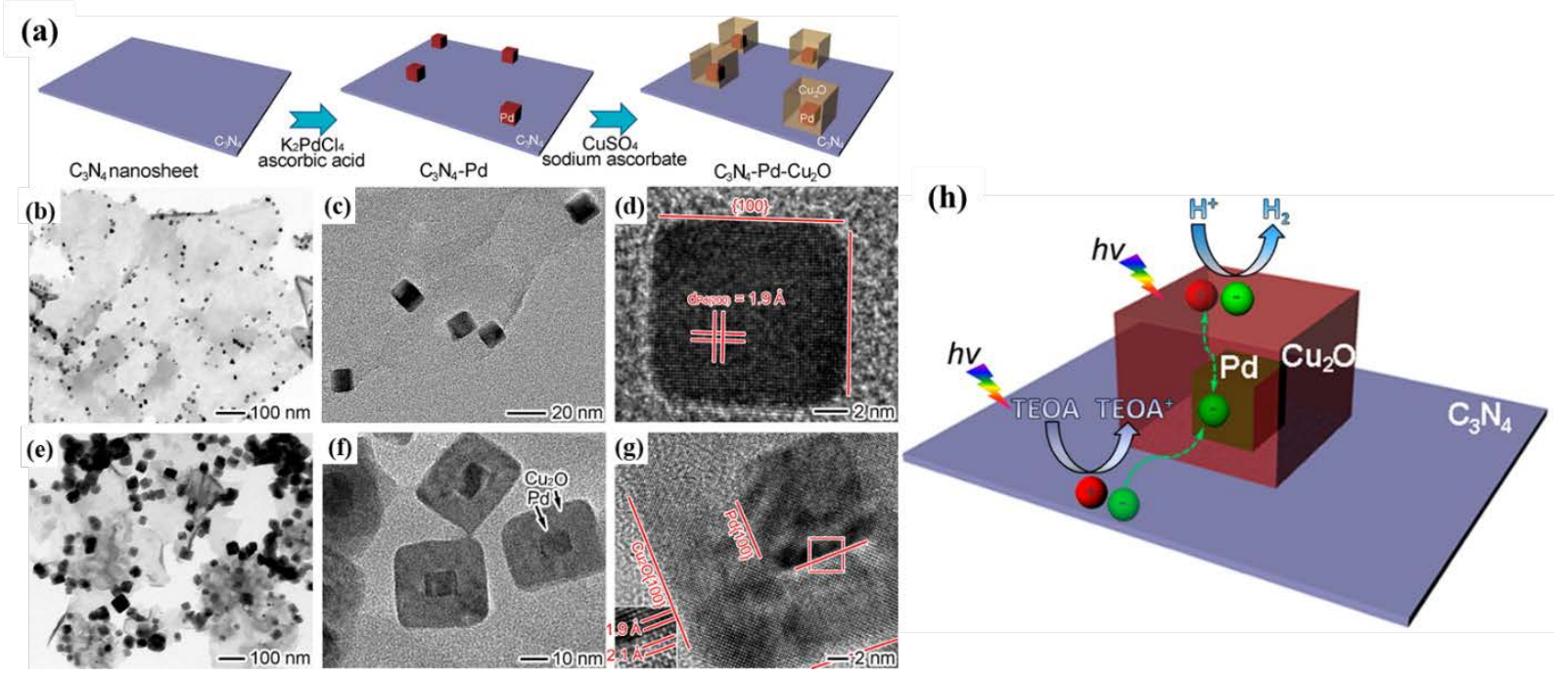

Figure 15. (a) Scheme of the synthesis of the $\mathrm{Pd} @ \mathrm{Cu}_{2} \mathrm{O} / \mathrm{g}-\mathrm{C}_{3} \mathrm{~N}_{4}$ hybrids. (b-g) TEM and HRTEM images of Pd/g- $\mathrm{C}_{3} \mathrm{~N}_{4}$ (b-d) and Pd@ $\mathrm{Cu}_{2} \mathrm{O} / \mathrm{g}-\mathrm{C}_{3} \mathrm{~N}_{4}$ hybrids (e-g). (h) Representation of the photocatalytic mechanism of $\mathrm{H}_{2}$ evolution on the $\mathrm{Pd} @ \mathrm{Cu}_{2} \mathrm{O} / \mathrm{g}-\mathrm{C}_{3} \mathrm{~N}_{4}$ hybrids. Reproduced with permission from ref ${ }^{338}$. Copyright 2016 American Chemical Society.

Other Z-scheme system that deserves attention is the g- $\mathrm{C}_{3} \mathrm{~N}_{4} / \mathrm{Ag} / \mathrm{MoS}_{2}$ ternary plasmonic photocatalyst. This material displayed a flower-like architecture of about $0.4-0.6 \mu \mathrm{m}$ in diameter (Fig. 16). It was successfully synthesized by Lu and collaborators. ${ }^{339}$ The authors reported that g- $\mathrm{C}_{3} \mathrm{~N}_{4} / \mathrm{Ag} / \mathrm{MoS}_{2}$ was 8.78 and 2.08 times more active in the production of $\mathrm{H}_{2}$ out of water than $\mathrm{Ag} / \mathrm{MoS}_{2}$ and $\mathrm{g}-\mathrm{C}_{3} \mathrm{~N}_{4} / \mathrm{MoS}_{2}$, respectively. The excellent photocatalytic activities were attributed to the synergistic effects of $\mathrm{Ag}$, g- $\mathrm{C}_{3} \mathrm{~N}_{4}$, and $\mathrm{MoS}_{2}$ nanostructures in

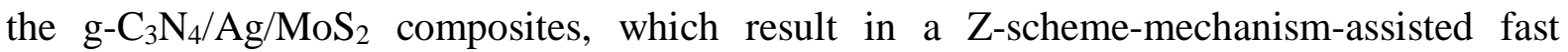
separation and slow recombination of photoinduced electron-hole pairs and consequently higher photocatalytic activity. ${ }^{339}$ 
(a)

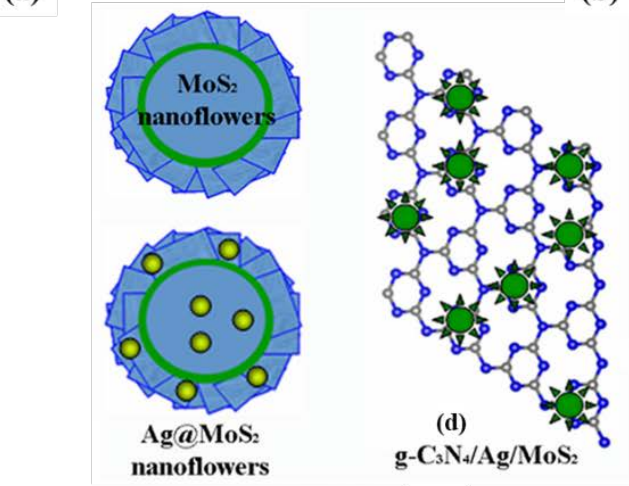

(c)

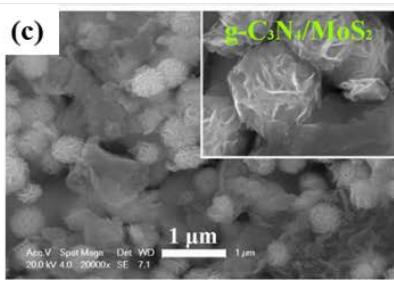

(d)

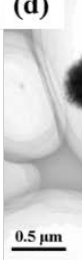

(b)

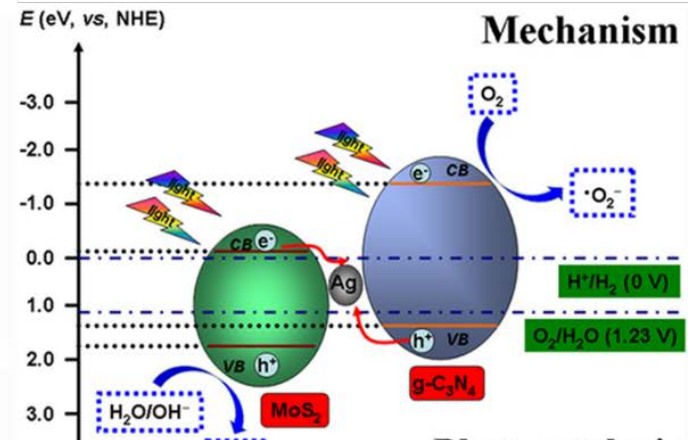

Photocatalysis

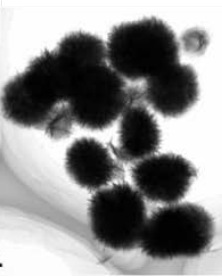

(e)
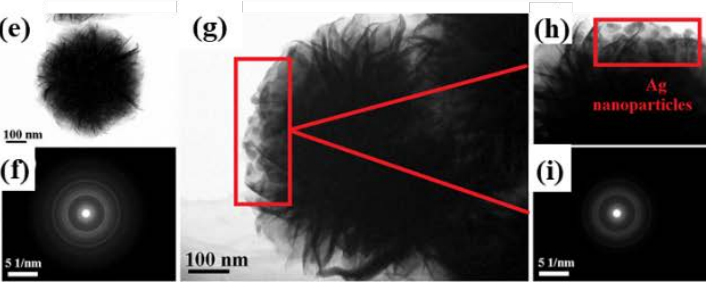

Figure 16. (a) Schematic illustration of hybrids composed of $\mathrm{Ag} / \mathrm{MoS}_{2}$ nanoflowers on g$\mathrm{C}_{3} \mathrm{~N}_{4}$; (b) Separation and transfer of photogenerated charges in the $\mathrm{Ag} / \mathrm{MoS}_{2} / g-\mathrm{C}_{3} \mathrm{~N}_{4}$ nanohybrids; (c) SEM image of $\mathrm{MoS}_{2} / \mathrm{g}-\mathrm{C}_{3} \mathrm{~N}_{4}$; (d-f) TEM images and SAED pattern for $\mathrm{MoS}_{2}$; (g-i) TEM images and SAED pattern of Ag/MoS 2 . Reproduced with permission from ref ${ }^{339}$. Copyright 2017 American Chemical Society.

A comparison of the photocatalytic activity towards the water-splitting reaction of all the systems discussed in this section is shown in Table 1.

Table 1. Photocatalytic $\mathrm{H}_{2}$ evolution on metal NPs/g- $\mathrm{C}_{3} \mathrm{~N}_{4}$ heterostructures

\begin{tabular}{|c|c|c|c|c|c|c|c|}
\hline Catalysts & $\begin{array}{l}\text { Fraction of } \\
\text { cocatalysts }\end{array}$ & $\begin{array}{c}\text { Total } \\
\text { mass of } \\
\text { catalysts }\end{array}$ & Reactant solution & $\begin{array}{c}\text { Light source } \\
\text { (wavelength-nm) }\end{array}$ & $\begin{array}{c}\text { Activity } \\
\left(\mu \mathrm{mol} \mathrm{h}^{-1}\right)\end{array}$ & QE (\%) & Ref. \\
\hline $\mathrm{g}-\mathrm{C}_{3} \mathrm{~N}_{4}$ & - & $0.1 \mathrm{~g}$ & $\begin{array}{c}100 \mathrm{~mL} \text { of } 10 \text { vol\% } \\
\text { TEOA and methanol } \\
\text { aqueous solution }\end{array}$ & $\begin{array}{c}300 \text { W Xe lamp } \\
(>420 \mathrm{~nm})\end{array}$ & $0.1-4$ & $<0.1 \%$ & 13 \\
\hline CDots/ g- $\mathrm{C}_{3} \mathrm{~N}_{4}$ & $0.016 \mathrm{wt} \%$ & $0.080 \mathrm{~g}$ & $150 \mathrm{~mL}$ of water & $\begin{array}{c}300 \text { W Xe lamp } \\
(>420 \mathrm{~nm})\end{array}$ & 8.4 & $\begin{array}{c}6.29 \% \\
(420 \mathrm{~nm})\end{array}$ & 128 \\
\hline $\mathrm{Pt} / \mathrm{g}-\mathrm{C}_{3} \mathrm{~N}_{4}$ & 1.13 wt $\%$ & $0.080 \mathrm{~g}$ & $100 \mathrm{~mL}$ of water & $\begin{array}{c}300 \text { W Xe lamp } \\
(>400 \mathrm{~nm})\end{array}$ & 0.531 & N/A & 261 \\
\hline $\mathrm{Au} / \mathrm{g}-\mathrm{C}_{3} \mathrm{~N}_{4}$ & $1.0 \mathrm{wt} \%$ & $0.1 \mathrm{~g}$ & $\begin{array}{c}100 \mathrm{~mL} \text { of } 10 \mathrm{vol} \% \\
\text { TEOA aqueous } \\
\text { solution }\end{array}$ & $\begin{array}{c}\text { 500WHBO lamp } \\
\text { (> } 420 \mathrm{~nm})\end{array}$ & 8.6 & N/A & 53 \\
\hline $\mathrm{CdS} / \mathrm{Au} / \mathrm{g}-\mathrm{C}_{3} \mathrm{~N}_{4}$ & $2.0 \mathrm{wt} \%$ & $0.1 \mathrm{~g}$ & $\begin{array}{c}50 \mathrm{~mL} \text { of } 25 \mathrm{vol} \% \\
\text { methanol aqueous } \\
\text { solution; }\end{array}$ & $\begin{array}{c}300 \text { W Xe lamp } \\
(>420 \mathrm{~nm})\end{array}$ & 19.0 & N/A & 335 \\
\hline $\mathrm{Pt}_{\text {Single-Atom }} / \mathrm{g}-\mathrm{C}_{3} \mathrm{~N}_{4}$ & $0.16 \mathrm{wt} \%$ & $0.05 \mathrm{~g}$ & $\begin{array}{c}100 \mathrm{~mL} \text { of } 10 \text { vol\% } \\
\text { TEOA aqueous } \\
\text { solution; }\end{array}$ & $\begin{array}{c}300 \text { W Xe lamp } \\
\text { (>420 nm) }\end{array}$ & 318 & N/A & 318 \\
\hline
\end{tabular}




\begin{tabular}{|c|c|c|c|c|c|c|c|}
\hline & & & $100 \mathrm{~mL}$ of $10 \mathrm{vol} \%$ & & & & \\
\hline $\mathrm{PtCo} / \mathrm{g}-\mathrm{C}_{3} \mathrm{~N}_{4}$ & $1.0 \mathrm{wt} \%$ & $0.05 \mathrm{~g}$ & $\begin{array}{c}\text { TEOA aqueous } \\
\text { solution; }\end{array}$ & $\begin{array}{c}300 \text { W Xe lamp } \\
(>400 \mathrm{~nm})\end{array}$ & 48 & N/A & 296 \\
\hline $\mathrm{PdAu} / \mathrm{g}-\mathrm{C}_{3} \mathrm{~N}_{4}$ & 0.5 wt\% & $0.05 \mathrm{~g}$ & $\begin{array}{c}100 \mathrm{~mL} \text { of } 10 \mathrm{vol} \% \\
\text { TEOA aqueous } \\
\text { solution; }\end{array}$ & $\begin{array}{l}300 \text { W Xe lamp } \\
\quad(>400 \mathrm{~nm})\end{array}$ & 16.3 & N/A & 297 \\
\hline $\mathrm{PdAg} / \mathrm{g}-\mathrm{C}_{3} \mathrm{~N}_{4}$ & $1.0 \mathrm{wt} \%$ & $0.01 \mathrm{~g}$ & $\begin{array}{c}22.5 \mathrm{~mL} \text { of } 10 \mathrm{vol} \% \\
\text { TEOA aqueous } \\
\text { solution; }\end{array}$ & $\begin{array}{l}\text { Solar Irradiation } \\
\qquad\left(840 \mathrm{~W} \mathrm{~m}^{-2}\right)\end{array}$ & 1250 & $8.7 \%$ & 332 \\
\hline $\mathrm{PtOAu} / \mathrm{g}-\mathrm{C}_{3} \mathrm{~N}_{4}$ & $1.0 \mathrm{wt} \%$ & $0.05 \mathrm{~g}$ & $\begin{array}{l}80 \mathrm{~mL} \text { of } 25 \mathrm{vol} \% \\
\text { methanol aqueous } \\
\text { solution; }\end{array}$ & $\begin{array}{l}350 \text { W Xe lamp } \\
\text { (>400 nm) }\end{array}$ & 16.9 & N/A & 334 \\
\hline $\mathrm{Rh} / \mathrm{g}-\mathrm{C}_{3} \mathrm{~N}_{4}$ & 0.25 wt $\%$ & $0.1 \mathrm{~g}$ & $\begin{array}{l}36 \mathrm{~mL} \text { of } 11 \mathrm{vol} \% \\
\text { methanol aqueous } \\
\text { solution; }\end{array}$ & $\begin{array}{l}\text { Xe Arc Lamp } \\
\left(320 \mathrm{~mW} / \mathrm{cm}^{2}\right)\end{array}$ & 14.9 & N/A & 259 \\
\hline $\mathrm{Ni} / \mathrm{g}-\mathrm{C}_{3} \mathrm{~N}_{4}$ & $10 \mathrm{wt} \%$ & $0.05 \mathrm{~g}$ & $\begin{array}{c}100 \mathrm{~mL} \text { of } 10 \mathrm{vol} \% \\
\text { TEOA aqueous } \\
\text { solution }\end{array}$ & 500 W Xe lamp & 15.66 & $\begin{array}{c}0.4 \% \\
(365 \mathrm{~nm})\end{array}$ & 340 \\
\hline $\mathrm{Ni} / \mathrm{g}-\mathrm{C}_{3} \mathrm{~N}_{4}$ & 10 wt $\%$ & $0.05 \mathrm{~g}$ & $\begin{array}{c}100 \mathrm{~mL} \text { of } 10 \mathrm{vol} \% \\
\text { TEOA aqueous } \\
\text { solution }\end{array}$ & 500 W Xe lamp & 8.41 & N/A & 290 \\
\hline $\mathrm{Ni}_{\text {(Single site) }} / \mathrm{g}-\mathrm{C}_{3} \mathrm{~N}_{4}$ & $0.1 \mathrm{wt} \%$ & $0.05 \mathrm{~g}$ & $\begin{array}{c}50 \mathrm{~mL} \text { of } 10 \mathrm{vol} \% \\
\text { TEOA aqueous } \\
\text { solution }\end{array}$ & $\begin{array}{l}\text { Xe lamp (125 } \\
\text { mW/cm²); } \\
\text { (>420 nm) }\end{array}$ & 5.5 & $\begin{array}{c}2.6 \% \\
(420 \mathrm{~nm})\end{array}$ & 323 \\
\hline $\mathrm{NiS} / \mathrm{Ni} / \mathrm{g}-\mathrm{C}_{3} \mathrm{~N}_{4}$ & $0.5 \mathrm{wt} \%$ & $0.05 \mathrm{~g}$ & $\begin{array}{c}100 \mathrm{~mL} \text { of } 15 \mathrm{vol} \% \\
\text { TEOA aqueous } \\
\text { solution }\end{array}$ & $\begin{array}{c}300 \mathrm{~W} \text { Xe lamp } \\
\left(160 \mathrm{~mW} / \mathrm{cm}^{2}\right) ; \\
(>420 \mathrm{~nm})\end{array}$ & 515 & N/A & 292 \\
\hline $\mathrm{Ag} / \mathrm{g}-\mathrm{C}_{3} \mathrm{~N}_{4}$ & $\sim 8 \%$ & $0.01 \mathrm{~g}$ & $\begin{array}{l}40 \mathrm{~mL} \text { of } 25 \mathrm{vol} \% \\
\text { methanol aqueous } \\
\text { solution; }\end{array}$ & Solar simulator & 2.8 & N/A & 326 \\
\hline $\mathrm{AgQC} / \mathrm{g}-\mathrm{C}_{3} \mathrm{~N}_{4}$ & 7.46 wt $\%$ & $0.01 \mathrm{~g}$ & $\begin{array}{l}40 \mathrm{~mL} \text { of } 25 \mathrm{vol} \% \\
\text { methanol aqueous } \\
\text { solution; }\end{array}$ & Solar simulator & 2.43 & N/A & 326 \\
\hline $\mathrm{Ag} / \mathrm{CQDs} / \mathrm{g}-\mathrm{C}_{3} \mathrm{~N}_{4}$ & 3 wt $\%$ & $0.005 \mathrm{~g}$ & $\begin{array}{c}70 \mathrm{~mL} \text { of } 14 \mathrm{vol} \% \\
\text { TEOA aqueous } \\
\text { solution; }\end{array}$ & 300 W Xe lamp & 626.93 & $\begin{array}{c}4.81 \% \\
(400 \mathrm{~nm})\end{array}$ & 327 \\
\hline $\begin{array}{l}\text { Fluorescein/Ag/g- } \\
\qquad \mathrm{C}_{3} \mathrm{~N}_{4}\end{array}$ & $2.95 w t \%$ & $0.005 \mathrm{~g}$ & $\begin{array}{c}70 \mathrm{~mL} \text { of } 10 \mathrm{vol} \% \\
\text { TEOA aqueous } \\
\text { solution; } \\
100 \mathrm{~mL} \text { of } 0.25 \mathrm{M}\end{array}$ & 300 W Xe lamp & 2014.20 & N/A & 328 \\
\hline $\begin{array}{c}\mathrm{CdZnS} / \mathrm{Au} / \mathrm{g}- \\
\mathrm{C}_{3} \mathrm{~N}_{4}\end{array}$ & - & $0.1 \mathrm{~g}$ & $\begin{array}{c}\mathrm{Na}_{2} \mathrm{~S} \text { and } 0.35 \mathrm{M} \\
\mathrm{Na}_{2} \mathrm{SO}_{3} \text { aqueous } \\
\text { solution; }\end{array}$ & $\begin{array}{l}300 \text { W Xe lamp } \\
\text { (>420 nm) }\end{array}$ & 6150 & N/A & 336 \\
\hline $\begin{array}{c}\mathrm{Cd}_{0.8} \mathrm{Zn}_{0.2} \mathrm{~S} / \mathrm{Au} / \mathrm{g}- \\
\mathrm{C}_{3} \mathrm{~N}_{4}\end{array}$ & $2.0 \mathrm{wt} \%$ & $0.05 \mathrm{~g}$ & $\begin{array}{c}70 \mathrm{~mL} \text { of } 0.1 \mathrm{M} \\
\text { glucose aqueous } \\
\text { solution; }\end{array}$ & $\begin{array}{c}300 \text { W Xe lamp } \\
\quad(>420 \mathrm{~nm})\end{array}$ & 123 & N/A & 337 \\
\hline $\mathrm{g}-\mathrm{C}_{3} \mathrm{~N}_{4} / \mathrm{Pd} / \mathrm{Cu}_{2} \mathrm{O}$ & - & $0.015 \mathrm{~g}$ & $\begin{array}{l}20 \mathrm{~mL} \text { of } 10 \mathrm{vol} \% \\
\text { TEOA aqueous } \\
\text { solution; }\end{array}$ & $\begin{array}{c}300 \mathrm{~W} \text { Xe lamp } \\
\left(100 \mathrm{~mW} \mathrm{~cm}^{-2}\right) ; \\
(>400 \mathrm{~nm})\end{array}$ & 32.5 & $\begin{array}{c}0.9 \% \\
(420 \mathrm{~nm})\end{array}$ & 338 \\
\hline $\mathrm{g}-\mathrm{C}_{3} \mathrm{~N}_{4} / \mathrm{Ag} / \mathrm{MoS}_{2}$ & $2.0 \mathrm{wt} \%$ & $0.10 \mathrm{~g}$ & $20 \mathrm{~mL}$ of $10 \mathrm{vol} \%$ & 300 W Xe lamp & 10.4 & N/A & 339 \\
\hline
\end{tabular}




\begin{tabular}{cc}
\hline TEOA aqueous & $\left(172 \mathrm{~mW} \mathrm{~cm}^{-2}\right) ;$ \\
solution; & $(>420 \mathrm{~nm})$ \\
\hline
\end{tabular}

\subsection{Photocatalytic Reduction of $\mathrm{CO}_{2}$}

Over the past century, our society has become heavily dependent on fossil fuel sources such as coal, gas, and oil to produce our daily energy needs and chemicals. ${ }^{341}$ The carbon dioxide produced by these non-renewable carbon sources has been significantly altering the climate on Earth ${ }^{342}$ and our heavy reliance make them more expensive and less abundant. ${ }^{341}$ A larger demand on fossil resources for the next few decades is expected since the global economy will continue to grow steadily. ${ }^{343}$ Recently, a great effort towards reducing the regional and global $\mathrm{CO}_{2}$ emissions has been pursued. However, a breakthrough technology which allows converting $\mathrm{CO}_{2}$ into energy-bearing products is required. Inspired by the natural photosynthesis, the photocatalytic conversion of $\mathrm{CO}_{2}$ into energy-bearing products has been regarded as an alternative option to address the diminishing of fossil resources and mitigate the greenhouse gas effect to attain solar energy conversion. ${ }^{344,} 345$ In this artificial photosynthesis approach, a photocatalyst directly captures $\mathrm{CO}_{2}$ and solar energy and converts them into hydrocarbon fuels. The photocatalytic $\mathrm{CO}_{2}$ reduction process is a multielectron transfer process. The possible reaction processes and corresponding redox potentials (vs. reversible hydrogen electrode, RHE) are shown below:

$$
\begin{array}{ll}
\mathrm{CO}_{2}+2 \mathrm{H}^{+}+2 \mathrm{e}^{-} \rightarrow \mathrm{HCOOH} & \left(\mathrm{E}_{\text {redox }}=-0.20 \mathrm{~V}\right) \\
\mathrm{CO}_{2}+2 \mathrm{H}^{+}+2 \mathrm{e}^{-} \rightarrow \mathrm{CO}+\mathrm{H}_{2} \mathrm{O} & \left(\mathrm{E}_{\text {redox }}=-0.12 \mathrm{~V}\right) \\
\mathrm{CO}_{2}+4 \mathrm{H}^{+}+4 \mathrm{e}^{-} \rightarrow \mathrm{HCHO}+\mathrm{H}_{2} \mathrm{O} & \left(\mathrm{E}_{\text {redox }}=-0.07 \mathrm{~V}\right) \\
\mathrm{CO}_{2}+6 \mathrm{H}^{+}+6 \mathrm{e}^{-} \rightarrow \mathrm{CH}_{3} \mathrm{OH}+\mathrm{H}_{2} \mathrm{O} & \left(\mathrm{E}_{\text {redox }}=+0.03 \mathrm{~V}\right) \\
\mathrm{CO}_{2}+8 \mathrm{H}^{+}+8 \mathrm{e}^{-} \rightarrow \mathrm{CH}_{4}+2 \mathrm{H}_{2} \mathrm{O} & \left(\mathrm{E}_{\text {redox }}=+0.17 \mathrm{~V}\right)
\end{array}
$$

The $\mathrm{CO}_{2}$ reduction reactions are complex with many pathways and products. Moreover, the $\mathrm{CO}_{2}$ molecule is extremely difficult to be activated and further reduced at room temperature due to its thermodynamic stability. These factors make photocatalytic $\mathrm{CO}_{2}$ reduction very challenging. ${ }^{24}$

Despite the very low efficiency, pure g- $\mathrm{C}_{3} \mathrm{~N}_{4}$ (without any cocatalyst) can catalyse the reduction of $\mathrm{CO}_{2}$ into other chemicals (e.g. $\mathrm{CO},{ }^{346} \mathrm{CH}_{3} \mathrm{CHO}^{347}$ and $\mathrm{CH}_{4}{ }^{347}$ ), and the nature of the major $\mathrm{CO}_{2}$ reduction product in the presence of water vapor can be modulated by the 
band structure of bulk g- $\mathrm{C}_{3} \mathrm{~N}_{4}$ and g- $\mathrm{C}_{3} \mathrm{~N}_{4}$ nanosheets, as reported by Niu et al. ${ }^{347}$ Other studies about the influence of electronic structure of $\mathrm{g}-\mathrm{C}_{3} \mathrm{~N}_{4}$-based systems on the product selectivity in $\mathrm{CO}_{2}$ reduction were also performed and proposed that not only band position is responsible by this effect, but also the electron sink effect as well as the promoted charge transfer between composite components. ${ }^{24,277,348-352}$

Similar to photocatalytic water splitting, noble metals can be used as efficient cocatalysts for enhancing the photocatalytic $\mathrm{CO}_{2}$ reduction performance of $\mathrm{g}-\mathrm{C}_{3} \mathrm{~N}_{4}$ (as summarized in Table 2). Yu et al. reported a great enhancement on the photocatalytic activity of $g-\mathrm{C}_{3} \mathrm{~N}_{4}$ for reduction of $\mathrm{CO}_{2}$ into hydrocarbon when Pt was added as cocatalyst in a range from 0.25 to 2 wt\%. More interestingly, they also reported an important influence on the product by the Pt loading (Fig. 17a). ${ }^{278}$ Other research group reported the reduction of $\mathrm{CO}_{2}$ to $\mathrm{CH}_{4}$ using g$\mathrm{C}_{3} \mathrm{~N}_{4}$ loaded with 0.5-10 wt\% of Pt. As shown in Fig. 17b, better yields for $\mathrm{CH}_{4}$ were obtained over the $2 \mathrm{Pt} / \mathrm{g}-\mathrm{C}_{3} \mathrm{~N}_{4}$ with an optimal $2 \mathrm{wt} \%$ content of $\mathrm{Pt}$, this catalyst presented reaction rate 5.1 times greater than pure g- $\mathrm{C}_{3} \mathrm{~N}_{4}$. The noticeably improved photoactivity of $\mathrm{Pt} / \mathrm{g}-\mathrm{C}_{3} \mathrm{~N}_{4}$ was assigned to the increased light absorption and effective interfacial electron transfer from $\mathrm{g}-\mathrm{C}_{3} \mathrm{~N}_{4}$ to Pt due to its lower Fermi level that prohibited the recombination of electron-hole pairs (Fig. 17c). In order to better understand the role of noble metals in the photocatalytic $\mathrm{CO}_{2}$ reduction process, Gao and collaborators investigated the photocatalytic $\mathrm{CO}_{2}$ reduction over g- $\mathrm{C}_{3} \mathrm{~N}_{4}$ modified with single-atom of Pd or Pt by using DFT calculation. Comparing the rate-determining barriers of different possible reaction pathways, they found that the $\mathrm{HCOOH}$ was the favourable product of $\mathrm{CO}_{2}$ reduction on the $\mathrm{Pd} / \mathrm{g}-\mathrm{C}_{3} \mathrm{~N}_{4}$ catalyst, while over Pt/g- $\mathrm{C}_{3} \mathrm{~N}_{4}$ was $\mathrm{CH}_{4}$ (Fig. 17d-e). This work provided a theoretical support for the empirically observed product selectivity of photocatalytic $\mathrm{CO}_{2}$ reduction. ${ }^{353}$ 

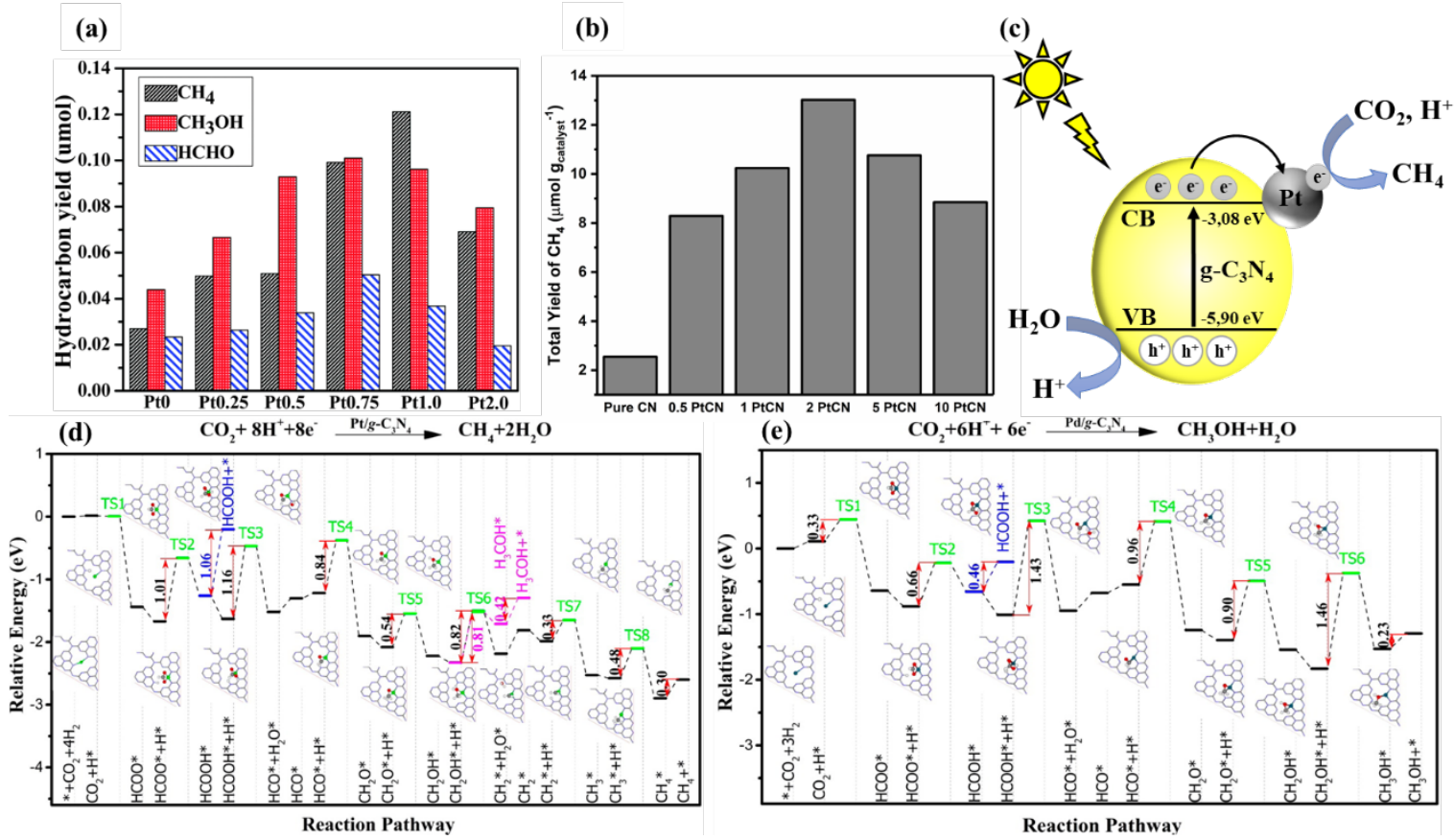

Figure 17. (a) Hydrocarbon yield produced by g- $\mathrm{C}_{3} \mathrm{~N}_{4}$ decorated with Pt displaying different metal loadings (0-2.0 wt\%) under the simulated solar light irradiation for $4 \mathrm{~h}$ of reaction. Reprinted with permission from ref ${ }^{278}$. Copyright 2014 Royal Society of Chemistry; (b) Total yield pf $\mathrm{CH}_{4}$ over g- $\mathrm{C}_{3} \mathrm{~N}_{4}$ loaded with Pt (0.25-2 wt\%) after 10h of reaction. Reprinted with permission from ref ${ }^{277}$. Copyright 2014 Royal Society of Chemistry; (c) Schematic representation of the reduction of $\mathrm{CO}_{2}$ with $\mathrm{H}_{2} \mathrm{O}$ to $\mathrm{CH}_{4}$ catalysed by $\mathrm{Pt} / \mathrm{g}-\mathrm{C}_{3} \mathrm{~N}_{4}$ heterostructures. Adapted with permission from ref ${ }^{277}$. Copyright 2014 Royal Society of Chemistry; (d) Reaction pathways for $\mathrm{CO}_{2}$ reduction to $\mathrm{HCOOH}, \mathrm{CH}_{3} \mathrm{OH}$, and $\mathrm{CH}_{4}$ on the $\mathrm{Pt} / \mathrm{g}-\mathrm{C}_{3} \mathrm{~N}_{4}$ catalyst and (e) $\mathrm{Pd} / \mathrm{g}-\mathrm{C}_{3} \mathrm{~N}_{4}$ catalyst. Under standard conditions $\left(\mathrm{pH} 0, p\left(\mathrm{H}_{2}\right)=1 \mathrm{bar}\right.$, $U=0 \mathrm{~V}$ vs SHE), the total energies of $\mathrm{H}^{+}(\mathrm{aq})+\mathrm{e}^{-}$and $(1 / 2) \mathrm{H}_{2(\mathrm{~g})}$ are equal. The reference energy (the total free energy of the catalyst, isolated $\mathrm{CO}_{2}$, and four $\mathrm{H}_{2}$ ) is set to zero. Color code: $\mathrm{Pd}$, pine green; C, gray; $\mathrm{O}$, red; $\mathrm{H}$, white. Reprinted with permission from ${ }^{353}$. Copyright 2016 American Chemical Society.

$\mathrm{Tu}$ and collaborators have studied the impact of tuneable nitrogen vacancies on photocatalytic activities of $\mathrm{Pt} / \mathrm{g}-\mathrm{C}_{3} \mathrm{~N}_{4}$ towards the $\mathrm{CO}_{2}$ reduction into CO. ${ }^{321}$ They observed a synergistic effect between nitrogen vacancies and Pt NPs, in which the density of nitrogen vacancies in an optimum range has a positive effect on the photocatalytic activities. This was due to the gradual enhancement of light harvesting, efficient charge separation and transportation, and the uniform binding of Pt on g- $\mathrm{C}_{3} \mathrm{~N}_{4}$ as active reaction sites (Fig. 18). However, further increase of nitrogen vacancies decreased the photocatalytic activity, 
because the deeper midgap states induced by overdoped nitrogen vacancies could become recombination sites of photogenerated electron-hole pairs. ${ }^{321} \mathrm{Pt}$ NPs cocatalyst on g- $\mathrm{C}_{3} \mathrm{~N}_{4}$ were also used in combination with other heterostructures and tested to reduce $\mathrm{CO}_{2}$ into $\mathrm{CH}_{4}$, such as $\mathrm{NaNbO}_{3}$ nanowires ${ }^{354}$ and $\mathrm{KNbO}_{3} .{ }^{355}$ Enhancements in the photocatalytic activity were observed in these systems.

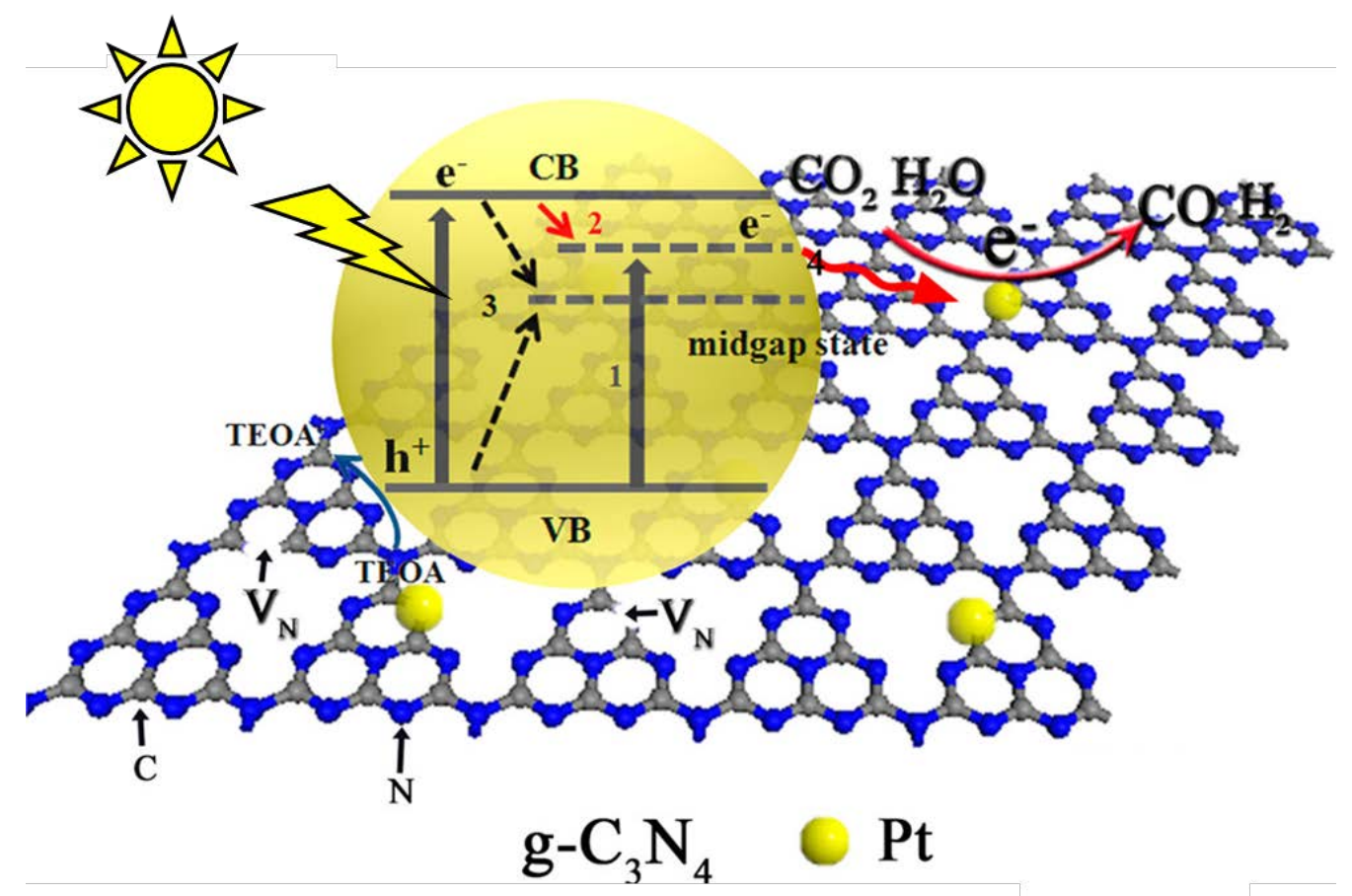

Figure 18. Schematic illustration of g- $\mathrm{C}_{3} \mathrm{~N}_{4}$ nanosheets with nitrogen vacancies (VN) for photoreduction of $\mathrm{CO}_{2}$ to $\mathrm{CO}$ and $\mathrm{H}_{2}$ evolution. Paths 1,2 , and 4 refer to the electron excitation from the valence band to midgap states, the electron trapping from the conduction band to midgap states, and the electron transfer to reaction sites, respectively. Path 3 refers to deeper midgap states that act as recombination sites for trapping photogenerated electrons and holes. Reprinted with permission from ref ${ }^{321}$. Copyright 2017 American Chemical Society.

The nature of the exposed facet in noble metals (shape effect) can also significantly influence the product selectivity in $\mathrm{CO}_{2}$ reduction, as demonstrated by Bai et al. ${ }^{283}$ The authors investigated the facet-dependent selectivity of $\mathrm{CO}_{2}$ reduction over $\mathrm{Pd}$ cocatalysts in the $\mathrm{Pd} / \mathrm{g}-\mathrm{C}_{3} \mathrm{~N}_{4}$ system employing Pd NPs with $\{100\}$ and $\{111\}$ surface facets (cubes and tetrahedrons, respectively). The photocatalytic $\mathrm{CO}_{2}$ reduction activity was significantly higher for g- $\mathrm{C}_{3} \mathrm{~N}_{4}$ loaded with $\mathrm{Pd}$ tetrahedrons. Analysing the facet-dependent $\mathrm{CO}_{2}$ reduction 
process by first-principles calculations, it was found that the adsorption energy of $\mathrm{CO}_{2}$ on the Pd- $\{100\}\left(E_{a}=0.064 \mathrm{eV}\right)$ was lower than that for Pd- $\{111\}\left(E_{a}=0.230 \mathrm{eV}\right)$. Moreover, the activation barrier $E_{B}$ was reduced from 7.15 to $3.98 \mathrm{eV}$ and from 6.79 to $4.15 \mathrm{eV}$ for Pd$\{111\}$ and Pd-\{100\} facets, respectively, when two electrons were brought to the surfaces to initiate the activation of $\mathrm{CO}_{2}$ (Fig. 19). This observation helped to explain why the Pd- $\{111\}$ facets were more reactive for the reduction of $\mathrm{CO}_{2}$. The $\mathrm{Pd} / \mathrm{g}-\mathrm{C}_{3} \mathrm{~N}_{4}$ system works essentially similar to the Pt loaded system. When it is irradiated by light, the photoexcitation of electrons took place in $\mathrm{g}-\mathrm{C}_{3} \mathrm{~N}_{4}$. Due to larger work functions of $\mathrm{Pd}-\{100\}(5.05 \mathrm{eV})$ and $\mathrm{Pd}-\{111\}$ $(5.23 \mathrm{eV})$ as compared with the $\mathrm{g}-\mathrm{C}_{3} \mathrm{~N}_{4}(4.31 \mathrm{eV})$ (Fig. 19e-f), the photoexcited electrons were rapidly shuttled to the Pd cocatalysts to retard the recombination of charge carriers, resulting in increased $\mathrm{CO}_{2}$ reduction to $\mathrm{CH}_{4}, \mathrm{CO}$ and $\mathrm{C}_{2} \mathrm{H}_{5} \mathrm{OH} .{ }^{28,}{ }^{283}$ Similar results were reported by Cao et al. They found that during this reduction reaction, tetrahedral Pd NPs with exposed Pd- $\{111\}$ facets are more active than cubic Pd NPs with exposed Pd- $\{100\}$ facets. Their mechanistic investigation revealed that the structure-sensitive photocatalytic $\mathrm{CO}_{2}$ reduction activity is mainly attributed to the more preferable electron sink effect, $\mathrm{CO}_{2}$ adsorption capability and $\mathrm{CH}_{3} \mathrm{OH}$ desorption capability of the $\mathrm{Pd}-\{111\}$ surface, as compared to $\mathrm{Pd}-\{100\}$, due to their different surface atomic structures. ${ }^{356}$

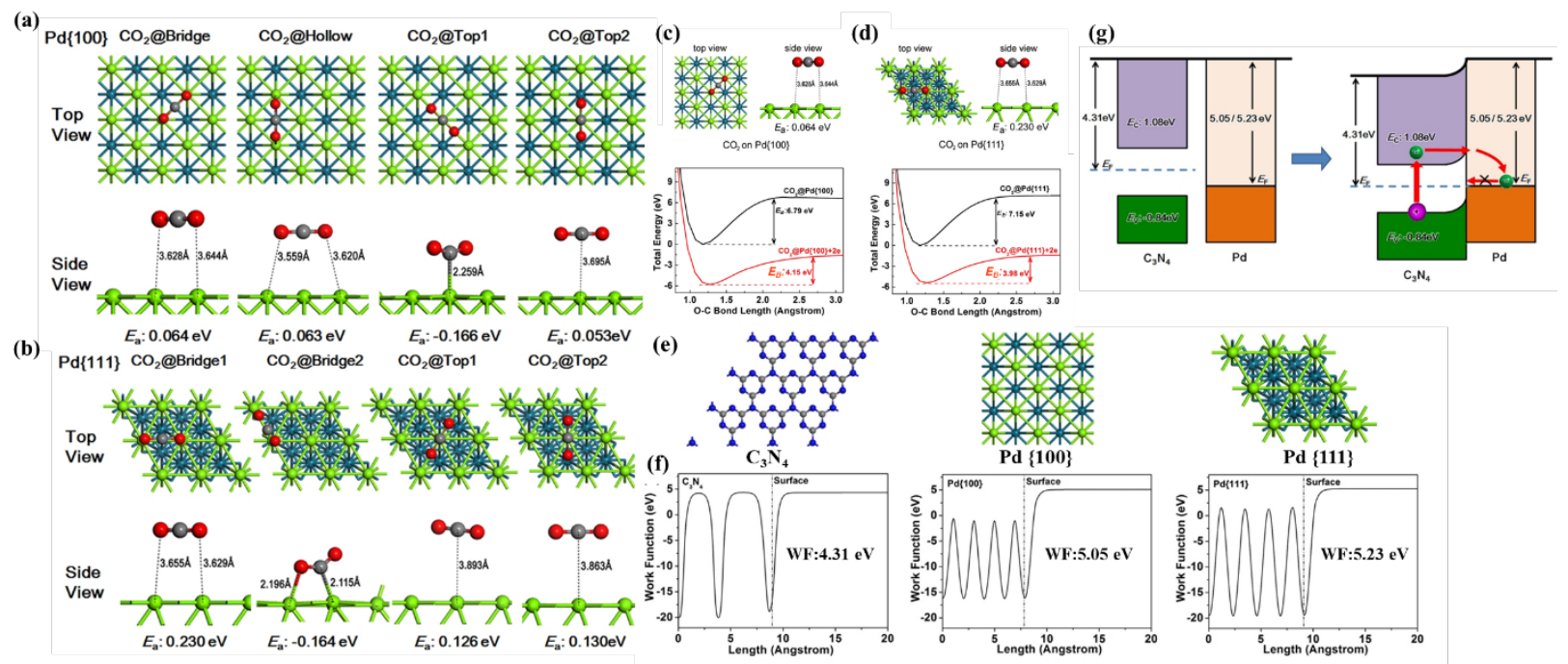

Fig. 19. (a and b) Top and side views of $\mathrm{CO}_{2}$ adsorption configurations for $\mathrm{Pd}-\{001\}$ (a) and Pd- $\{111\}$ (b) and their respective adsorption energy $\left(E_{a}\right)$ according to the geometry optimization simulations; (c) Optimized configurations for the adsorption of $\mathrm{CO}_{2}$ on the Pd$\{100\}$ and (d) Pd-\{111\} facets and their respective potential energy along the bond length O$\mathrm{C}$ of the $\mathrm{CO}_{2}$ molecule adsorbed under neutral conditions or charged with two electrons, from which the activation energy $\mathrm{E}_{\mathrm{B}}$ of $\mathrm{CO}_{2}$ is subtracted; (e) Model systems and (f) calculated 
potentials with work functions for $\mathrm{C}_{3} \mathrm{~N}_{4}, \mathrm{Pd}-\{100\}$, and $\mathrm{Pd}-\{111\}$; (g) Energy level diagrams for $\mathrm{C}_{3} \mathrm{~N}_{4}$ and Pd before and after forming the interfaces for electron transfer based on firstprinciples calculations. Reprinted with permission from ${ }^{283}$. Copyright 2014 Royal Society of Chemistry.

Park and co-workers have investigated $\mathrm{Pd} / \mathrm{g}-\mathrm{C}_{3} \mathrm{~N}_{4}$ on the direct synthesis of $\mathrm{HCOOH}$ under neutral conditions from $\mathrm{CO}_{2}$. The g- $\mathrm{C}_{3} \mathrm{~N}_{4}$ support was able to adsorb $\mathrm{CO}_{2}$ and provide an activated form of carbonate or formate species to the Pd NPs. As a result, the activity of $\mathrm{Pd} / \mathrm{g}-\mathrm{C}_{3} \mathrm{~N}_{4}$ catalyst was remarkably higher when compared to an inert support such as CNT. Moreover, the $\mathrm{Pd} / \mathrm{g}-\mathrm{C}_{3} \mathrm{~N}_{4}$ catalyst exhibits remarkable stability during the catalytic reaction under neutral conditions, which is an essential property for the practical applications. ${ }^{357} \mathrm{Pd}$ NPs were also tested as a cocatalyst on $\mathrm{g}-\mathrm{C}_{3} \mathrm{~N}_{4}$ combined with layered double hydroxides ( $\mathrm{LDH})$. The authors reported that the close interaction of $\mathrm{LDH}$ nanosheets with $\mathrm{g}-\mathrm{C}_{3} \mathrm{~N}_{4}$ and Pd NPs leads to a more efficient interlayer $\mathrm{CO}_{3}{ }^{2-}$ reduction as compared with the system without LDH. ${ }^{358}$

Au NPs have been tested towards the $\mathrm{CO}_{2}$ reduction in a g- $\mathrm{C}_{3} \mathrm{~N}_{4}$-based system only in Zschemes, where the Au NPs and $g-\mathrm{C}_{3} \mathrm{~N}_{4}$ are coupled with $\mathrm{BiOBr}{ }^{359}$ Bai et al. studied the influence of the $\mathrm{Au}$ NPs size in $\mathrm{Au} / \mathrm{g}-\mathrm{C}_{3} \mathrm{~N}_{4} / \mathrm{BiOBr}$ system for photocatalytic $\mathrm{CO}_{2}$ reduction. The results revealed that larger Au NPs (100-150 nm) mainly displayed Z-scheme bridge role and presented higher photocatalytic activity than $g-\mathrm{C}_{3} \mathrm{~N}_{4} / \mathrm{BiOBr}$ under $380 \mathrm{~nm}$ monochromatic light irradiation. Smaller Au NPs (10-20 nm) mainly displayed LSPR effect and showed higher photocatalytic activity than g- $\mathrm{C}_{3} \mathrm{~N}_{4} / \mathrm{BiOBr}$ under $550 \mathrm{~nm}$ monochromatic light irradiation. ${ }^{359} \mathrm{Ag}$ NPs were also tested in a Z-Scheme for $\mathrm{CO}_{2}$ reductions. He et al. observed the photoreduction of $\mathrm{Ag}^{+}$in $\mathrm{Ag}_{3} \mathrm{PO}_{4} / \mathrm{g}-\mathrm{C}_{3} \mathrm{~N}_{4}$ after 1 h of irradiation (500 W Xe lamp). The resulting $\mathrm{Ag}_{3} \mathrm{PO}_{4} / \mathrm{Ag} / \mathrm{g}-\mathrm{C}_{3} \mathrm{~N}_{4}$ system presented an enhanced photocatalytic activity for $\mathrm{CO}_{2}$ reduction due to efficient separation of electron-hole pairs by a Z-scheme mechanism. The optimal $\mathrm{Ag}_{3} \mathrm{PO}_{4} / \mathrm{Ag} / \mathrm{g}-\mathrm{C}_{3} \mathrm{~N}_{4}$ photocatalyst showed a $\mathrm{CO}_{2}$ conversion rate of $57.5 \mu \mathrm{mol} \mathrm{h}{ }^{-1}$ gcat $^{-1}$, which was 6.1 higher than pure g- $\mathrm{C}_{3} \mathrm{~N}_{4}$, under simulated sunlight irradiation. ${ }^{360} \mathrm{Ag}$ NPs were also tested in a system combining g- $\mathrm{C}_{3} \mathrm{~N}_{4}$ and $\mathrm{TiO}_{2}$. Despite not claimed by authors, the reported system seems to work in a Z-scheme. They reported that $\mathrm{Ag} / \mathrm{g}-\mathrm{C}_{3} \mathrm{~N}_{4} / \mathrm{TiO}_{2}$ was 12.7 times more active for $\mathrm{CO}_{2}$ reduction than $\mathrm{TiO}_{2}$ and 7.9 relatives to g- $\mathrm{C}_{3} \mathrm{~N}_{4}$. According to the authors, the Ag NPs deposited on the g- $\mathrm{C}_{3} \mathrm{~N}_{4} / \mathrm{TiO}_{2}$ surface played an important role. They not only retarded the recombination of electron-hole pairs through extracting electrons from the conduction band of $\mathrm{TiO}_{2}$ but also utilized the LSPR effect to 
enhance the energy level of electrons accumulated on their surface. ${ }^{361}$ It is important to highlight the urchin-like $\alpha-\mathrm{Fe}_{2} \mathrm{O}_{3} / \mathrm{g}-\mathrm{C}_{3} \mathrm{~N}_{4}$ hybrid in Z-scheme recently reported by Jiang and collaborators, which presented excellent activity $\left(10.3 \mu \mathrm{mol} \mathrm{g} \mathrm{g}^{-1} \mathrm{~h}^{-1}\right)$ to reduce $\mathrm{CO}_{2}$ into $\mathrm{CO}$ without cocatalyst and sacrifice reagent. ${ }^{309}$ A comparison of the photocatalytic activity for $\mathrm{CO}_{2}$ reduction of all the systems presented in this section is shown in Table 2.

Table 2. Photocatalytic $\mathrm{CO}_{2}$ reduction on metal NPs/g- $\mathrm{C}_{3} \mathrm{~N}_{4}$ heterostructures

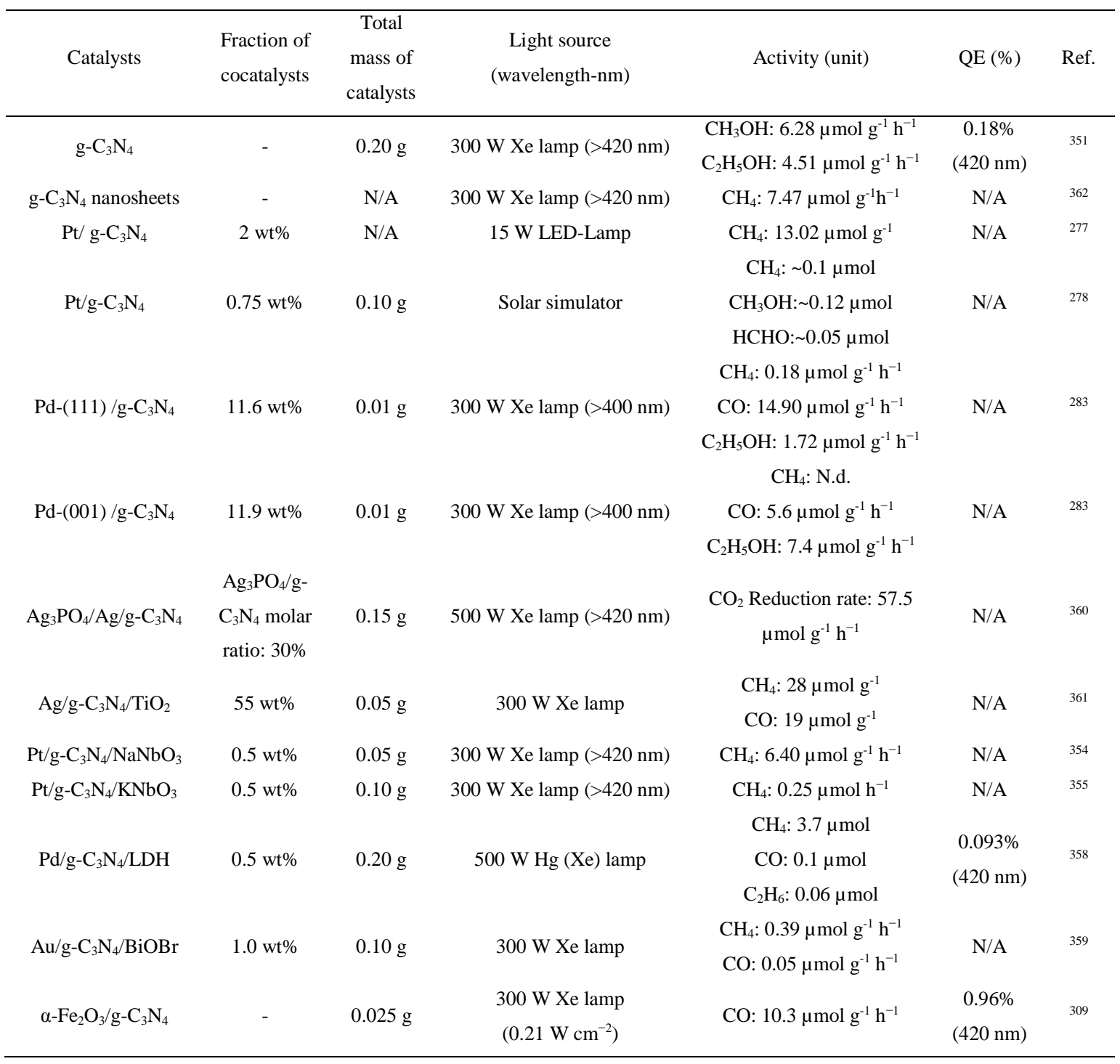

\subsection{Photocatalytic Degradation of Pollutants}

Environmental pollution is a serious problem faced by the human race, hindering our sustainable development. In this context, the photocatalytic degradation of pollutants and environmental remediation constitute an important and wide-impact concern of the scientific community. ${ }^{28}$ Photocatalysis has proven to be a promising strategy for environmental 
decontamination due to its high efficiency and low cost. ${ }^{363-365}$ g- $\mathrm{C}_{3} \mathrm{~N}_{4}$ is a promising photocatalyst for pollutants degradation, due to its band position which exhibits moderately high oxidation ability. Its photogenerated electrons can reduce $\mathrm{O}_{2}$ to produce $\cdot \mathrm{O}_{2}{ }^{-}$, while the photogenerated $\mathrm{h}^{+}$in some g- $\mathrm{C}_{3} \mathrm{~N}_{4}$-based heterojunctions can oxidize $\mathrm{OH}^{-}$to produce the highly oxidant radical $\bullet \mathrm{OH}$. These active species $\left(\mathrm{h}^{+}, \cdot \mathrm{O}_{2}{ }^{-}, \cdot \mathrm{OH}\right)$ can be put towards the oxidation of certain pollutants to mineralization $\left(\mathrm{CO}_{2}\right.$ and $\left.\mathrm{H}_{2} \mathrm{O}\right)$. In general, the photocatalytic degradation reactions over g- $\mathrm{C}_{3} \mathrm{~N}_{4}$ can be categorized into two types: liquid phase removal of organic pollutants and gas phase degradation of pollutants, as summarized in Table 3 . The photocatalytic degradation of pollutants also represents a simple approach to evaluate the photocatalytic activity of g- $\mathrm{C}_{3} \mathrm{~N}_{4}$-based composites. Therefore, many studies which focus on the mechanistic investigation of the photoactivity of $\mathrm{g}-\mathrm{C}_{3} \mathrm{~N}_{4}$-based composites employ the photocatalytic degradation of pollutants as a model transformation.

Table 3. Utilization of g- $\mathrm{C}_{3} \mathrm{~N}_{4}$-based photocatalysts in the degradation of pollutants

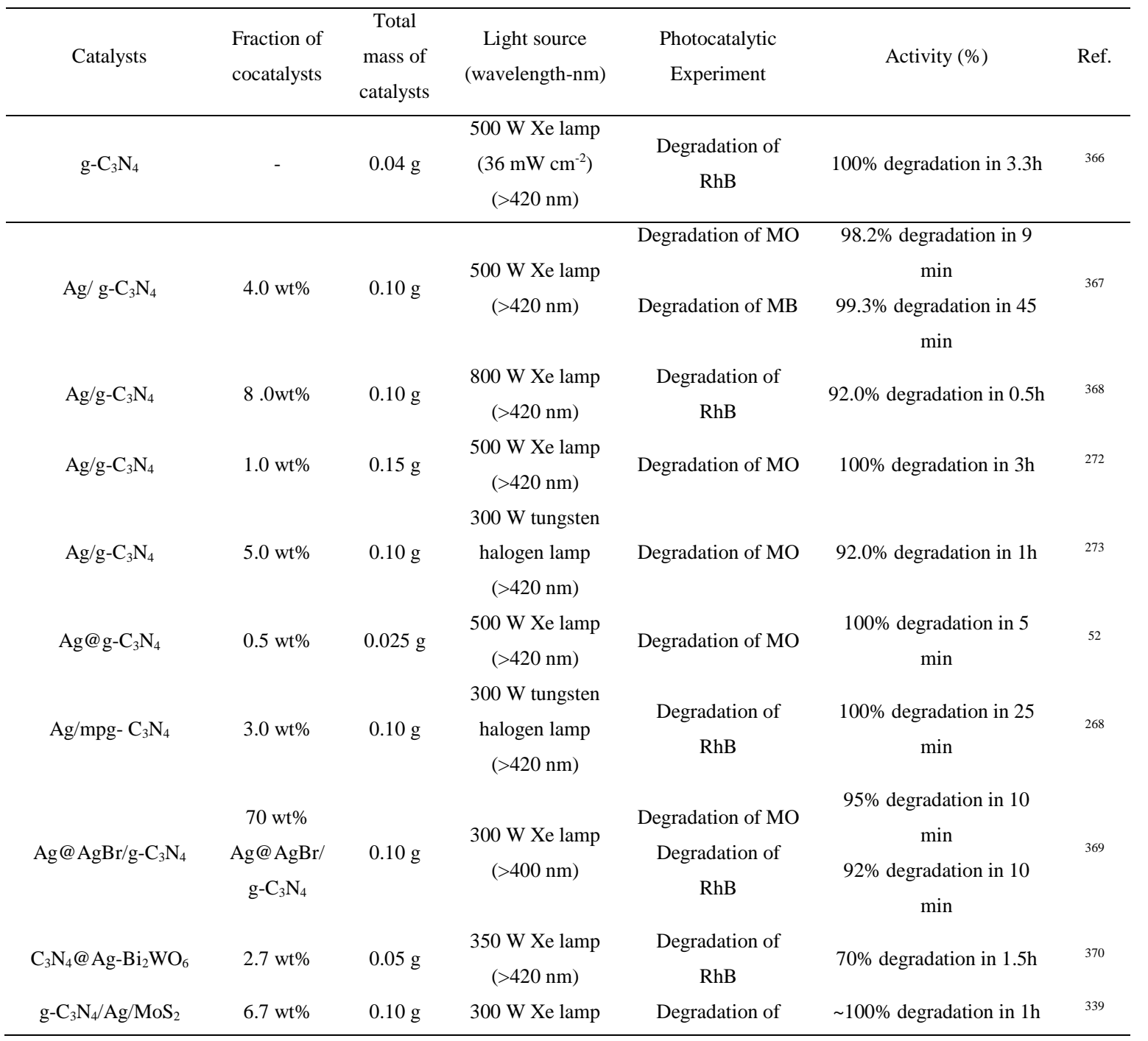




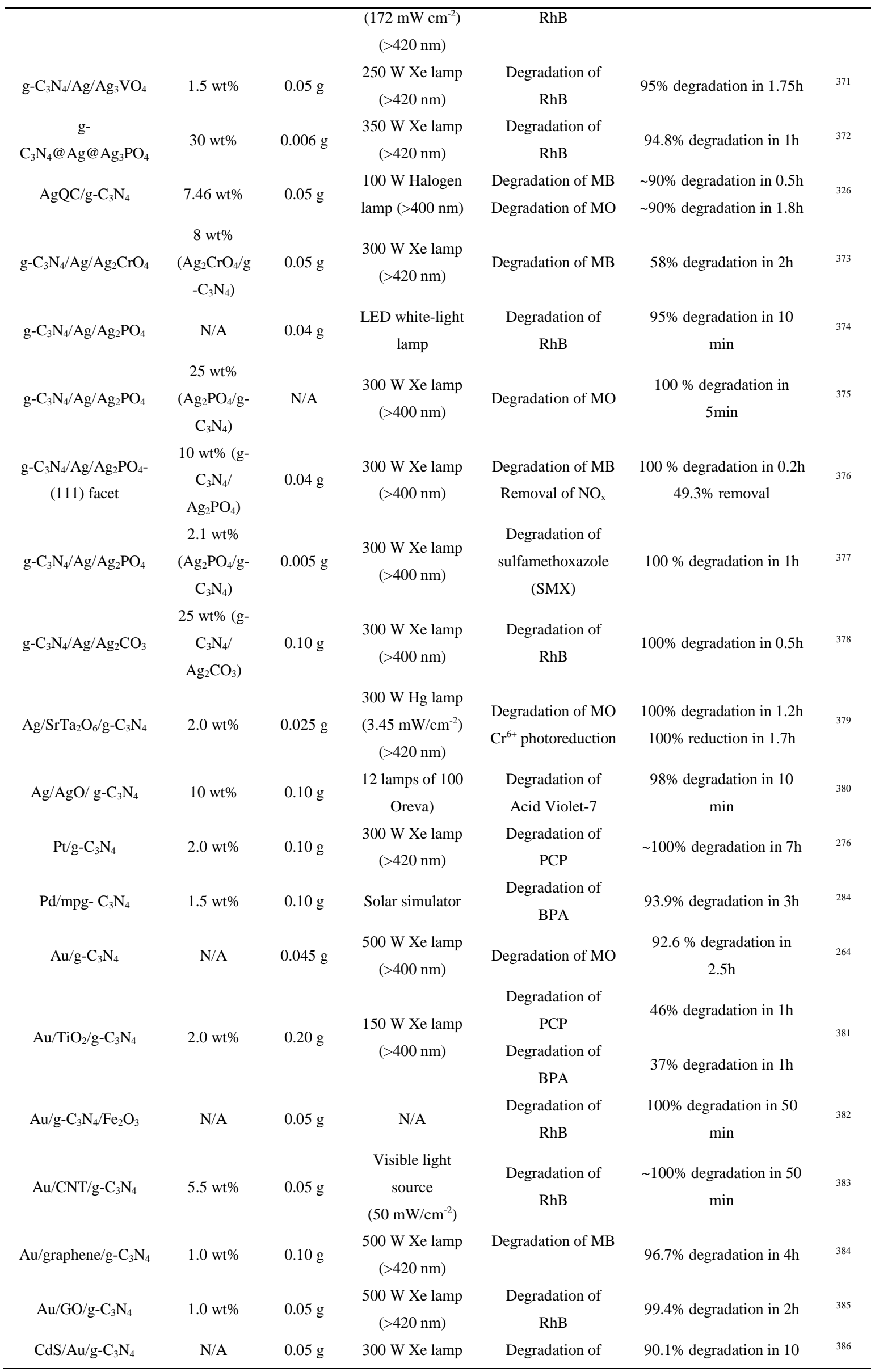




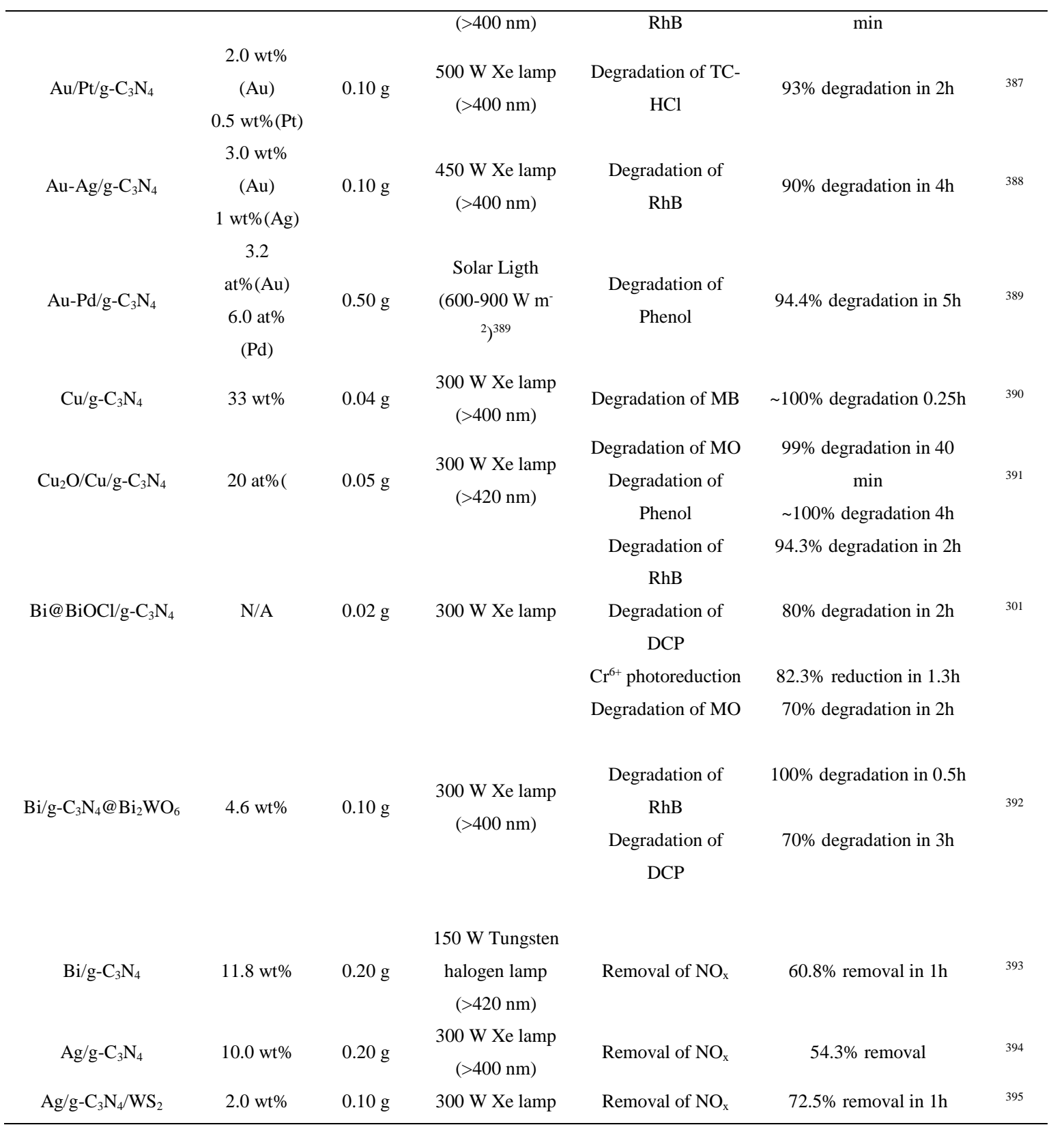

\subsubsection{Liquid Phase Degradation of Pollutants}

The removal of pollutants in wastewater effluents, especially organic pollutants (e.g. dyes, antibiotics, bisphenol A, phenols), has been addressed by advanced oxidation processes commonly catalysed by a variety of photocatalysts, which include g- $\mathrm{C}_{3} \mathrm{~N}_{4}$-based materials. In these studies, the dyes methyl orange, methylene blue and Rhodamine B (RhB) have been employed as model molecules (so that the reaction can be monitored by a spectrophotometer). In the context of water purification, $\mathrm{H}_{2} \mathrm{O}_{2}$ is one of the most widely used green oxidants, which typically requires a catalyst for activation into more reactive oxidizing intermediates. ${ }^{28,}{ }^{366}$ Cui et al. have demonstrated the metal-free activation of $\mathrm{H}_{2} \mathrm{O}_{2}$ by g- $\mathrm{C}_{3} \mathrm{~N}_{4}$ 
under visible light irradiation, using the decomposition of RhB in aqueous solution as a proof-of-concept reaction. The authors reported that g- $\mathrm{C}_{3} \mathrm{~N}_{4}$ was capable of activating $\mathrm{H}_{2} \mathrm{O}_{2}$ to generate reactive oxy-radicals, which in turn led to the mineralization of the dye. ${ }^{366}$ Interestingly, other studies have used $\mathrm{O}_{2}$ as oxidant. For example, Yang et al. exploited the LSPR effect of Ag NPs in Ag-deposited g- $\mathrm{C}_{3} \mathrm{~N}_{4}$ plasmonic photocatalysts towards the methyl orange degradation. In general, when $g-\mathrm{C}_{3} \mathrm{~N}_{4}$ is excited by visible-light, the generation of $\cdot \mathrm{O}_{2}{ }^{-}$and $\mathrm{h}^{+}$takes place. Here, its band structure does not promote the formation of $\bullet \mathrm{OH}$ species. It was found that for $\mathrm{Ag} / \mathrm{g}-\mathrm{C}_{3} \mathrm{~N}_{4}$ systems, $\cdot \mathrm{OH}$ radicals also took part in the photocatalytic reactions, thus giving the direct evidence to contribute to its increased catalytic performance. ${ }^{273}$ The same research group later reported the fabrication of Z-scheme plasmonic photocatalyst Ag@AgBr/g- $\mathrm{C}_{3} \mathrm{~N}_{4}$ to further enhance the photocatalytic activity. The high activity achieved in the degradation of methyl orange was attributed to the Zscheme system, which retained the photoinduced electrons with strong reduction power in the conduction band of $\mathrm{g}-\mathrm{C}_{3} \mathrm{~N}_{4}$ and $\mathrm{h}^{+}$with strong oxidation power in the valence band of $\mathrm{AgBr}^{369}$

Recently, Ag NPs have been used to improve photocatalytic activities in g- $\mathrm{C}_{3} \mathrm{~N}_{4}$-based Zscheme systems. $^{299,339,370,396}$ For example, Xiao et al. reported enhanced photocatalytic performances for degradation of RhB by a $\mathrm{C}_{3} \mathrm{~N}_{4} @ \mathrm{Ag}-\mathrm{Bi}_{2} \mathrm{WO}_{6}$ material. ${ }^{370}$ Ag NPs also have been used in a Z-scheme system for $\mathrm{RhB}^{339}, 371,372$ and methyl orange (MO) ${ }^{326,} 373$ photodegradation. Several studies have reported the spontaneously photodeposition of Ag NPs during the photocatalytic reaction for $\mathrm{Ag}$ compounds/g- $\mathrm{C}_{3} \mathrm{~N}_{4}$ materials due to the $\mathrm{Ag}^{+}$ photoreduction to generate Ag NPs under light irradiation. ${ }^{373,374,397}$ g- $_{3} \mathrm{~N}_{4}$ have been reported to construct Z-scheme systems via the formation of Ag NPs during the photocatalytic reaction with $\mathrm{Ag}_{3} \mathrm{PO}_{4},{ }^{360}, 374-377,397 \mathrm{Ag}_{2} \mathrm{CrO}_{4}{ }^{373}$ and $\mathrm{Ag}_{2} \mathrm{CO}_{3} .{ }^{378}$ Generally, the Ag-compounds/g- $\mathrm{C}_{3} \mathrm{~N}_{4}$ system behaves according to a traditional heterojunction. However, the excited electrons have enough reduction ability to convert $\mathrm{Ag}^{+}$into $\mathrm{Ag}^{0}$. Consequently, the two-phase system is gradually transformed into a three-phase Z-scheme system under light illumination. Notably, Ag NPs can strongly absorb the visible light by LSPR effect. ${ }^{398-}$ ${ }^{400}$ It has been reported that Ag NPs can simultaneously exhibit the LSPR effect and serve as electron mediators in some Ag-compound/Ag/g- $\mathrm{C}_{3} \mathrm{~N}_{4}$ systems improving its photocatalyst activity. 299 , 339, 369, 401

g- $\mathrm{C}_{3} \mathrm{~N}_{4}$-based Z-scheme systems were also applied for $\mathrm{NO}$ oxidation ${ }^{396}$ and $\mathrm{Cr}(\mathrm{VI})$ photoreduction. ${ }^{379} \mathrm{Su}$ et al. decorated $\mathrm{SrTa}_{2} \mathrm{O}_{6} / \mathrm{g}-\mathrm{C}_{3} \mathrm{~N}_{4}$ with $\mathrm{Ag}$ NPs as catalysts. An enhancement of the visible light absorption efficiency and a promotion of the photocatalytic 
activity by a factor of 2.8 for $\operatorname{Cr}(\mathrm{VI})$ photoreduction and 4.6 for methyl orange degradation were observed as compared with only $\mathrm{SrTa}_{2} \mathrm{O}_{6} / g-\mathrm{C}_{3} \mathrm{~N}_{4}$ (Fig. 20a-d). Ag decoration on $\mathrm{SrTa}_{2} \mathrm{O}_{6} / \mathrm{g}-\mathrm{C}_{3} \mathrm{~N}_{4}$ not only extended the visible light absorption region due to LSPR effects but also act as an electron mediator for efficient migration of photogenerated electrons and simultaneously prevent the recombination of photogenerated electron-hole pairs (Fig. 19e). ${ }^{379}$
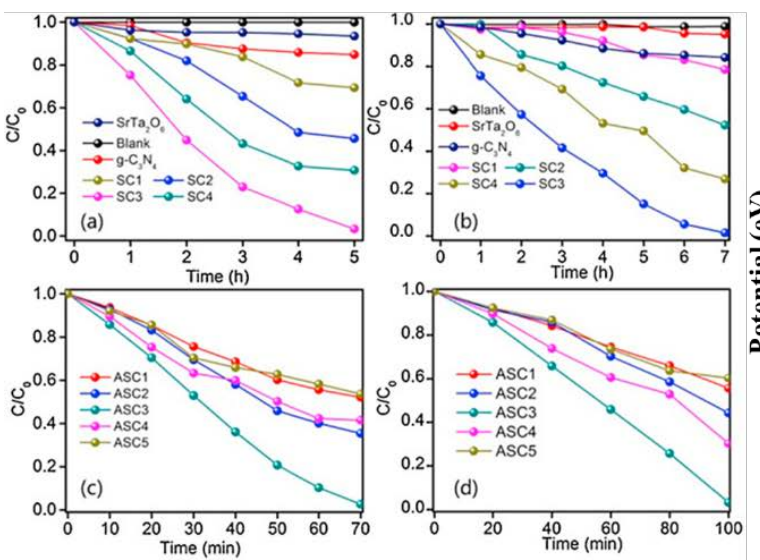

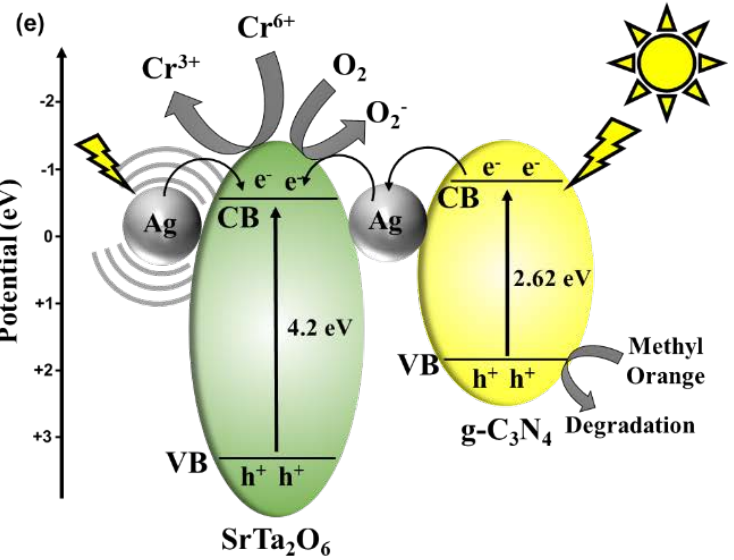

Figure 20. Change in methyl orange concentration (a and c) and in $\operatorname{Cr}(\mathrm{VI})$ concentration (b and d) as a function of the irradiation time for $\mathrm{SrTa}_{2} \mathrm{O}_{6} / g-\mathrm{C}_{3} \mathrm{~N}_{4}$ (a and b) and $\mathrm{Ag} / \mathrm{SrTa}_{2} \mathrm{O}_{6} / \mathrm{g}-$ $\mathrm{C}_{3} \mathrm{~N}_{4}$ photocatalysts. Reprinted with permission from ref ${ }^{379}$. Copyright 2015 Elsevier; (e) Schematic representation of a possible mechanism for $\operatorname{Cr}(\mathrm{VI})$ photoreduction and methyl orange degradation over $\mathrm{Ag} / \mathrm{SrTa}_{2} \mathrm{O}_{6} / \mathrm{g}-\mathrm{C}_{3} \mathrm{~N}_{4}$ photocatalytic system under visible light irradiation. Adapted with permission from ref ${ }^{379}$. Copyright 2015 Elsevier.

Ag NPs also display antibacterial activity. Bing and co-workers successfully improved visible-light-driven antibacterial activity and dispersal of biofilms by embedding Ag NPs on g- $\mathrm{C}_{3} \mathrm{~N}_{4} \cdot{ }^{271}$ The $\mathrm{Ag} / \mathrm{g}-\mathrm{C}_{3} \mathrm{~N}_{4}$ hybrids were much more effective to reactive oxygen species (ROS) generation under visible light. The composite was efficient as a bactericidal agent for both Gram-negative $\left(\mathrm{G}^{-}\right)$E. coli and Gram-positive $\left(\mathrm{G}^{+}\right)$Staphylococcus aureus (S. aureus) under visible-light illumination. ${ }^{271}$ Muñoz-Batista et al. tested $\mathrm{Ag} / \mathrm{g}-\mathrm{C}_{3} \mathrm{~N}_{4}$ biocidal capability against E. coli and it system displayed significantly higher antibacterial capabilities compared to the single components of Ag NPs and $g-\mathrm{C}_{3} \mathrm{~N}_{4} .{ }^{270}$ Upon UV light illumination, the Ag/g$\mathrm{C}_{3} \mathrm{~N}_{4}$ system was demonstrated be more effective on charge separation, which left holerelated radicals at the g- $\mathrm{C}_{3} \mathrm{~N}_{4}$ support and electrons on the Ag NPs. Meanwhile, under visible excitation, the LSPR effect of Ag played an essential role in the biocidal action. In this regard, a complex phenomenon involving adsorption, radical attack as well as deactivation process of the interaction between microorganism and photocatalyst took place 
simultaneously. ${ }^{270}$ It is noteworthy that the bactericidal action was greatly influenced by both electron and hole-related charge species, which could be confirmed by the EPR measurements of the charge radicals produced from the photoactivity. ${ }^{28}$

In addition to $\mathrm{Ag}, \mathrm{Au}$ also has been widely used to improve the g- $\mathrm{C}_{3} \mathrm{~N}_{4}$ photodegradation performance. Cheng et al. reported superior photocatalytic activities for the decomposition of methyl orange under visible-light after decorating g- $\mathrm{C}_{3} \mathrm{~N}_{4}$ nanosheets prepared by ultrasonication-assisted liquid exfoliation of bulk g- $\mathrm{C}_{3} \mathrm{~N}_{4}$ with Au NPs deposited via green photoreduction of $\mathrm{HAuCl}_{4} \cdot{ }^{264}$ Chang et al. reported an $\mathrm{Au} / \mathrm{g}-\mathrm{C}_{3} \mathrm{~N}_{4}$ nanorods with high activity for photodegradation of a range of pollutants, such as RhB, 4-chlorophenol (4-CP), tetracycline (TC) and reduce $(\mathrm{Cr}(\mathrm{VI})) .{ }^{402} \mathrm{Au}$ NPs also have been used to decorate $\mathrm{g}-\mathrm{C}_{3} \mathrm{~N}_{4}$ combined with other heterostructures (e.g. $\mathrm{TiO}_{2},{ }^{381} \mathrm{Fe}_{2} \mathrm{O}_{3}{ }^{382}$ and $\mathrm{CdS}$ ) ${ }^{386}$ for the photodegradation of pollutants. It is noteworthy the results obtained by Zada and co-workers using the ternary component $\mathrm{Au} / \mathrm{TiO}_{2} / \mathrm{g}-\mathrm{C}_{3} \mathrm{~N}_{4}$ ), which presented an improvement of 5.11folds for photodecomposition of 2,4-dichlorophenol (2,4-DCP) when compared with pure g$\mathrm{C}_{3} \mathrm{~N}_{4}$. They reported an exceptional visible-light for the fabricated $\mathrm{Au}-\left(\mathrm{TiO} \mathrm{O}_{2} / \mathrm{g}-\mathrm{C}_{3} \mathrm{~N}_{4}\right)$ nanohybrids, which was attributed to the extended visible-light response due to the Au NPs LSPR and its catalytic function, and to the enhanced charge separation by transferring electrons from g- $\mathrm{C}_{3} \mathrm{~N}_{4}$ and $\mathrm{Au}$ to $\mathrm{TiO}_{2}$. This promoted electron transfer for the $\mathrm{TiO}_{2}$ favored the formation of hydroxyl radicals $(\bullet \mathrm{OH})$, which are very effective in the photocatalytic oxidation process of 2,4-DCP. ${ }^{381}$ Furthermore, Au NPs also have been widely used in combination with carbon nanostructures, such as $\mathrm{CNT}^{383}$ and GO. ${ }^{385}$ This carbon nanostructures, in general, work as an electron transporter and acceptor facilitating the charge transfer and avoiding the recombination of photoexcited electron-hole pairs. ${ }^{385}$

Despite its more restrict use in photodegradation applications, possibly due to its prohibitive price, the activity of Pt NPs has also been evaluated to degradation of pollutants. In order to minimize the influence of the Pt price in the application feasibility of Pt/g- ${ }_{3} \mathrm{~N}_{4}$ for photodegradation, $\mathrm{Xu}$ and collaborators wisely coupled the photodegradation of the macrolide antibiotics Roxithromycin (Rox) with $\mathrm{H}_{2}$ production reaction. The authors found that macrolide antibiotics present in water act as a sacrificial agent to consume $\mathrm{H}_{2} \mathrm{O}_{2}$ (side product from $\mathrm{H}_{2}$ production), itself being degraded, leading to an enhancement of the $\mathrm{H}_{2}$ yield (Fig. 21). ${ }^{403}$ Pt NPs were also tested on g- $\mathrm{C}_{3} \mathrm{~N}_{4}$ nanotubes towards the photodegradation of p-chlorophenol, p-nitrophenol, methylene blue and RhB, under visible-light irradiation. The authors reported a superior photocatalytic activity as compared to only g- $\mathrm{C}_{3} \mathrm{~N}_{4}$ nanotubes 
and attributed it to the synergic effect of Pt NPs on the unique tubular nanostructure of g$\mathrm{C}_{3} \mathrm{~N}_{4}$ nanotubes. ${ }^{276}$
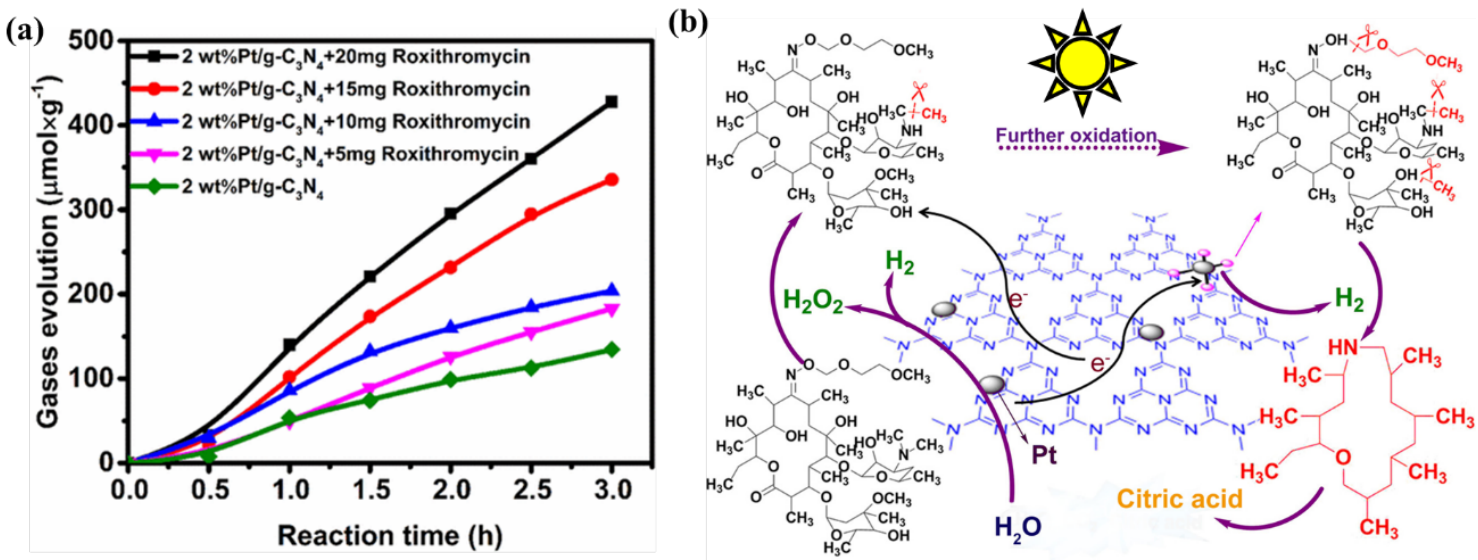

Figure 21. (a) Photocatalytic water splitting to $\mathrm{H}_{2}$ catalyzed by $40 \mathrm{mg}$ of $2 \mathrm{wt} \% \mathrm{Pt} / \mathrm{g}-\mathrm{C}_{3} \mathrm{~N}_{4}$ in $100 \mathrm{~mL}$ of water with different amounts of Rox; (b) Proposed reaction mechanism for the enhancement in the simultaneous water splitting and degradation of the Rox reaction by using $\mathrm{Pt} / \mathrm{g}-\mathrm{C}_{3} \mathrm{~N}_{4}$ under the visible light irradiation. Reprinted with permission from ref ${ }^{403}$. Copyright 2017 American Chemical Society.

Bisphenol A (BPA) is another common pollutant. It is widely used in the manufacturing of consumer goods. Owing to its wide application, a large amount of bisphenol A has been released into the environment, leading to ubiquitous presence of bisphenol $\mathrm{A}$ in natural water. $^{404}$ Thus, an extensive research effort has been devoted to the remediation of this problem. Chang et al. investigated the degradation of BPA in water by $\mathrm{Pd}$ decorated mesoporous g- $\mathrm{C}_{3} \mathrm{~N}_{4}\left(\mathrm{Pd} / \mathrm{mpg}-\mathrm{C}_{3} \mathrm{~N}_{4}\right){ }^{284}$ The catalyst modified with Pd NPs presented a higher photoactivity compared with only mpg- $\mathrm{C}_{3} \mathrm{~N}_{4}$. This higher activity was attributed to the enhanced light absorbance in the UV-VIS region, along with the ability of the Pd NPs to act as electron traps and facilitate the separation of charge carriers. ${ }^{284}$

There are some successful examples where g- $\mathrm{C}_{3} \mathrm{~N}_{4}$ was decorated with bimetallic NPs in order to improve its photocatalytic activity towards photodegradation reactions. Xue et al. fabricated $\mathrm{Au} / \mathrm{Pt}$ co-decorated $\mathrm{g}-\mathrm{C}_{3} \mathrm{~N}_{4}$ heterostructure by a facile calcination-photodeposition technique, which displayed enhanced photocatalytic activity for antibiotic tetracycline hydrochloride (TC-HCl) degradation. The degradation rates were up to 3.4 times higher than that of pure $g-\mathrm{C}_{3} \mathrm{~N}_{4}$ under visible light irradiation. The authors attributed this enhancement in the photocatalytic activity to the LSPR effect of Au and electron-sink function of Pt NPs, which improve the optical absorption property and photogenerated charge carriers separation 
of g- $\mathrm{C}_{3} \mathrm{~N}_{4}$, synergistically facilitating the photocatalysis process. ${ }^{387}$ Gondal et al. used a different approach, instead of using co-decorated bimetallic NPs, they used AuAg NPs alloys in order to take better advantage of the LSPR properties of these NPs. As a result, AuAg/g$\mathrm{C}_{3} \mathrm{~N}_{4}$ photocatalysts exhibited significantly higher activity for the decolorization of $\mathrm{RhB}$ in the visible light as compared to the monometallic Ag and Au NPs counterparts on $g-\mathrm{C}_{3} \mathrm{~N}_{4}{ }^{388}$ Bimetallic AuPd NPs alloys on g- $\mathrm{C}_{3} \mathrm{~N}_{4}$ was recently applied for photodegradation of carcinogenic phenolic compounds and displayed superior photocatalytic activity compared with the previously reported AuPd/rGO. Photoluminescence results demonstrated that the efficient charge separation and delayed recombination of photo-induced electron-hole pairs in the $\mathrm{AuPd} / \mathrm{g}-\mathrm{C}_{3} \mathrm{~N}_{4}$ nanocomposite were responsible for its superior activity. ${ }^{389}$

Besides the noble metals, non-noble metals such as $\mathrm{Bi}$ and $\mathrm{Cu}$ can be very useful to improve photocatalytic properties of g- $\mathrm{C}_{3} \mathrm{~N}_{4}$. The most common strategy consists in making use of the plasmonic properties of the metal NPs to improve visible light absorption and reduce the recombination of electron-hole pairs. This strategy has been reported by Sierra et al. for the $\mathrm{Bi}$ spheres/Bi mixed oxides/g- $\mathrm{C}_{3} \mathrm{~N}_{4}$ nanohybrids ${ }^{405}$ and Gao et al. for the system $\mathrm{Cu}-\mathrm{g}-\mathrm{C}_{3} \mathrm{~N}_{4}$ synthesised by a supramolecular approach. ${ }^{390}$ Other interesting example using the low-cost metal $\mathrm{Bi}$ to improve progradation was reported by Wang et al. ${ }^{392}$ The authors deposited plasmonic Bi NPs on g- $\mathrm{C}_{3} \mathrm{~N}_{4} @ \mathrm{Bi}_{2} \mathrm{WO}_{6}$ microspheres via a hydrothermal method. Bi NPs inserted in the interlayer between $g-\mathrm{C}_{3} \mathrm{~N}_{4}$ and the surface of $\mathrm{Bi}_{2} \mathrm{WO}_{6}$ microspheres worked as an electron-conduction bridge enhancing the visible light absorption due to the LSPR effect, consequently facilitating the efficient electron-carrier separation. As a result, they observed an extraordinary enhanced photocatalytic activity for decomposition of 2,4DCP relative to the g- $\mathrm{C}_{3} \mathrm{~N}_{4}, \mathrm{Bi}_{2} \mathrm{WO}_{6}$, and $\mathrm{g}-\mathrm{C}_{3} \mathrm{~N}_{4}(20 \%) @ \mathrm{Bi}_{2} \mathrm{WO}_{6}$ samples. It implies that the heterostructured combination of $\mathrm{g}-\mathrm{C}_{3} \mathrm{~N}_{4}$, metallic $\mathrm{Bi} \mathrm{NPs}$, and $\mathrm{Bi}_{2} \mathrm{WO}_{6}$ microspheres provided synergistic photocatalytic activity via an efficient electron transfer process. The low-cost metals $\mathrm{Bi}$ and $\mathrm{Cu}$ were also used to fabricate Z-scheme systems, such as $\mathrm{Bi} @ \mathrm{BiOCl} / \mathrm{g}-\mathrm{C}_{3} \mathrm{~N}_{4}$ and $\mathrm{Cu}_{2} \mathrm{O} / \mathrm{Cu} / \mathrm{g}-\mathrm{C}_{3} \mathrm{~N}_{4},{ }^{391}$ which were applied for photodegradation of pollutants. ${ }^{301}$

\subsubsection{Gas Phase Degradation of Pollutants}

The use of metal NPs/g- $\mathrm{C}_{3} \mathrm{~N}_{4}$ heterostructures in the topic of gas phase photodegradation is essentially limited to the oxidation of nitric oxide (NO). Nitrogen dioxide and nitric oxide, also known as $\mathrm{NO}_{\mathrm{x}}$, are common air pollutants generated from the combustion of fossil fuels 
and vehicle exhaust. They are responsible for atmospheric pollutions (e.g. acid rain and urban smog). In view of these facts, there is a growing environmental concern and thereby an intense search for efficient catalysts capable to oxidize NO. ${ }^{28}$ Sano et al. were the first to report the application of $\mathrm{g}-\mathrm{C}_{3} \mathrm{~N}_{4}$ photocatalysts for the oxidation of NO. However, the authors observed low oxidation rates under visible light. ${ }^{406}$ Despite the efforts of Wang and coworkers a few years later trying to improve the surface area of the $\mathrm{g}^{-} \mathrm{C}_{3} \mathrm{~N}_{4}$ hoping to obtain higher oxidation rates, no satisfactory improvements on the NO oxidation was observed. Thus, the combination of g- $\mathrm{C}_{3} \mathrm{~N}_{4}$ with a cocatalyst seems to be an interesting strategy to improve the photocatalytic activity for NO oxidation reaction. ${ }^{407}$ Sun et al. resorted to this strategy by hybridizing g- $\mathrm{C}_{3} \mathrm{~N}_{4}$ with Ag NPs. Their results showed that the decoration of Ag NPs not only enhanced the visible light absorption of the hybrid but also benefited the oxidation of $\mathrm{NO}$ to the final products $\left(\mathrm{NO}_{2}\right.$ and $\left.\mathrm{NO}_{3}{ }^{-}\right)$. The authors attributed the visible enhancement in light absorption due to the LSPR of Ag NPs and the increase in the NO oxidation due to improved separation and transfer of photoinduced carriers over $\mathrm{Ag} / \mathrm{g}-\mathrm{C}_{3} \mathrm{~N}_{4}$ composites, which was supported by the PL spectra. ${ }^{394} \mathrm{Ma}$ and co-workers reported even more significant increment on the activity for $\mathrm{NO}$ oxidation in $\mathrm{g}-\mathrm{C}_{3} \mathrm{~N}_{4} / \mathrm{WS}_{2}$ decorated with Ag NPs. Their optimized system was 3.70, 1.90 and 1.17 times more active for NO oxidation than that of $\mathrm{g}-\mathrm{C}_{3} \mathrm{~N}_{4}, \mathrm{WS}_{2}$, and $\mathrm{g}-\mathrm{C}_{3} \mathrm{~N}_{4} / \mathrm{WS} 2$, respectively. ${ }^{395}$

Another promising cocatalyst for NO oxidation due to its low-cost is Bi. Jiang et al. reported the deposition of $\mathrm{Bi}$ NPs on $\mathrm{g}-\mathrm{C}_{3} \mathrm{~N}_{4}$. This system was employed as a photocatalyst in removing ppb-level NO in a continuous gas flow under visible light illumination. The Bi NPs significantly enhanced the performance of g- $\mathrm{C}_{3} \mathrm{~N}_{4}$, and this enhancement arises from the heterojunction effect and LSPR effect of Bi NPs. However, Jiang et al. also investigated the contribution of each effect (heterojunction and LSPR effect), since they are highly dependent on the size of Bi NPs. By tuning the size of Bi NPs, the authors concluded that Bi NPs with $12 \mathrm{~nm}$ represents the optimum size to favor the synergy of these two effects (Fig. 22c-d). ${ }^{393}$ In another paper, Dong et al. constructed an $\mathrm{Bi} \mathrm{NPs} / \mathrm{g}-\mathrm{C}_{3} \mathrm{~N}_{4}$ displaying highly enhanced visible-light photoactivity and stability for NO purification as compared to that of pristine g$\mathrm{C}_{3} \mathrm{~N}_{4}{ }^{285}$ The strengthened photocatalytic performance was attributed to the co-contributions of the notably improved light-harvesting, owing to the LSPR effects of Bi nanospheres, and the increased separation efficiency of electron-hole pairs due to the electron trapping effect of $\mathrm{Bi}$ metal in the heterostructured system. The local electromagnetic field arising from the LSPR effects of Bi was simulated with a rigorous Maxwell's solver based on the finite integration techniques (Fig. 22a), where a significant enhancement of electromagnetic field 
under visible light could be observed. This electromagnetic field accelerates the photoexcited electrons and holes separation. Furthermore, the nearby Bi NPs can act as electron traps to facilitate the separation of photoinduced electron-hole pairs (Fig. 22b). ${ }^{285}$
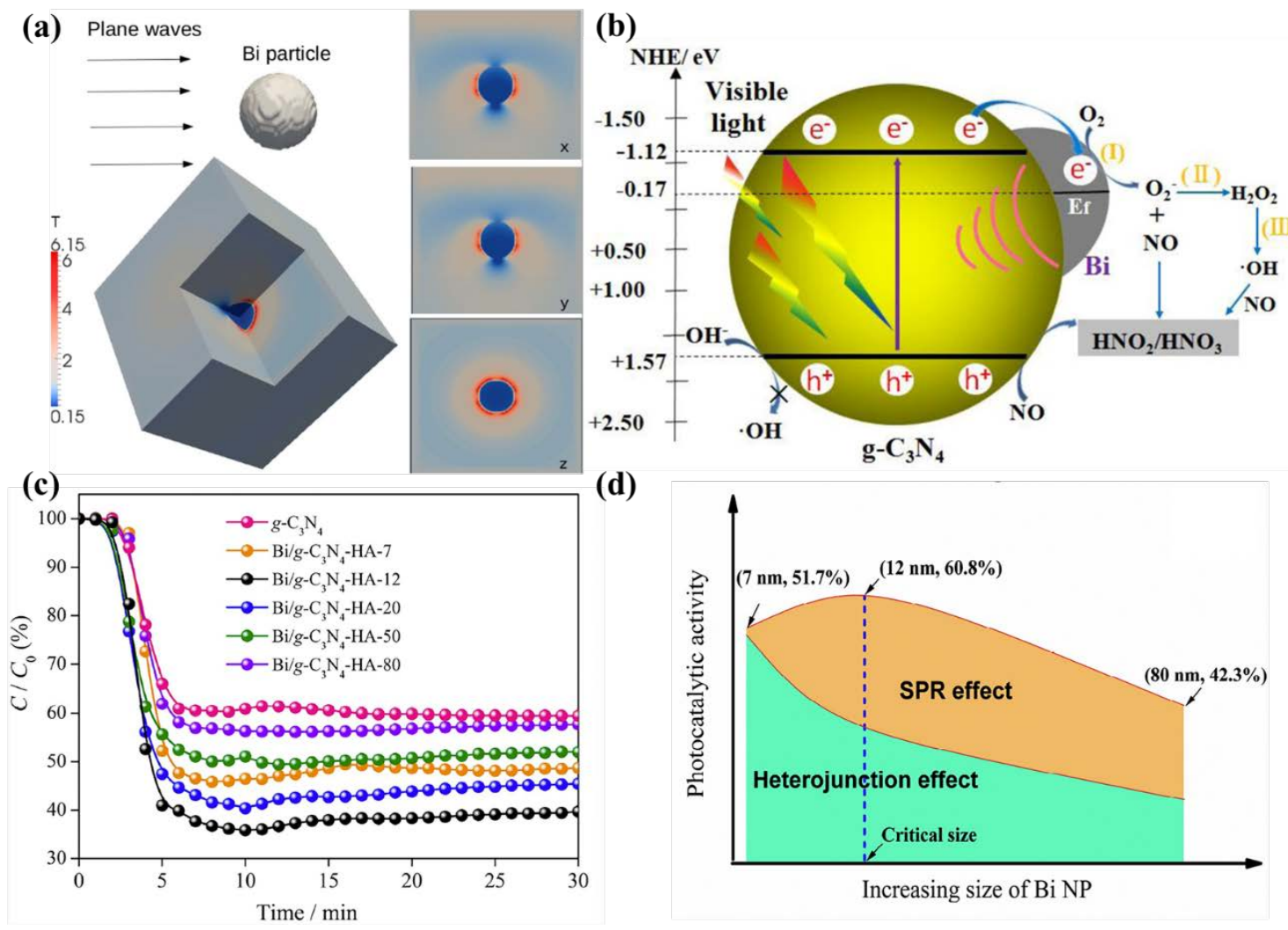

(d)

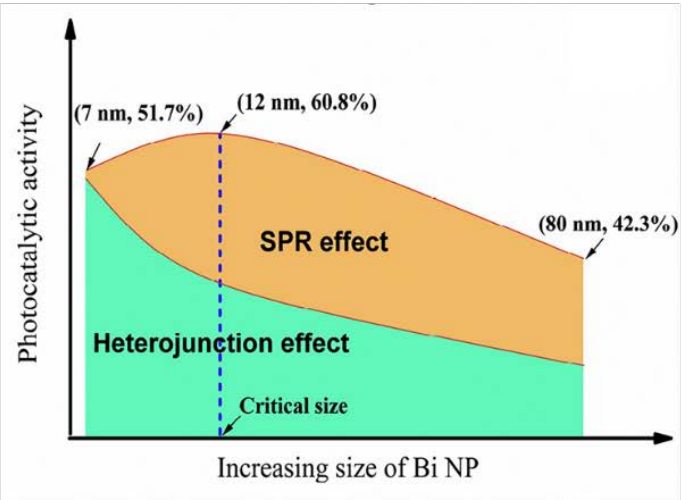

Figure 22. (a) Simulation of the LSPR-induced local electromagnetic field in the Bi NPs when it is illuminated by a plane wave with a wavelength of $420 \mathrm{~nm}$ from the z-direction. A three-dimensional view and two-dimensional cross-sections perpendicular to the $\mathrm{x}, \mathrm{y}$, and $\mathrm{z}$ axes are shown. The scale bar shows the relative increase in field enhancement $T=\left|\mathrm{E} / \mathrm{E}_{\text {inc }}\right|^{2}$. (b) Visible-light-induced charge separation and a proposed mechanism for NO oxidation photocatalysed by $\mathrm{Bi} / \mathrm{g}-\mathrm{C}_{3} \mathrm{~N}_{4}$. Reprinted with permission from ref ${ }^{393}$. Copyright 2015 American Chemical Society. (c) Photocatalytic activity for NO oxidation catalyzed by $\mathrm{gC}_{3} \mathrm{~N}_{4}$ and $\mathrm{Bi} / \mathrm{gC}_{3} \mathrm{~N}_{4}$ materials containing Bi NPs of different sizes (Bi loading of $11.8 \pm 4 \mathrm{wt} \%$ ); (d) Schematic of the synergy of the size-dependent heterojunction and LSPR effect of Bi NPs on the photocatalytic activity. Reprinted with permission from ref ${ }^{285}$. Copyright 2017 Elsevier.

\subsection{Other Photocatalytic Applications}


In addition to the transformations presented in the previous sections, metal $\mathrm{NPs} / \mathrm{g}-\mathrm{C}_{3} \mathrm{~N}_{4}$ have also been employed for other transformations. For example, Verma and collaborators studied the photocatalytic C-H activation and oxidative esterification photocatalysed by Pd/g$\mathrm{C}_{3} \mathrm{~N}_{4}$. The authors reported excellent yields (>90\%) for the conversion of a broad scope of aromatic alcohols into esters. Although only preliminary investigations about the reaction mechanism been performed, it is possible to affirm that the reaction proceeds via a $\mathrm{C}-\mathrm{H}$ activation, which depends on $\mathrm{O}_{2}$ to occur. The activated carbon is then attacked by the alcohol used as reaction solvent, in this case methanol, leading to the ester as final product. ${ }^{408}$

It is important to note that the applications of carbon nitrides are not limited to only photoreactions. Despite not being reviewed in this publication, carbon nitrides and metal NPs/g- $\mathrm{C}_{3} \mathrm{~N}_{4}$ hybrids have been put to work in electrocatalysis, hydrogenations, and oxidations. Moreover, a number of emerging intrinsic properties of g- $\mathrm{C}_{3} \mathrm{~N}_{4}$ allow its novel applications outside of conventional catalysis. Recently, Antonietti et al. compiled these unconventional applications in an excellent review, covering applications of $\mathrm{g}^{-} \mathrm{C}_{3} \mathrm{~N}_{4}$ in a range of areas, such as sensing, bioimaging, photovoltaic cells, templating, and the construction of carbon nitride based devices. ${ }^{409}$

\section{Conclusions and Perspectives}

We presented herein a comprehensive overview of metal NPs/g- $\mathrm{C}_{3} \mathrm{~N}_{4}$-based heterostructures, focusing on their design principles, photocatalytic applications, and chargetransfer mechanisms. The versatility of the g- $\mathrm{C}_{3} \mathrm{~N}_{4}$ with respect to control over its electronic band structure, composition, crystallinity, vacancies sites, porosity, and active sites at its surface, make this material an exceptional candidate for the formation of hybrids with metal NPs. The metal NPs can possess a range of tunable properties (e.g. optical and catalytic properties as a function of shape, size, and composition) that, when combined with a g- $\mathrm{C}_{3} \mathrm{~N}_{4}$, can be harnessed for improved photocatalysis. The recent and intense investigation in the synthesis and application of NPs/g- $\mathrm{C}_{3} \mathrm{~N}_{4}$-based hybrids confirm that these materials represent an important class of photocatalysts for transitioning towards a sustainable future.

Despite the great progress in the area, we believe that we are still at the early stages in terms of material design and photocatalytic efficiency, which remains low for widespread applications. In order to overcome these challenges, we believe that several issues need to be addressed as described below: 
(1) A fundamental understanding of the mechanism behind the charge transport in metal $\mathrm{NPs} / \mathrm{g}-\mathrm{C}_{3} \mathrm{~N}_{4}$-based photocatalysts is critical. It is essential to unravel the charge cascading process in detail to allow an optimum utilization of light through photogenerated charge carriers for driving charge-transfer reactions. It is required to understand the charge generation, separation, and transportation across the nanoscale. This is especially important for Z-scheme systems, which remain poorly understood. For instance, in situ characterization can be very valuable for probing the electronhole transfer pathways, being quite promising for enabling the design of more efficient metal NPs/g- $\mathrm{C}_{3} \mathrm{~N}_{4}$-based photocatalysts having higher quantum efficiencies and thus economic viability.

(2) The interface of metal NPs/g- $\mathrm{C}_{3} \mathrm{~N}_{4}$-based photocatalyst is a complex system, but very important for photocatalytic activity. Consequently, it is imperative to investigate interface effects in detail, especially regarding metal-support interactions, shape effect, nanoscale assembly, composition, density of defects, vacancies, and bandgap adjustment.

(3) The development and utilization of theoretical models and approaches to understand metal NPs/g- $\mathrm{C}_{3} \mathrm{~N}_{4}$-based systems, such as electronic structure modelling of surfaceadsorbate interactions and its integration it with the effect of light excitation.

(4) Metal NPs/g- $\mathrm{C}_{3} \mathrm{~N}_{4}$ systems exhibit high photocatalytic activities. However, their practical application is limited by the high price and low abundance of noble metals. This limitation can be circumvented by replacing the expensive metal by for low-cost alternatives. This review presented some examples of low-cost metals (e.g. $\mathrm{Cu}, \mathrm{Bi}$, and Fe) being used as alternative photocatalysts to noble metals. Another strategy is to enhance the atom utilization efficiency of noble metals, for example by synthesizing highly active systems containing noble metals (which enable one to reduce its loading in the reaction) and single-atom noble metal-deposited g- $\mathrm{C}_{3} \mathrm{~N}_{4}$ materials. So far, facile and efficient methods for preparing single-atom noble metal modified g- $\mathrm{C}_{3} \mathrm{~N}_{4}$ systems are challenging and deserve further exploration. The stability of these systems it is also extremely important to make them economically viable. Hence, it is critical to address chemical corrosion and/or degradation of the photocatalysts.

(5) Finally, synergistic efforts in the areas of controlled synthesis, precise characterization (both $e x$ and in situ), mechanistic investigation, and modelling will be needed in order to move beyond the state-of-the-art in the field of photocatalysis and enable the 
widespread utilization of metal NPs/g- $\mathrm{C}_{3} \mathrm{~N}_{4}$ materials towards sustainable molecular transformations.

It is a consensus in the scientific community that a sustainable economy must have its process driven by sunlight. Hence, photocatalytic systems will have a protagonist role in our journey to a green future. In this context, photocatalytic systems based on earth-abundant elements, such as g- $\mathrm{C}_{3} \mathrm{~N}_{4}$, are particularly attractive. Furthermore, the synthesis of metal NPs and g- $_{3} \mathrm{~N}_{4}$ have been recently successfully scaled-up to the kilogram scale, ${ }^{92,410,411}$ which make these hybrids photocatalysts, even more, promising for future practical applications.

The precise understanding of the charge transport mechanism combined with the high level of control over the materials syntheses, their combination, and characterization can take the topic of photocatalysis with g- $\mathrm{C}_{3} \mathrm{~N}_{4}$ to a new level, potentially enabling us to move from an observation-driven to a design-driven approach (Fig. 23). In this case, specific properties and the performance of the photocatalytic systems can be planned in advance, and the target material synthesized accordingly. We are confident that the continuous efforts of the scientific community in synthesis, characterization, and mechanistic understanding, modelling, and assessment in photocatalysis is paving the way for cleaner energy generation as well as more efficient and sustainable processes.

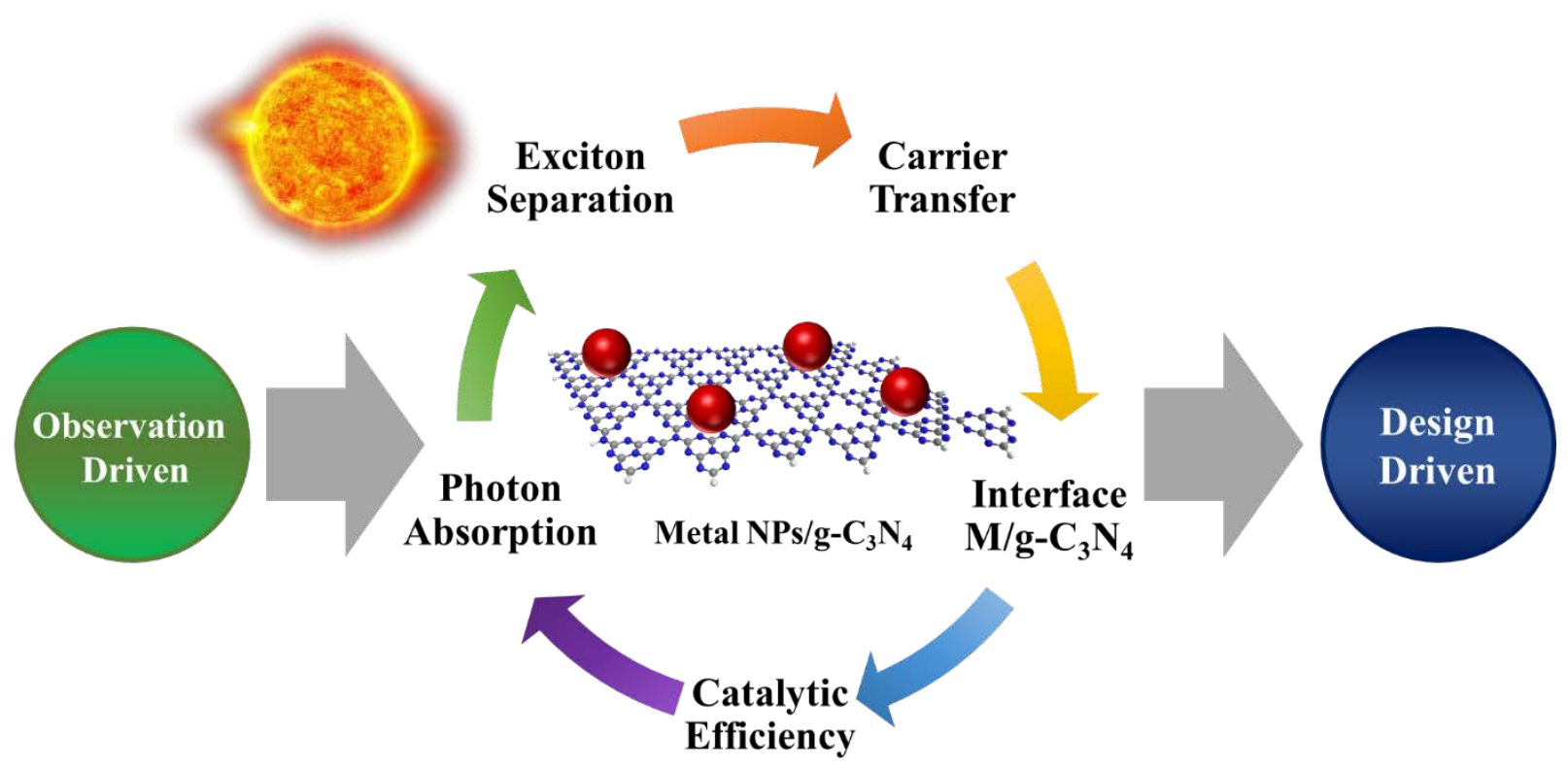

Figure 23. Schematic representation of the critical points which must be understood in photocatalysis promoted by metal NPs/g- $\mathrm{C}_{3} \mathrm{~N}_{4}$ to allow the transition from an observationdriven to a design-driven approach. 


\section{References}

1. N. S. Lewis and D. G. Nocera, Proceedings of the National Academy of Sciences, 2006, 103, 15729-15735.

2. J. Bisquert, Nature Photonics, 2008, 2, 648-649.

3. A. J. Ragauskas, C. K. Williams, B. H. Davison, G. Britovsek, J. Cairney, C. A. Eckert, W. J. Frederick, Jr., J. P. Hallett, D. J. Leak, C. L. Liotta, J. R. Mielenz, R. Murphy, R. Templer and T. Tschaplinski, Science 2006, 311, 484-489.

4. $\quad$ C. Chen, W. Ma and J. Zhao, Chemical Society Reviews, 2010, 39, 4206-4219.

5. $\quad$ S. Linic, P. Christopher and D. B. Ingram, Nat Mater, 2011, 10, 911-921.

6. A. J. Esswein and D. G. Nocera, Chemical reviews, 2007, 107, 4022-4047.

7. J. Yu, J. Low, W. Xiao, P. Zhou and M. Jaroniec, Journal of the American Chemical Society, 2014, 136, 8839-8842.

8. G. Liu, L. Wang, H. G. Yang, H.-M. Cheng and G. Q. M. Lu, Journal of Materials Chemistry, 2010, 20, 831-843.

9. M. D. Hernández-Alonso, F. Fresno, S. Suárez and J. M. Coronado, Energy \& Environmental Science, 2009, 2, 1231-1257.

10. H. Tong, S. Ouyang, Y. Bi, N. Umezawa, M. Oshikiri and J. Ye, Advanced materials, 2012, 24, 229-251.

11. S. Peiris, J. McMurtrie and H.-Y. Zhu, Catalysis Science \& Technology, 2016, 6, 320-338.

12. M. A. Fox and M. T. Dulay, Chemical reviews, 1993, 93, 341-357.

13. X. Wang, K. Maeda, A. Thomas, K. Takanabe, G. Xin, J. M. Carlsson, K. Domen and M. Antonietti, Nat Mater, 2009, 8, 76-80.

14. Y. Wang, X. Wang and M. Antonietti, Angewandte Chemie International Edition, 2012, 51, 68-89.

15. X. Wang, S. Blechert and M. Antonietti, ACS Catalysis, 2012, 2, 1596-1606.

16. A. Thomas, A. Fischer, F. Goettmann, M. Antonietti, J.-O. Müller, R. Schlögl and J. M. Carlsson, Journal of Materials Chemistry, 2008, 18, 4893-4908.

17. D. S. Su, J. Zhang, B. Frank, A. Thomas, X. Wang, J. Paraknowitsch and R. Schlögl, ChemSusChem, 2010, 3, 169-180.

18. S. Cao, J. Low, J. Yu and M. Jaroniec, Advanced Materials, 2015, 27, 2150-2176.

19. Y. Zheng, J. Liu, J. Liang, M. Jaroniec and S. Z. Qiao, Energy \& Environmental Science, 2012, 5, 6717-6731.

20. F. Su, M. Antonietti and X. Wang, Catalysis Science \& Technology, 2012, 2, 1005-1009.

21. Y. Si, J. Zhong, J. Li, X. Liu, W. Hu, J. Song, F. Zhang, K. Liu, K. Huang and S. Wu, Journal of Advanced Oxidation Technologies, 2016, 19, 158-164.

22. Q. Yu, X. Li and M. Zhang, Micro \& Nano Letters, 2014, 9, 1-5.

23. L. Shi, L. Liang, F. Wang, J. Ma and J. Sun, Catalysis Science \& Technology, 2014, 4, 32353243.

24. J. Fu, J. Yu, C. Jiang and B. Cheng, Advanced Energy Materials, 2017.

25. S. Ye, R. Wang, M.-Z. Wu and Y.-P. Yuan, Applied Surface Science, 2015, 358, 15-27.

26. G. Mamba and A. Mishra, Applied Catalysis B: Environmental, 2016, 198, 347-377.

27. Y. Zheng, L. Lin, B. Wang and X. Wang, Angewandte Chemie International Edition, 2015, 54, 12868-12884.

28. W.-J. Ong, L.-L. Tan, Y. H. Ng, S.-T. Yong and S.-P. Chai, Chem. Rev, 2016, 116, 7159-7329.

29. X. Ma, Y. Lv, J. Xu, Y. Liu, R. Zhang and Y. Zhu, The Journal of Physical Chemistry C, 2012, 116, 23485-23493.

30. G. Liu, P. Niu, C. Sun, S. C. Smith, Z. Chen, G. Q. Lu and H.-M. Cheng, Journal of the American Chemical Society, 2010, 132, 11642-11648.

31. Y. Wang, H. Li, J. Yao, X. Wang and M. Antonietti, Chemical Science, 2011, 2, 446-450. 
32. J. Li, B. Shen, Z. Hong, B. Lin, B. Gao and Y. Chen, Chemical Communications, 2012, 48, 12017-12019.

33. Y. Zhang, T. Mori, J. Ye and M. Antonietti, Journal of the American Chemical Society, 2010, 132, 6294-6295.

34. Y. Zhou, L. Zhang, J. Liu, X. Fan, B. Wang, M. Wang, W. Ren, J. Wang, M. Li and J. Shi, Journal of Materials Chemistry A, 2015, 3, 3862-3867.

35. F. Dong, Z. Zhao, T. Xiong, Z. Ni, W. Zhang, Y. Sun and W.-K. Ho, ACS Applied Materials \& Interfaces, 2013, 5, 11392-11401.

36. F. Dong, Z. Ni, P. Li and Z. Wu, New Journal of Chemistry, 2015, 39, 4737-4744.

37. F. Goettmann, A. Fischer, M. Antonietti and A. Thomas, Angewandte Chemie International Edition, 2006, 45, 4467-4471.

38. F. Su, S. C. Mathew, G. Lipner, X. Fu, M. Antonietti, S. Blechert and X. Wang, Journal of the American Chemical Society, 2010, 132, 16299-16301.

39. Y.-P. Yuan, L.-S. Yin, S.-W. Cao, L.-N. Gu, G.-S. Xu, P. Du, H. Chai, Y.-S. Liao and C. Xue, Green Chemistry, 2014, 16, 4663-4668.

40. M. J. Bojdys, J. O. Müller, M. Antonietti and A. Thomas, Chemistry-A European Journal, 2008, $14,8177-8182$.

41. L. Xu, J. Xia, H. Xu, S. Yin, K. Wang, L. Huang, L. Wang and H. Li, Journal of Power Sources, 2014, 245, 866-874.

42. J. Xu, L. Zhang, R. Shi and Y. Zhu, Journal of Materials Chemistry A, 2013, 1, 14766-14772.

43. P. Niu, L. Zhang, G. Liu and H. M. Cheng, Advanced Functional Materials, 2012, 22, 47634770.

44. P. Xia, B. Zhu, J. Yu, S. Cao and M. Jaroniec, Journal of Materials Chemistry A, 2017, 5, 32303238.

45. S. Yang, Y. Gong, J. Zhang, L. Zhan, L. Ma, Z. Fang, R. Vajtai, X. Wang and P. M. Ajayan, Advanced Materials, 2013, 25, 2452-2456.

46. G. Dong, K. Zhao and L. Zhang, Chemical Communications, 2012, 48, 6178-6180.

47. X. Zhou, F. Peng, H. Wang, H. Yu and Y. Fang, Chemical Communications, 2011, 47, 1032310325.

48. Y. Wang, R. Shi, J. Lin and Y. Zhu, Energy \& Environmental Science, 2011, 4, 2922-2929.

49. C. Pan, J. Xu, Y. Wang, D. Li and Y. Zhu, Advanced Functional Materials, 2012, 22, 1518-1524.

50. Y. Hou, A. B. Laursen, J. Zhang, G. Zhang, Y. Zhu, X. Wang, S. Dahl and I. Chorkendorff, Angewandte Chemie International Edition, 2013, 52, 3621-3625.

51. M. Li, L. Zhang, M. Wu, Y. Du, X. Fan, M. Wang, L. Zhang, Q. Kong and J. Shi, Nano Energy, 2016, 19, 145-155.

52. X. Bai, R. Zong, C. Li, D. Liu, Y. Liu and Y. Zhu, Applied Catalysis B: Environmental, 2014, 147, 82-91.

53. Y. Di, X. Wang, A. Thomas and M. Antonietti, ChemCatChem, 2010, 2, 834-838.

54. S. Samanta, S. Martha and K. Parida, ChemCatChem, 2014, 6, 1453-1462.

55. R. Wang, L. Gu, J. Zhou, X. Liu, F. Teng, C. Li, Y. Shen and Y. Yuan, Advanced Materials Interfaces, 2015, 2, 1500037-n/a.

56. H. Wang, X. Yuan, Y. Wu, G. Zeng, X. Chen, L. Leng and H. Li, Applied Catalysis B: Environmental, 2015, 174, 445-454.

57. F. He, G. Chen, Y. Zhou, Y. Yu, L. Li, S. Hao and B. Liu, Journal of Materials Chemistry A, 2016, 4, 3822-3827.

58. Q. Su, J. Sun, J. Wang, Z. Yang, W. Cheng and S. Zhang, Catalysis Science \& Technology, 2014, 4, 1556-1562.

59. J. Zhu, P. Xiao, H. Li and S. n. A. Carabineiro, ACS applied materials \& interfaces, 2014, 6, 16449-16465.

60. J. Zhang, X. Chen, K. Takanabe, K. Maeda, K. Domen, J. D. Epping, X. Fu, M. Antonietti and X. Wang, Angewandte Chemie International Edition, 2010, 49, 441-444. 
61. Y. Zhang, J. Liu, G. Wu and W. Chen, Nanoscale, 2012, 4, 5300-5303.

62. H.-J. Li, B.-W. Sun, L. Sui, D.-J. Qian and M. Chen, Physical Chemistry Chemical Physics, 2015, 17, 3309-3315.

63. Y. Zhang, H. Zhang, L. Cheng, Y. Wang, Y. Miao, G. Ding and Z. Jiao, RSC Advances, 2016, 6, 14002-14008.

64. Y. Yu, Q. Zhou and J. Wang, Chemical Communications, 2016, 52, 3396-3399.

65. B. Jürgens, E. Irran, J. Senker, P. Kroll, H. Müller and W. Schnick, Journal of the American Chemical Society, 2003, 125, 10288-10300.

66. B. Zhu, P. Xia, W. Ho and J. Yu, Applied Surface Science, 2015, 344, 188-195.

67. K. Wang, Q. Li, B. Liu, B. Cheng, W. Ho and J. Yu, Applied Catalysis B: Environmental, 2015, 176, 44-52.

68. C. Yang, B. Wang, L. Zhang, L. Yin and X. Wang, Angewandte Chemie, 2017, 129, 6727-6731.

69. X.-H. Li, X. Wang and M. Antonietti, Chemical Science, 2012, 3, 2170-2174.

70. J. Sun, J. Zhang, M. Zhang, M. Antonietti, X. Fu and X. Wang, Nature Communications, 2012, 3, 1139.

71. X.-H. Li, J. Zhang, X. Chen, A. Fischer, A. Thomas, M. Antonietti and X. Wang, Chemistry of Materials, 2011, 23, 4344-4348.

72. J. Liu, J. Huang, D. Dontosova and M. Antonietti, RSC Advances, 2013, 3, 22988-22993.

73. S. Wang, C. Li, T. Wang, P. Zhang, A. Li and J. Gong, Journal of Materials Chemistry A, 2014, 2, 2885-2890.

74. H. Zhao, H. Yu, X. Quan, S. Chen, Y. Zhang, H. Zhao and H. Wang, Applied Catalysis B: Environmental, 2014, 152, 46-50.

75. K. S. Lakhi, D.-H. Park, K. Al-Bahily, W. Cha, B. Viswanathan, J.-H. Choy and A. Vinu, Chemical Society Reviews, 2017, 46, 72-101.

76. X. Bai, L. Wang, R. Zong and Y. Zhu, The Journal of Physical Chemistry C, 2013, 117, $9952-$ 9961.

77. M. Tahir, C. Cao, N. Mahmood, F. K. Butt, A. Mahmood, F. Idrees, S. Hussain, M. Tanveer, Z. Ali and I. Aslam, ACS applied materials \& interfaces, 2013, 6, 1258-1265.

78. W. Wang, C. Y. Jimmy, Z. Shen, D. K. L. Chan and T. Gu, Chemical Communications, 2014, 50, 10148-10150.

79. Y. Yin, J. Han, X. Zhang, Y. Zhang, J. Zhou, D. Muir, R. Sutarto, Z. Zhang, S. Liu and B. Song, RSC Advances, 2014, 4, 32690-32697.

80. L. Ma, H. Fan, M. Li, H. Tian, J. Fang and G. Dong, Journal of Materials Chemistry A, 2015, 3, 22404-22412.

81. H. Xu, J. Yan, X. She, L. Xu, J. Xia, Y. Xu, Y. Song, L. Huang and H. Li, Nanoscale, 2014, 6, 14061415.

82. Q. Han, B. Wang, J. Gao, Z. Cheng, Y. Zhao, Z. Zhang and L. Qu, ACS nano, 2016, 10, 27452751.

83. L. Ma, H. Fan, J. Wang, Y. Zhao, H. Tian and G. Dong, Applied Catalysis B: Environmental, 2016, 190, 93-102.

84. F. Cheng, H. Wang and X. Dong, Chemical communications, 2015, 51, 7176-7179.

85. J. Tong, L. Zhang, F. Li, K. Wang, L. Han and S. Cao, RSC Advances, 2015, 5, 88149-88153.

86. P. Qiu, H. Chen, C. Xu, N. Zhou, F. Jiang, X. Wang and Y. Fu, Journal of Materials Chemistry A, 2015, 3, 24237-24244.

87. J. Zhu, Y. Wei, W. Chen, Z. Zhao and A. Thomas, Chemical Communications, 2010, 46, 69656967.

88. P. Sharma and Y. Sasson, RSC Advances, 2017, 7, 25589-25596.

89. J. Xu, K. Shen, B. Xue and Y.-X. Li, Journal of Molecular Catalysis A: Chemical, 2013, 372, 105113.

90. H. Wang, C. Wang, Y. Yang, M. Zhao and Y. Wang, Catalysis Science \& Technology, 2017, 7, 405-417. 
91. Y. Shiraishi, S. Kanazawa, Y. Sugano, D. Tsukamoto, H. Sakamoto, S. Ichikawa and T. Hirai, Acs Catalysis, 2014, 4, 774-780.

92. Y. Dai, C. Li, Y. Shen, T. Lim, J. Xu, Y. Li, H. Niemantsverdriet, F. Besenbacher, N. Lock and R. Su, Nature communications, 2018, 9, 60.

93. M. A. Khan, I. F. Teixeira, M. M. J. Li, Y. Koito and S. C. E. Tsang, Chemical Communications, 2016, 52, 2772-2775.

94. Z. Lin and X. Wang, Angewandte Chemie International Edition, 2013, 52, 1735-1738.

95. Y. Wang, J. Zhang, X. Wang, M. Antonietti and H. Li, Angewandte Chemie International Edition, 2010, 49, 3356-3359.

96. S. C. Yan, Z. S. Li and Z. G. Zou, Langmuir, 2010, 26, 3894-3901.

97. D.-H. Lan, H.-T. Wang, L. Chen, C.-T. Au and S.-F. Yin, Carbon, 2016, 100, 81-89.

98. J. Hong, X. Xia, Y. Wang and R. Xu, Journal of Materials Chemistry, 2012, 22, 15006-15012.

99. G. Zhang, M. Zhang, X. Ye, X. Qiu, S. Lin and X. Wang, Advanced Materials, 2014, 26, 805809.

100. Q. Han, C. Hu, F. Zhao, Z. Zhang, N. Chen and L. Qu, Journal of Materials Chemistry A, 2015, 3, 4612-4619.

101. X. Wang, X. Chen, A. Thomas, X. Fu and M. Antonietti, Advanced Materials, 2009, 21, 16091612.

102. Z. Ding, X. Chen, M. Antonietti and X. Wang, ChemSusChem, 2011, 4, 274-281.

103. S. Hu, X. Qu, P. Li, F. Wang, Q. Li, L. Song, Y. Zhao and X. Kang, Chemical Engineering Journal, 2018, 334, 410-418.

104. S. Hu, F. Li, Z. Fan, F. Wang, Y. Zhao and Z. Lv, Dalton Transactions, 2015, 44, 1084-1092.

105. J. Zhang, S. Hu and Y. Wang, RSC Advances, 2014, 4, 62912-62919.

106. H. Gao, S. Yan, J. Wang and Z. Zou, Dalton Transactions, 2014, 43, 8178-8183.

107. J. Zhao, L. Ma, H. Wang, Y. Zhao, J. Zhang and S. Hu, Applied Surface Science, 2015, 332, 625630.

108. T. Xiong, W. Cen, Y. Zhang and F. Dong, Acs Catalysis, 2016, 6, 2462-2472.

109. Z. Zhou, Y. Zhang, Y. Shen, S. Liu and Y. Zhang, Chemical Society Reviews, 2018, 47, 22982321.

110. L. Jiang, X. Yuan, Y. Pan, J. Liang, G. Zeng, Z. Wu and H. Wang, Applied Catalysis B: Environmental, 2017, 217, 388-406.

111. S. C. Yan, S. B. Lv, Z. S. Li and Z. G. Zou, Dalton Transactions, 2010, 39, 1488-1491.

112. X. Dong and F. Cheng, Journal of Materials Chemistry A, 2015, 3, 23642-23652.

113. Y. Zhang and M. Antonietti, Chemistry-An Asian Journal, 2010, 5, 1307-1311.

114. S. Zhang, J. Li, X. Wang, Y. Huang, M. Zeng and J. Xu, Journal of Materials Chemistry A, 2015, 3, 10119-10126.

115. A. K. Geim and K. S. Novoselov, Nature materials, 2007, 6, 183.

116. A. K. Geim, science, 2009, 324, 1530-1534.

117. Z. Zhao, Y. Sun and F. Dong, Nanoscale, 2015, 7, 15-37.

118. Y. Sun, C. Li, Y. Xu, H. Bai, Z. Yao and G. Shi, Chemical Communications, 2010, 46, 4740-4742.

119. Q. Xiang, J. Yu and M. Jaroniec, The Journal of Physical Chemistry C, 2011, 115, 7355-7363.

120. Y. Li, H. Zhang, P. Liu, D. Wang, Y. Li and H. Zhao, Small, 2013, 9, 3336-3344.

121. W.-J. Ong, L.-L. Tan, S.-P. Chai, S.-T. Yong and A. R. Mohamed, Nano Energy, 2015, 13, 757770.

122. L. Ge and C. Han, Applied Catalysis B: Environmental, 2012, 117, 268-274.

123. Y. Xu, H. Xu, L. Wang, J. Yan, H. Li, Y. Song, L. Huang and G. Cai, Dalton Transactions, 2013, 42, 7604-7613.

124. B. Chai, X. Liao, F. Song and H. Zhou, Dalton Transactions, 2014, 43, 982-989.

125. X. Bai, L. Wang, Y. Wang, W. Yao and Y. Zhu, Applied Catalysis B: Environmental, 2014, 152, 262-270.

126. Y. Guo, P. Yao, D. Zhu and C. Gu, Journal of Materials Chemistry A, 2015, 3, 13189-13192. 
127. H. Zhang, L. Zhao, F. Geng, L.-H. Guo, B. Wan and Y. Yang, Applied Catalysis B: Environmental, 2016, 180, 656-662.

128. J. Liu, Y. Liu, N. Liu, Y. Han, X. Zhang, H. Huang, Y. Lifshitz, S. T. Lee, J. Zhong and Z. Kang, Science, 2015, 347, 970-974.

129. S. Fang, Y. Xia, K. Lv, Q. Li, J. Sun and M. Li, Applied Catalysis B: Environmental, 2016, 185, 225-232.

130. G. Gao, Y. Jiao, F. Ma, Y. Jiao, E. Waclawik and A. Du, Physical Chemistry Chemical Physics, 2015, 17, 31140-31144.

131. X. Jian, X. Liu, H.-m. Yang, J.-g. Li, X.-I. Song, H.-y. Dai and Z.-h. Liang, Applied Surface Science, 2016, 370, 514-521.

132. L. Ge, C. Han and J. Liu, Journal of Materials Chemistry, 2012, 22, 11843-11850.

133. Y. Sui, J. Liu, Y. Zhang, X. Tian and W. Chen, Nanoscale, 2013, 5, 9150-9155.

134. H. Yan and Y. Huang, Chemical communications, 2011, 47, 4168-4170.

135. Z. Xing, Z. Chen, X. Zong and L. Wang, Chemical Communications, 2014, 50, 6762-6764.

136. S. Hu, L. Ma, H. Wang, L. Zhang, Y. Zhao and G. Wu, RSC Advances, 2015, 5, 31947-31953.

137. F. He, G. Chen, Y. Yu, S. Hao, Y. Zhou and Y. Zheng, ACS applied materials \& interfaces, 2014, 6, 7171-7179.

138. X. Xia, N. Deng, G. Cui, J. Xie, X. Shi, Y. Zhao, Q. Wang, W. Wang and B. Tang, Chemical communications, 2015, 51, 10899-10902.

139. J. Zhang, M. Zhang, R. Q. Sun and X. Wang, Angewandte Chemie, 2012, 124, 10292-10296.

140. L. Ye, D. Wang and S. Chen, ACS applied materials \& interfaces, 2016, 8, 5280-5289.

141. S. Samanta, S. Khilari, D. Pradhan and R. Srivastava, ACS Sustainable Chemistry \& Engineering, 2017, 5, 2562-2577.

142. J. Yu, S. Wang, J. Low and W. Xiao, Physical Chemistry Chemical Physics, 2013, 15, $16883-$ 16890.

143. Z. Jiang, C. Zhu, W. Wan, K. Qian and J. Xie, Journal of Materials Chemistry A, 2016, 4, 18061818.

144. Q. Sun, K. Lv, Z. Zhang, M. Li and B. Li, Applied Catalysis B: Environmental, 2015, 164, 420427.

145. M. J. Muñoz-Batista, A. Kubacka and M. Fernandez-Garcia, Catalysis Science \& Technology, 2014, 4, 2006-2015.

146. C. Han, Y. Wang, Y. Lei, B. Wang, N. Wu, Q. Shi and Q. Li, Nano Research, 2015, 8, 1199-1209.

147. K. Sridharan, E. Jang and T. J. Park, Applied Catalysis B: Environmental, 2013, 142, 718-728.

148. K. Yang, C. Meng, L. Lin, X. Peng, X. Chen, X. Wang, W. Dai and X. Fu, Catalysis Science \& Technology, 2016, 6, 829-839.

149. G. Li, X. Nie, J. Chen, Q. Jiang, T. An, P. K. Wong, H. Zhang, H. Zhao and H. Yamashita, Water research, 2015, 86, 17-24.

150. W. Li, C. Li, B. Chen, X. Jiao and D. Chen, RSC Advances, 2015, 5, 34281-34291.

151. X. Chen, J. Wei, R. Hou, Y. Liang, Z. Xie, Y. Zhu, X. Zhang and H. Wang, Applied Catalysis B: Environmental, 2016, 188, 342-350.

152. R. Hao, G. Wang, H. Tang, L. Sun, C. Xu and D. Han, Applied Catalysis B: Environmental, 2016, 187, 47-58.

153. K. Li, Z. Zeng, L. Yan, M. Huo, Y. Guo, S. Luo and X. Luo, Applied Catalysis B: Environmental, 2016, 187, 269-280.

154. Y. Li, J. Wang, Y. Yang, Y. Zhang, D. He, Q. An and G. Cao, Journal of hazardous materials, 2015, 292, 79-89.

155. J. Yan, H. Wu, H. Chen, Y. Zhang, F. Zhang and S. F. Liu, Applied Catalysis B: Environmental, 2016, 191, 130-137.

156. H. Li, L. Zhou, L. Wang, Y. Liu, J. Lei and J. Zhang, Physical Chemistry Chemical Physics, 2015, 17, 17406-17412. 
157. K. Dai, L. Lu, C. Liang, Q. Liu and G. Zhu, Applied Catalysis B: Environmental, 2014, 156, 331340.

158. D. Lu, G. Zhang and Z. Wan, Applied Surface Science, 2015, 358, 223-230.

159. X. Song, Y. Hu, M. Zheng and C. Wei, Applied Catalysis B: Environmental, 2016, 182, 587-597.

160. H. Chen, Y. Xie, X. Sun, M. Lv, F. Wu, L. Zhang, L. Li and X. Xu, Dalton Transactions, 2015, 44, 13030-13039.

161. L. Zhang, D. Jing, X. She, H. Liu, D. Yang, Y. Lu, J. Li, Z. Zheng and L. Guo, Journal of Materials Chemistry A, 2014, 2, 2071-2078.

162. Y. Zang, L. Li, Y. Xu, Y. Zuo and G. Li, Journal of Materials Chemistry A, 2014, 2, 15774-15780.

163. D. Chen, K. Wang, T. Ren, H. Ding and Y. Zhu, Dalton Transactions, 2014, 43, 13105-13114.

164. J.-X. Sun, Y.-P. Yuan, L.-G. Qiu, X. Jiang, A.-J. Xie, Y.-H. Shen and J.-F. Zhu, Dalton Transactions, 2012, 41, 6756-6763.

165. J. Li, M. Zhou, Z. Ye, H. Wang, C. Ma, P. Huo and Y. Yan, RSC Advances, 2015, 5, 91177-91189.

166. W. Liu, M. Wang, C. Xu and S. Chen, Chemical Engineering Journal, 2012, 209, 386-393.

167. S. Kumar, A. Baruah, S. Tonda, B. Kumar, V. Shanker and B. Sreedhar, Nanoscale, 2014, 6, 4830-4842.

168. K.-i. Katsumata, R. Motoyoshi, N. Matsushita and K. Okada, Journal of hazardous materials, 2013, 260, 475-482.

169. L. Huang, H. Xu, Y. Li, H. Li, X. Cheng, J. Xia, Y. Xu and G. Cai, Dalton Transactions, 2013, 42, 8606-8616.

170. J. Ding, Q. Liu, Z. Zhang, X. Liu, J. Zhao, S. Cheng, B. Zong and W.-L. Dai, Applied Catalysis B: Environmental, 2015, 165, 511-518.

171. J. Chen, S. Shen, P. Guo, M. Wang, P. Wu, X. Wang and L. Guo, Applied Catalysis B: Environmental, 2014, 152, 335-341.

172. S. Ye, L.-G. Qiu, Y.-P. Yuan, Y.-J. Zhu, J. Xia and J.-F. Zhu, Journal of Materials Chemistry A, 2013, 1, 3008-3015.

173. J. Zhang, M. Grzelczak, Y. Hou, K. Maeda, K. Domen, X. Fu, M. Antonietti and X. Wang, Chemical Science, 2012, 3, 443-446.

174. L. Ge, C. Han and J. Liu, Applied Catalysis B: Environmental, 2011, 108, 100-107.

175. J. Ran, J. Yu and M. Jaroniec, Green Chemistry, 2011, 13, 2708-2713.

176. X. Dai, M. Xie, S. Meng, X. Fu and S. Chen, Applied Catalysis B: Environmental, 2014, 158, 382-390.

177. H. Yu, F. Chen, F. Chen and X. Wang, Applied Surface Science, 2015, 358, 385-392.

178. J. Fu, B. Chang, Y. Tian, F. Xi and X. Dong, Journal of Materials Chemistry A, 2013, 1, 30833090.

179. M. Lu, Z. Pei, S. Weng, W. Feng, Z. Fang, Z. Zheng, M. Huang and P. Liu, Physical Chemistry Chemical Physics, 2014, 16, 21280-21288.

180. J. Zhang, Y. Wang, J. Jin, J. Zhang, Z. Lin, F. Huang and J. Yu, ACS applied materials \& interfaces, 2013, 5, 10317-10324.

181. J. Xie, H. Zhang, S. Li, R. Wang, X. Sun, M. Zhou, J. Zhou, X. W. D. Lou and Y. Xie, Advanced materials, 2013, 25, 5807-5813.

182. H. Zhao, Y. Dong, P. Jiang, H. Miao, G. Wang and J. Zhang, Journal of Materials Chemistry A, 2015, 3, 7375-7381.

183. H. Tian, M. Liu and W. Zheng, Applied Catalysis B: Environmental, 2018, 225, 468-476.

184. J. Wang, Z. Guan, J. Huang, Q. Li and J. Yang, Journal of Materials Chemistry A, 2014, 2, 79607966.

185. Y. Hou, Y. Zhu, Y. Xu and X. Wang, Applied Catalysis B: Environmental, 2014, 156, 122-127.

186. Z. Zhang, J. Huang, M. Zhang, Q. Yuan and B. Dong, Applied Catalysis B: Environmental, 2015, 163, 298-305.

187. L. Yin, Y.-P. Yuan, S.-W. Cao, Z. Zhang and C. Xue, Rsc Advances, 2014, 4, 6127-6132. 
188. Y. Zhu, Y. Xu, Y. Hou, Z. Ding and X. Wang, International Journal of Hydrogen Energy, 2014, 39, 11873-11879.

189. Y. Shi, S. Jiang, K. Zhou, B. Wang, B. Wang, Z. Gui, Y. Hu and R. K. K. Yuen, RSC Advances, 2014, 4, 2609-2613.

190. P. Suyana, K. R. Sneha, B. N. Nair, V. Karunakaran, A. P. Mohamed, K. G. K. Warrier and U. S. Hareesh, RSC Advances, 2016, 6, 17800-17809.

191. J. Wang, P. Guo, Q. Guo, P. G. Jönsson and Z. Zhao, CrystEngComm, 2014, 16, 4485-4492.

192. D. Jiang, L. Chen, J. Xie and M. Chen, Dalton Transactions, 2014, 43, 4878-4885.

193. A. Dhakshinamoorthy, A. M. Asiri and H. García, Angewandte Chemie International Edition, 2016, 55, 5414-5445.

194. R. Chen, J. Zhang, Y. Wang, X. Chen, J. A. Zapien and C.-S. Lee, Nanoscale, 2015, 7, 1729917305.

195. J. Hong, C. Chen, F. E. Bedoya, G. H. Kelsall, D. O'Hare and C. Petit, Catalysis Science \& Technology, 2016, 6, 5042-5051.

196. R. Jiang, B. Li, C. Fang and J. Wang, Advanced materials, 2014, 26, 5274-5309.

197. C. M. Cobley, S. E. Skrabalak, D. J. Campbell and Y. Xia, Plasmonics, 2009, 4, 171-179.

198. M. Hu, J. Chen, Z.-Y. Li, L. Au, G. V. Hartland, X. Li, M. Marquez and Y. Xia, Chemical Society Reviews, 2006, 35, 1084-1094.

199. M. Rycenga, C. M. Cobley, J. Zeng, W. Li, C. H. Moran, Q. Zhang, D. Qin and Y. Xia, Chemical reviews, 2011, 111, 3669-3712.

200. Y. Xia and N. J. Halas, MRS bulletin, 2005, 30, 338-348.

201. H. A. Atwater and A. Polman, Nature materials, 2010, 9, 205.

202. J. N. Anker, W. P. Hall, O. Lyandres, N. C. Shah, J. Zhao and R. P. Van Duyne, Nature materials, 2008, 7, 442.

203. W. Hou and S. B. Cronin, Advanced Functional Materials, 2013, 23, 1612-1619.

204. S. Linic, P. Christopher and D. B. Ingram, Nature materials, 2011, 10, 911.

205. W. A. Murray and W. L. Barnes, Advanced materials, 2007, 19, 3771-3782.

206. K. A. Willets and R. P. Van Duyne, Annu. Rev. Phys. Chem., 2007, 58, 267-297.

207. Y. Huang, Z. Liu, G. Gao, G. Xiao, A. Du, S. Bottle, S. Sarina and H. Zhu, ACS Catalysis, 2017, 7, 4975-4985.

208. P. A. DeSario, J. J. Pietron, T. H. Brintlinger, M. McEntee, J. F. Parker, O. Baturina, R. M. Stroud and D. R. Rolison, Nanoscale, 2017, 9, 11720-11729.

209. T. V. Alves, W. Hermoso, F. R. Ornellas and P. H. C. Camargo, Chemical Physics Letters, 2012, 544, 64-69.

210. J. M. McMahon, G. C. Schatz and S. K. Gray, Physical Chemistry Chemical Physics, 2013, 15, 5415-5423.

211. B. Clark, C. R. Jacobson, M. Lou, J. Yang, L. Zhou, S. Gottheim, P. Nordlander, N. J. Halas and C. J. DeSantis, Nano letters, 2017.

212. M.-N. Su, P. D. Dongare, D. Chakraborty, Y. Zhang, C. Yi, F. Wen, W.-S. Chang, P. Nordlander, J. E. Sader and N. J. Halas, Nano letters, 2017, 17, 2575-2583.

213. M. W. Knight, N. S. King, L. Liu, H. O. Everitt, P. Nordlander and N. J. Halas, ACS nano, 2013, 8, 834-840.

214. M. J. McClain, A. E. Schlather, E. Ringe, N. S. King, L. Liu, A. Manjavacas, M. W. Knight, I. Kumar, K. H. Whitmire, H. O. Everitt, P. Nordlander and N. J. Halas, Nano letters, 2015, 15, 2751-2755.

215. T. Tumkur, X. Yang, C. Zhang, J. Yang, Y. Zhang, G. V. Naik, P. Nordlander and N. J. Halas, Nano Letters, 2018, 18, 2040-2046.

216. M. L. Tseng, J. Yang, M. Semmlinger, C. Zhang, P. Nordlander and N. J. Halas, Nano Letters, 2017, 17, 6034-6039.

217. S. Linic, U. Aslam, C. Boerigter and M. Morabito, Nature materials, 2015, 14, 567.

218. E. Hao and G. C. Schatz, The Journal of chemical physics, 2004, 120, 357-366. 
219. P. Christopher, H. Xin, A. Marimuthu and S. Linic, Nature materials, 2012, 11, 1044.

220. D. B. Ingram, P. Christopher, J. L. Bauer and S. Linic, ACS Catalysis, 2011, 1, 1441-1447.

221. P. Christopher, H. Xin and S. Linic, Nat Chem, 2011, 3, 467-472.

222. D. B. Ingram and S. Linic, Journal of the American Chemical Society, 2011, 133, 5202-5205.

223. G. Baffou and R. Quidant, Chemical Society Reviews, 2014, 43, 3898-3907.

224. C. E. Talley, J. B. Jackson, C. Oubre, N. K. Grady, C. W. Hollars, S. M. Lane, T. R. Huser, P. Nordlander and N. J. Halas, Nano letters, 2005, 5, 1569-1574.

225. M. J. Kale, T. Avanesian and P. Christopher, Acs Catalysis, 2013, 4, 116-128.

226. M. J. Kale, T. Avanesian, H. Xin, J. Yan and P. Christopher, Nano letters, 2014, 14, 5405-5412.

227. J. W. Gadzuk, The Journal of chemical physics, 1983, 79, 6341-6348.

228. M. L. Brongersma, N. J. Halas and P. Nordlander, Nature nanotechnology, 2015, 10, 25.

229. E. Boisselier and D. Astruc, Chemical society reviews, 2009, 38, 1759-1782.

230. B. Pelaz, C. Alexiou, R. A. Alvarez-Puebla, F. Alves, A. M. Andrews, S. Ashraf, L. P. Balogh, L. Ballerini, A. Bestetti and C. Brendel, Journal, 2017.

231. F. Meng, W. Hao, S. Yu, R. Feng, Y. Liu, F. Yu, P. Tao, W. Shang, J. Wu and C. Song, Journal of the American Chemical Society, 2017, 139, 12362-12365.

232. L. Cao, D. N. Barsic, A. R. Guichard and M. L. Brongersma, Nano letters, 2007, 7, 3523-3527.

233. L. Zhou, Y. Tan, J. Wang, W. Xu, Y. Yuan, W. Cai, S. Zhu and J. Zhu, Nature Photonics, 2016, 10, 393.

234. C. Wadell, T. J. Antosiewicz and C. Langhammer, Nano letters, 2012, 12, 4784-4790.

235. B. Hammer and J. K. Norskov, Nature, 1995, 376, 238.

236. S. Murphy, L. Huang and P. V. Kamat, The Journal of Physical Chemistry C, 2013, 117, 47404747.

237. B. Sharma, R. R. Frontiera, A.-I. Henry, E. Ringe and R. P. Van Duyne, Materials today, 2012, 15, 16-25.

238. J. Wang, R. A. Ando and P. H. C. Camargo, Angewandte Chemie, 2015, 127, 7013-7016.

239. D. Tsukamoto, Y. Shiraishi, Y. Sugano, S. Ichikawa, S. Tanaka and T. Hirai, Journal of the American Chemical Society, 2012, 134, 6309-6315.

240. Z. Zhang and J. T. Yates Jr, Chemical reviews, 2012, 112, 5520-5551.

241. U. Banin, Y. Ben-Shahar and K. Vinokurov, Chemistry of Materials, 2013, 26, 97-110.

242. P. D. Cozzoli, R. Comparelli, E. Fanizza, M. L. Curri, A. Agostiano and D. Laub, Journal of the American Chemical Society, 2004, 126, 3868-3879.

243. Y. Zheng, L. Zheng, Y. Zhan, X. Lin, Q. Zheng and K. Wei, Inorganic chemistry, 2007, 46, 69806986.

244. C. Gu, C. Cheng, H. Huang, T. Wong, N. Wang and T.-Y. Zhang, Crystal Growth and Design, 2009, 9, 3278-3285.

245. C. K. N. Peh, L. Ke and G. W. Ho, Materials Letters, 2010, 64, 1372-1375.

246. H. Zhu, E. Zhu, G. Ou, L. Gao and J. Chen, Nanoscale research letters, 2010, 5, 1755.

247. C. George, A. Genovese, F. Qiao, K. Korobchevskaya, A. Comin, A. Falqui, S. Marras, A. Roig, Y. Zhang and R. Krahne, Nanoscale, 2011, 3, 4647-4654.

248. T. C. Damato, C. C. S. de Oliveira, R. A. Ando and P. H. C. Camargo, Langmuir, 2013, 29, 16421649.

249. F. V. E. dos Reis, V. S. Antonin, P. Hammer, M. C. Santos and P. H. C. Camargo, Journal of Catalysis, 2015, 326, 100-106.

250. E. C. M. Barbosa, J. L. Fiorio, T. Mou, B. Wang, L. M. Rossi and P. Camargo, Chemistry-A European Journal, 2018.

251. X.-F. Wu, H.-Y. Song, J.-M. Yoon, Y.-T. Yu and Y.-F. Chen, Langmuir, 2009, 25, 6438-6447.

252. L. Zhang, D. A. Blom and H. Wang, Chemistry of Materials, 2011, 23, 4587-4598.

253. N. Zhang, S. Liu, X. Fu and Y.-J. Xu, The Journal of Physical Chemistry C, 2011, 115, 91369145. 
254. P. Ramasamy, D.-M. Seo, S.-H. Kim and J. Kim, Journal of Materials Chemistry, 2012, 22, 11651-11657.

255. P. Du, P. Jing, D. Li, Y. Cao, Z. Liu and Z. Sun, Small, 2015, 11, 2454-2462.

256. C.-H. Kuo, T.-E. Hua and M. H. Huang, Journal of the American Chemical Society, 2009, 131, 17871-17878.

257. M. Fan, C. Song, T. Chen, X. Yan, D. Xu, W. Gu, W. Shi and L. Xiao, RSC Advances, 2016, 6, 34633-34640.

258. S. Ma, S. Zhan, Y. Jia, Q. Shi and Q. Zhou, Applied Catalysis B: Environmental, 2016, 186, 7787.

259. Y. Zhang, D. A. J. M. Ligthart, X.-Y. Quek, L. Gao and E. J. M. Hensen, International Journal of Hydrogen Energy, 2014, 39, 11537-11546.

260. F. Fina, H. Menard and J. T. S. Irvine, Physical Chemistry Chemical Physics, 2015, 17, 1392913936.

261. J. Liu, Y. Zhang, L. Lu, G. Wu and W. Chen, Chemical Communications, 2012, 48, 8826-8828.

262. Y. Guo, L. Zhang, K. Zhou, Y. Shen, Q. Zhang and C. Gu, Journal of Materials Chemistry A, 2014, 2, 19594-19597.

263. J. Liu, Y. Yang, N. Liu, Y. Liu, H. Huang and Z. Kang, Green Chemistry, 2014, 16, 4559-4565.

264. N. Cheng, J. Tian, Q. Liu, C. Ge, A. H. Qusti, A. M. Asiri, A. O. Al-Youbi and X. Sun, ACS applied materials \& interfaces, 2013, 5, 6815-6819.

265. T. Bhowmik, M. K. Kundu and S. Barman, RSC Advances, 2015, 5, 38760-38773.

266. S. Tonda, S. Kumar and V. Shanker, Materials Research Bulletin, 2016, 75, 51-58.

267. O. Fontelles-Carceller, M. J. Muñoz-Batista, M. Fernández-García and A. Kubacka, ACS applied materials \& interfaces, 2016, 8, 2617-2627.

268. Y. Bu, Z. Chen and W. Li, Applied Catalysis B: Environmental, 2014, 144, 622-630.

269. J. Chen, C. L. Dong, Y. Du, D. Zhao and S. Shen, Advanced Materials Interfaces, 2015, 2.

270. M. J. Munoz-Batista, O. Fontelles-Carceller, M. Ferrer, M. Fernández-García and A. Kubacka, Applied Catalysis B: Environmental, 2016, 183, 86-95.

271. W. Bing, Z. Chen, H. Sun, P. Shi, N. Gao, J. Ren and X. Qu, Nano Research, 2015, 8, 16481658.

272. L. Ge, C. Han, J. Liu and Y. Li, Applied Catalysis A: General, 2011, 409, 215-222.

273. Y. Yang, Y. Guo, F. Liu, X. Yuan, Y. Guo, S. Zhang, W. Guo and M. Huo, Applied Catalysis B: Environmental, 2013, 142, 828-837.

274. S. Patnaik, D. P. Sahoo and K. Parida, Renewable and Sustainable Energy Reviews, 2018, 82, 1297-1312.

275. Y. Shiraishi, Y. Kofuji, S. Kanazawa, H. Sakamoto, S. Ichikawa, S. Tanaka and T. Hirai, Chemical communications, 2014, 50, 15255-15258.

276. K. Li, Z. Zeng, L. Yan, S. Luo, X. Luo, M. Huo and Y. Guo, Applied Catalysis B: Environmental, 2015, 165, 428-437.

277. W.-J. Ong, L.-L. Tan, S.-P. Chai and S.-T. Yong, Dalton Transactions, 2015, 44, 1249-1257.

278. J. Yu, K. Wang, W. Xiao and B. Cheng, Physical Chemistry Chemical Physics, 2014, 16, $11492-$ 11501.

279. Y. Wang, D. Cao, M. Liu and X. Zhao, Catalysis Communications, 2017, 102, 85-88.

280. Z. Li, R. Lin, Z. Liu, D. Li, H. Wang and Q. Li, Electrochimica Acta, 2016, 191, 606-615.

281. H. Qian, H. Huang and X. Wang, Journal of Power Sources, 2015, 275, 734-741.

282. S. Verma, R. B. Nasir Baig, M. N. Nadagouda and R. S. Varma, Catalysis Today, 2017.

283. S. Bai, X. Wang, C. Hu, M. Xie, J. Jiang and Y. Xiong, Chemical communications, 2014, 50, 6094-6097.

284. C. Chang, Y. Fu, M. Hu, C. Wang, G. Shan and L. Zhu, Applied Catalysis B: Environmental, 2013, 142, 553-560.

285. F. Dong, Z. Zhao, Y. Sun, Y. Zhang, S. Yan and Z. Wu, Environmental science \& technology, 2015, 49, 12432-12440. 
286. P. Zhang, T. Wang and H. Zeng, Applied Surface Science, 2017, 391, 404-414.

287. N. Wang, Z. Han, H. Fan and S. Ai, RSC Advances, 2015, 5, 91302-91307.

288. X. Zhou, Z. Luo, P. Tao, B. Jin, Z. Wu and Y. Huang, Materials Chemistry and Physics, 2014, $143,1462-1468$.

289. Z. Li, C. Kong and G. Lu, The Journal of Physical Chemistry C, 2015, 120, 56-63.

290. L. Bi, D. Xu, L. Zhang, Y. Lin, D. Wang and T. Xie, Physical Chemistry Chemical Physics, 2015, 17, 29899-29905.

291. L. Kong, Y. Dong, P. Jiang, G. Wang, H. Zhang and N. Zhao, Journal of Materials Chemistry A, 2016, 4, 9998-10007.

292. J. Wen, J. Xie, H. Zhang, A. Zhang, Y. Liu, X. Chen and X. Li, ACS Applied Materials \& Interfaces, 2017, 9, 14031-14042.

293. C. H. Choi, L. Lin, S. Gim, S. Lee, H. Kim, X. Wang and W. Choi, ACS Catalysis, 2018, 42414256.

294. R. Mu, Q. Fu, H. Xu, H. Zhang, Y. Huang, Z. Jiang, S. Zhang, D. Tan and X. Bao, Journal of the American Chemical Society, 2011, 133, 1978-1986.

295. B. T. Sneed, A. P. Young, D. Jalalpoor, M. C. Golden, S. Mao, Y. Jiang, Y. Wang and C.-K. Tsung, Acs Nano, 2014, 8, 7239-7250.

296. C. Han, Y. Lu, J. Zhang, L. Ge, Y. Li, C. Chen, Y. Xin, L. Wu and S. Fang, Journal of Materials Chemistry A, 2015, 3, 23274-23282.

297. C. Han, L. Wu, L. Ge, Y. Li and Z. Zhao, Carbon, 2015, 92, 31-40.

298. Q. Lang, Y. Yang, Y. Zhu, W. Hu, W. Jiang, S. Zhong, P. Gong, B. Teng, L. Zhao and S. Bai, Journal of Materials Chemistry A, 2017, 5, 6686-6694.

299. F. Chen, Q. Yang, Y. Wang, J. Zhao, D. Wang, X. Li, Z. Guo, H. Wang, Y. Deng and C. Niu, Applied Catalysis B: Environmental, 2017, 205, 133-147.

300. F. Shi, L. Chen, M. Chen and D. Jiang, Chemical Communications, 2015, 51, 17144-17147.

301. W. Feng, J. Fang, G. Zhou, L. Zhang, S. Lu, S. Wu, Y. Chen, Y. Ling and Z. Fang, Molecular Catalysis, 2017, 434, 69-79.

302. W. Li, C. Feng, S. Dai, J. Yue, F. Hua and H. Hou, Applied Catalysis B: Environmental, 2015, 168, 465-471.

303. K.-E. Byun, H.-J. Chung, J. Lee, H. Yang, H. J. Song, J. Heo, D. H. Seo, S. Park, S. W. Hwang and I. Yoo, Nano letters, 2013, 13, 4001-4005.

304. S. T. Kochuveedu, Y. H. Jang and D. H. Kim, Chemical Society Reviews, 2013, 42, 8467-8493.

305. L. Jiang, X. Yuan, G. Zeng, J. Liang, Z. Wu and H. Wang, Environmental Science: Nano, 2018.

306. H. Li, Y. Zhou, W. Tu, J. Ye and Z. Zou, Advanced Functional Materials, 2015, 25, 998-1013.

307. P. Zhou, J. Yu and M. Jaroniec, Advanced Materials, 2014, 26, 4920-4935.

308. J. Low, C. Jiang, B. Cheng, S. Wageh, A. A. Al-Ghamdi and J. Yu, Small Methods, 2017.

309. Z. Jiang, W. Wan, H. Li, S. Yuan, H. Zhao and P. K. Wong, Advanced Materials, 2018.

310. H. Xu, J. Yi, X. She, Q. Liu, L. Song, S. Chen, Y. Yang, Y. Song, R. Vajtai and J. Lou, Applied Catalysis B: Environmental, 2018, 220, 379-385.

311. J. Yu, S. Wang, B. Cheng, Z. Lin and F. Huang, Catalysis Science \& Technology, 2013, 3, 17821789.

312. Y. Li, X. Cheng, X. Ruan, H. Song, Z. Lou, Z. Ye and L. Zhu, Nano Energy, 2015, 12, 775-784.

313. A. Mettenbörger, Y. Gönüllü, T. Fischer, T. Heisig, A. Sasinska, C. Maccato, G. Carraro, C. Sada, D. Barreca and L. Mayrhofer, Nano energy, 2016, 19, 415-427.

314. S. Cao and J. Yu, The journal of physical chemistry letters, 2014, 5, 2101-2107.

315. H. Yan, Y. Chen and S. Xu, International Journal of hydrogen energy, 2012, 37, 125-133.

316. X. Zhang, T. Peng, L. Yu, R. Li, Q. Li and Z. Li, ACS Catalysis, 2014, 5, 504-510.

317. R. Marschall, Advanced Functional Materials, 2014, 24, 2421-2440.

318. X. Li, W. Bi, L. Zhang, S. Tao, W. Chu, Q. Zhang, Y. Luo, C. Wu and Y. Xie, Advanced Materials, 2016, 28, 2427-2431. 
319. A. B. Jorge, D. J. Martin, M. T. S. Dhanoa, A. S. Rahman, N. Makwana, J. Tang, A. Sella, F. Corà, S. Firth and J. A. Darr, The Journal of Physical Chemistry C, 2013, 117, 7178-7185.

320. D. J. Martin, K. Qiu, S. A. Shevlin, A. D. Handoko, X. Chen, Z. Guo and J. Tang, Angewandte Chemie International Edition, 2014, 53, 9240-9245.

321. W. Tu, Y. Xu, J. Wang, B. Zhang, T. Zhou, S. Yin, S. Wu, C. Li, Y. Huang and Y. Zhou, ACS Sustainable Chemistry \& Engineering, 2017, 5, 7260-7268.

322. X. An, W. Wang, J. Wang, H. Duan, J. Shi and X. Yu, Physical Chemistry Chemical Physics, 2018.

323. Y. Chen, B. Lin, W. Yu, Y. Yang, S. M. Bashir, H. Wang, K. Takanabe, H. Idriss and J.-M. Basset, Chemistry - A European Journal, 2015, 21, 10290-10295.

324. A. Indra, P. W. Menezes, K. Kailasam, D. Hollmann, M. Schröder, A. Thomas, A. Brückner and M. Driess, Chemical Communications, 2016, 52, 104-107.

325. G. Zhang, C. Huang and X. Wang, Small, 2015, 11, 1215-1221.

326. K. Sridharan, E. Jang, J. H. Park, J. H. Kim, J. H. Lee and T. J. Park, Chemistry-A European Journal, 2015, 21, 9126-9132.

327. J. Qin and H. Zeng, Applied Catalysis B: Environmental, 2017, 209, 161-173.

328. J. Qin, J. Huo, P. Zhang, J. Zeng, T. Wang and H. Zeng, Nanoscale, 2016, 8, 2249-2259.

329. S. C. Warren and E. Thimsen, Energy \& Environmental Science, 2012, 5, 5133-5146.

330. X. Wang, R. Long, D. Liu, D. Yang, C. Wang and Y. Xiong, Nano Energy, 2016, 24, 87-93.

331. A. O. Govorov, J. Lee and N. A. Kotov, Physical Review B, 2007, 76, 125308.

332. I. Majeed, U. Manzoor, F. K. Kanodarwala, M. A. Nadeem, E. Hussain, H. Ali, A. Badshah, J. A. Stride and M. A. Nadeem, Catalysis Science \& Technology, 2018.

333. C. Han, Y. Gao, S. Liu, L. Ge, N. Xiao, D. Dai, B. Xu and C. Chen, International Journal of Hydrogen Energy, 2017, 42, 22765-22775.

334. J. Jiang, J. Yu and S. Cao, Journal of colloid and interface science, 2016, 461, 56-63.

335. X. Ding, Y. Li, J. Zhao, Y. Zhu, Y. Li, W. Deng and C. Wang, APL Materials, 2015, 3, 104410.

336. X. Ma, Q. Jiang, W. Guo, M. Zheng, W. Xu, F. Ma and B. Hou, RSC Advances, 2016, 6, 2826328269.

337. H. Zhao, X. Ding, B. Zhang, Y. Li and C. Wang, Science Bulletin, 2017, 62, 602-609.

338. W. Yin, L. Bai, Y. Zhu, S. Zhong, L. Zhao, Z. Li and S. Bai, ACS applied materials \& interfaces, 2016, 8, 23133-23142.

339. D. Lu, H. Wang, X. Zhao, K. K. Kondamareddy, J. Ding, C. Li and P. Fang, ACS Sustainable Chemistry \& Engineering, 2017, 5, 1436-1445.

340. L. Bi, D. Meng, Q. Bu, Y. Lin, D. Wang and T. Xie, Physical Chemistry Chemical Physics, 2016, 18, 31534-31541.

341. A. Brandt, J. Graesvik, J. P. Hallett and T. Welton, Green Chem., 2013, 15, 550-583.

342. A. J. Ragauskas, C. K. Williams, B. H. Davison, G. Britovsek, J. Cairney, C. A. Eckert, W. J. Frederick Jr, J. P. Hallett, D. J. Leak, C. L. Liotta, J. R. Mielenz, R. Murphy, R. Templer and T. Tschaplinski, Science, 2006, 311, 484-489.

343. W.-H. Wang, Y. Himeda, J. T. Muckerman, G. F. Manbeck and E. Fujita, Chemical reviews, 2015, 115, 12936-12973.

344. L.-L. Tan, W.-J. Ong, S.-P. Chai and A. R. Mohamed, Applied Catalysis B: Environmental, 2015, 166, 251-259.

345. X. Chang, T. Wang and J. Gong, Energy \& Environmental Science, 2016, 9, 2177-2196.

346. G. Dong and L. Zhang, Journal of Materials Chemistry, 2012, 22, 1160-1166.

347. P. Niu, Y. Yang, J. C. Yu, G. Liu and H.-M. Cheng, Chemical Communications, 2014, 50, 1083710840.

348. S. Zhou, Y. Liu, J. Li, Y. Wang, G. Jiang, Z. Zhao, D. Wang, A. Duan, J. Liu and Y. Wei, Applied Catalysis B: Environmental, 2014, 158, 20-29.

349. W. Yu, D. Xu and T. Peng, Journal of Materials Chemistry A, 2015, 3, 19936-19947. 
350. K. Li, B. Peng, J. Jin, L. Zan and T. Peng, Applied Catalysis B: Environmental, 2017, 203, $910-$ 916.

351. J. Mao, T. Peng, X. Zhang, K. Li, L. Ye and L. Zan, Catalysis Science \& Technology, 2013, 3, 1253-1260.

352. M. Li, L. Zhang, X. Fan, Y. Zhou, M. Wu and J. Shi, Journal of Materials Chemistry A, 2015, 3, 5189-5196.

353. G. Gao, Y. Jiao, E. R. Waclawik and A. Du, Journal of the American Chemical Society, 2016, $138,6292-6297$.

354. H. Shi, G. Chen, C. Zhang and Z. Zou, Acs Catalysis, 2014, 4, 3637-3643.

355. H. Shi, C. Zhang, C. Zhou and G. Chen, RSC Advances, 2015, 5, 93615-93622.

356. S. Cao, Y. Li, B. Zhu, M. Jaroniec and J. Yu, Journal of Catalysis, 2017, 349, 208-217.

357. H. Park, J. H. Lee, E. H. Kim, K. Y. Kim, Y. H. Choi, D. H. Youn and J. S. Lee, Chemical Communications, 2016, 52, 14302-14305.

358. J. Hong, W. Zhang, Y. Wang, T. Zhou and R. Xu, ChemCatChem, 2014, 6, 2315-2321.

359. Y. Bai, T. Chen, P. Wang, L. Wang, L. Ye, X. Shi and W. Bai, Solar Energy Materials and Solar Cells, 2016, 157, 406-414.

360. Y. He, L. Zhang, B. Teng and M. Fan, Environmental science \& technology, 2014, 49, 649-656.

361. H. Li, Y. Gao, X. Wu, P.-H. Lee and K. Shih, Applied Surface Science, 2017, 402, 198-207.

362. Y. Huang, Y. Wang, Y. Bi, J. Jin, M. F. Ehsan, M. Fu and T. He, RSC Advances, 2015, 5, 3325433261.

363. M. R. Hoffmann, S. T. Martin, W. Choi and D. W. Bahnemann, Chemical reviews, 1995, 95, 69-96.

364. M. Humayun, Y. Qu, F. Raziq, R. Yan, Z. Li, X. Zhang and L. Jing, Environmental science \& technology, 2016, 50, 13600-13610.

365. Q. Zheng, D. P. Durkin, J. E. Elenewski, Y. Sun, N. A. Banek, L. Hua, H. Chen, M. J. Wagner, W. Zhang and D. Shuai, Environmental science \& technology, 2016, 50, 12938-12948.

366. Y. Cui, Z. Ding, P. Liu, M. Antonietti, X. Fu and X. Wang, Physical Chemistry Chemical Physics, 2012, 14, 1455-1462.

367. Y. Fu, T. Huang, L. Zhang, J. Zhu and X. Wang, Nanoscale, 2015, 7, 13723-13733.

368. Z. Li, J. Wang, K. Zhu, F. Ma and A. Meng, Materials Letters, 2015, 145, 167-170.

369. Y. Yang, W. Guo, Y. Guo, Y. Zhao, X. Yuan and Y. Guo, Journal of hazardous materials, 2014, 271, 150-159.

370. X. Xiao, J. Wei, Y. Yang, R. Xiong, C. Pan and J. Shi, ACS Sustainable Chemistry \& Engineering, 2016, 4, 3017-3023.

371. J. Wu, X. Shen, X. Miao, Z. Ji, J. Wang, T. Wang and M. Liu, European Journal of Inorganic Chemistry, 2017, 2017, 2845-2853.

372. X. Li, T. Wan, J. Qiu, H. Wei, F. Qin, Y. Wang, Y. Liao, Z. Huang and X. Tan, Applied Catalysis B: Environmental, 2017, 217, 591-602.

373. J. Luo, X. Zhou, L. Ma and X. Xu, Applied Surface Science, 2016, 390, 357-367.

374. X. Yang, H. Tang, J. Xu, M. Antonietti and M. Shalom, ChemSusChem, 2015, 8, 1350-1358.

375. H. Katsumata, T. Sakai, T. Suzuki and S. Kaneco, Industrial \& Engineering Chemistry Research, 2014, 53, 8018-8025.

376. C. Tang, E. Liu, J. Fan, X. Hu, Y. Ma and J. Wan, RSC Advances, 2015, 5, 91979-91987.

377. L. Zhou, W. Zhang, L. Chen and H. Deng, Journal of colloid and interface science, 2017, 487, 410-417.

378. L. Shi, L. Liang, F. Wang, M. Liu and J. Sun, Journal of materials science, 2015, 50, 1718-1727.

379. Y. Su, Y. Zhao, Y. Zhao, J. Lang, X. Xin and X. Wang, Applied Surface Science, 2015, 358, 213222.

380. D. Vidyasagar, S. G. Ghugal, A. Kulkarni, P. Mishra, A. G. Shende, Jagannath, S. S. Umare and R. Sasikala, Applied Catalysis B: Environmental, 2018, 221, 339-348. 
381. A. Zada, Y. Qu, S. Ali, N. Sun, H. Lu, R. Yan, X. Zhang and L. Jing, Journal of hazardous materials, 2018, 342, 715-723.

382. R. C. Pawar, Y. Pyo, S. H. Ahn and C. S. Lee, Applied Catalysis B: Environmental, 2015, 176, 654-666.

383. R. C. Pawar, S. Kang, S. H. Ahn and C. S. Lee, Rsc Advances, 2015, 5, 24281-24292.

384. J. Xue, S. Ma, Y. Zhou and Q. Wang, Rsc Advances, 2015, 5, 88249-88257.

385. J. Wu, Y. Zhang, T. Wang, Y. Xin and D. Ma, Materials Research Bulletin, 2017.

386. D. Peng, H. Wang, K. Yu, Y. Chang, X. Ma and S. Dong, RSC Advances, 2016, 6, 77760-77767.

387. J. Xue, S. Ma, Y. Zhou, Z. Zhang and M. He, ACS Applied Materials \& Interfaces, 2015, 7, 9630-9637.

388. M. A. Gondal, A. A. Adeseda, S. G. Rashid, A. Hameed, M. Aslam, I. M. I. Ismail, U. Baig, M. A. Dastageer, A. R. Al-Arfaj and A. U. Rehman, Journal of Molecular Catalysis A: Chemical, 2016, 423, 114-125.

389. G. Darabdhara and M. R. Das, Chemosphere, 2018.

390. J. Gao, J. Wang, X. Qian, Y. Dong, H. Xu, R. Song, C. Yan, H. Zhu, Q. Zhong and G. Qian, Journal of Solid State Chemistry, 2015, 228, 60-64.

391. Y. Bao and K. Chen, Molecular Catalysis, 2017, 432, 187-195.

392. J. Wang, L. Tang, G. Zeng, Y. Liu, Y. Zhou, Y. Deng, J. Wang and B. Peng, ACS Sustainable Chemistry \& Engineering, 2016, 5, 1062-1072.

393. G. Jiang, X. Li, M. Lan, T. Shen, X. Lv, F. Dong and S. Zhang, Applied Catalysis B: Environmental, 2017, 205, 532-540.

394. Y. Sun, T. Xiong, Z. Ni, J. Liu, F. Dong, W. Zhang and W.-K. Ho, Applied Surface Science, 2015, 358, 356-362.

395. Y. Ma, J. Li, E. Liu, J. Wan, X. Hu and J. Fan, Applied Catalysis B: Environmental, 2017, 219, 467-478.

396. M. Ou, S. Wan, Q. Zhong, S. Zhang, Y. Song, L. Guo, W. Cai and Y. Xu, Applied Catalysis B: Environmental, 2018, 221, 97-107.

397. X. Yang, Z. Chen, J. Xu, H. Tang, K. Chen and Y. Jiang, ACS applied materials \& interfaces, $2015,7,15285-15293$.

398. H. Li, Y. Sun, B. Cai, S. Gan, D. Han, L. Niu and T. Wu, Applied Catalysis B: Environmental, 2015, 170, 206-214.

399. Y. Liang, S. Lin, L. Liu, J. Hu and W. Cui, Applied Catalysis B: Environmental, 2015, 164, 192203.

400. H. Ji, L. Lyu, L. Zhang, X. An and C. Hu, Applied Catalysis B: Environmental, 2016, 199, 230240.

401. Y. Bao and K. Chen, Nano-Micro Letters, 2016, 8, 182-192.

402. Y. Chang, Z. Liu, X. Shen, B. Zhu, D. K. Macharia, Z. Chen and L. Zhang, Journal of Hazardous Materials, 2018, 344, 1188-1197.

403. Z. Xu, S. Xu, N. Li, F. Wu, S. Chen, W. Lu and W. Chen, ACS Sustainable Chemistry \& Engineering, 2017, 5, 9667-9672.

404. D. P. Subagio, M. Srinivasan, M. Lim and T.-T. Lim, Applied Catalysis B: Environmental, 2010, 95, 414-422.

405. M. Sierra, E. Borges, P. Esparza, J. Méndez-Ramos, J. Martín-Gil and P. Martín-Ramos, Science and Technology of advanced MaTerialS, 2016, 17, 659-668.

406. T. Sano, S. Tsutsui, K. Koike, T. Hirakawa, Y. Teramoto, N. Negishi and K. Takeuchi, Journal of materials chemistry A, 2013, 1, 6489-6496.

407. A. Nikokavoura and C. Trapalis, Applied Surface Science, 2018, 430, 18-52.

408. S. Verma, R. B. N. Baig, M. N. Nadagouda and R. S. Varma, Catalysis Today, 2017.

409. J. Liu, H. Wang and M. Antonietti, Chemical Society Reviews, 2016, 45, 2308-2326.

410. H. Hiramatsu and F. E. Osterloh, Chemistry of Materials, 2004, 16, 2509-2511.

411. H. Duan, D. Wang and Y. Li, Chemical Society Reviews, 2015, 44, 5778-5792. 
